\title{
Peptide Nucleic Acid Conjugates of Quinone Methide Precursors Alkylate Ribonucleic Acid after Activation with Light
}

\author{
Jan-Erik Hornung, ${ }^{\dagger}$ Nils Hellwig, ${ }^{\ddagger}$ Michael W. Göbel*† \\ ${ }^{\dagger}$ Institute of Organic Chemistry and Chemical Biology, Goethe University Frankfurt \\ Max-von-Laue-Str. 7, D-60438 Frankfurt am Main (Germany) \\ ${ }^{\ddagger}$ Institute of Physical and Theoretical Chemistry, Goethe University Frankfurt \\ Max-von-Laue-Str. 7, D-60438 Frankfurt am Main (Germany) \\ Email: Michael W. Göbel-m.goebel@chemie.uni-frankfurt.de \\ * Corresponding author
}

\section{Supporting Information}

\section{Table of contents:}

General

Synthesis of quinone methide precursor 2

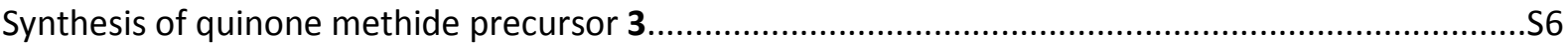

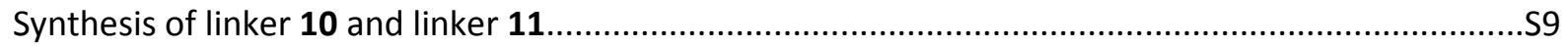

Synthesis and purification of PNA

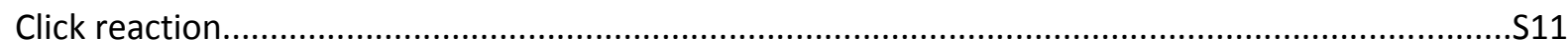

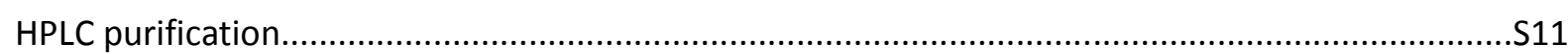

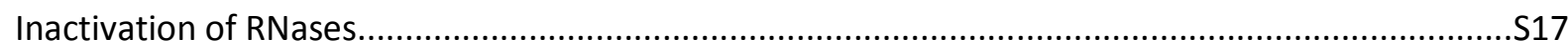

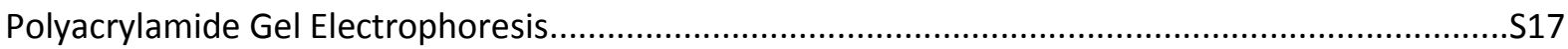

Photochemical deprotection of quinone methide precursors...........................................................S17

Irradiation of PNA and measuring self-alkylation kinetics............................................................. 18

Isolation of the unstable photolysis product 13c...........................................................................

Mass spectrometric characterization of self-alkylation products.................................................... 19

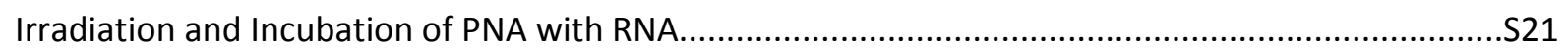

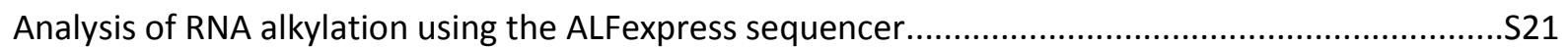

RNA alkylation requires irradiation of the PNA-QMP conjugates..................................................... 22

Correspondence of HPLC peaks and signals in the sequencer..................................................... 23

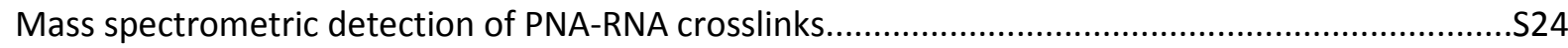

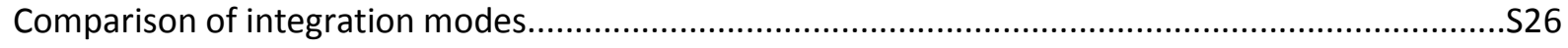

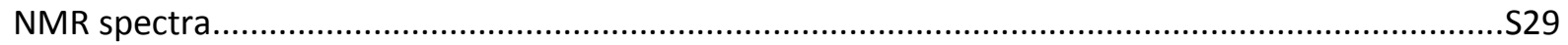




\section{General}

All chemicals were reagent grade and used as purchased. All of the reactions except acetonide hydrolysis were performed under an argon atmosphere. Reactions were monitored by TLC using Merck TLC silica gel 60 F-254 aluminium sheets. Compounds were visualized by UV light $(254 \mathrm{~nm})$. Column chromatography was carried out on silica gel $60(0.04-0.063 \mathrm{~mm})$.

Melting points (uncorrected) were recorded on a Kofler system. ${ }^{1} \mathrm{H}$ and ${ }^{13} \mathrm{C}$ NMR spectra were recorded on a BRUKER DPX 250 or a BRUKER AV 500 spectrometer. Chemical shifts are expressed in parts per million $(\mathrm{ppm})$ relative to the nondeuterated solvent signal DHO $\left(\delta_{\mathrm{H}}=4.75\right), \mathrm{DMSO}-d_{5}\left(\delta_{\mathrm{H}}=\right.$ 2.50, $\left.\delta_{\mathrm{C}}=39.51\right)$ or $\mathrm{CHCl}_{3}\left(\delta_{\mathrm{H}}=7.26, \delta_{\mathrm{C}}=77.16\right)$ as an internal reference. ESI mass spectroscopy was performed on a ThermoFisher Surveyor MSQ. High-resolution mass spectra (HRMS) were obtained with a ThermoScientific LTQ Orbitrap XL.

\section{Synthesis of quinone methide precursor 2}

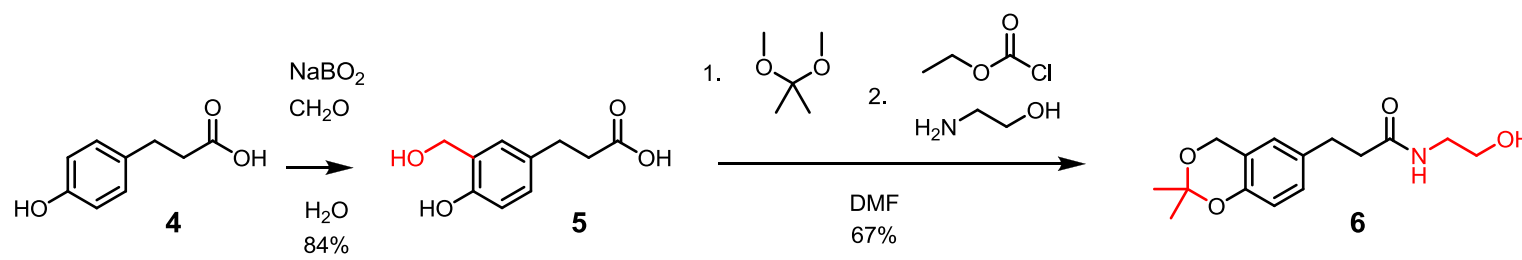<smiles>N#CCNC(=O)CCc1ccc(O)c(CO)c1</smiles><smiles>CC1(C)OCc2cc(CCC(=O)NCCN)ccc2O1</smiles><smiles>CC[14C](C)[18OH]</smiles>

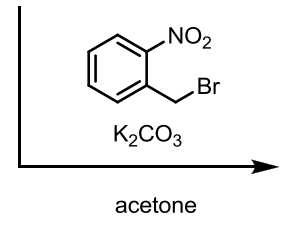

$81 \%$<smiles>NCCNC(=O)CCc1ccc(OCc2ccccc2[N+](=O)[O-])c(CO)c1</smiles>
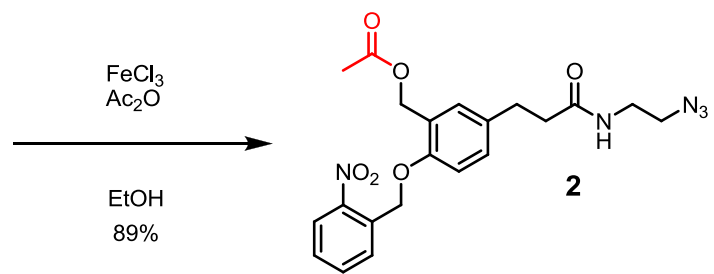


\section{3-(4-Hydroxy-3-(hydroxymethyl)phenyl)propanoic acid 5}<smiles>O=C(O)CCc1ccc(O)cc1</smiles>

3-(4-Hydroxyphenyl)propanoic acid 4 (2.00 g; $12 \mathrm{mmol} ; 1$ eq), $\mathrm{NaBO}_{2} \cdot 4 \mathrm{H}_{2} \mathrm{O}$ (13.3 g; $96.5 \mathrm{mmol} ; 8$ eq) and aq. formaldehyde solution ( $37 \% ; 4.5 \mathrm{~mL} ; 60.5 \mathrm{mmol} ; 5$ eq) were suspended in $\mathrm{H}_{2} \mathrm{O}(60 \mathrm{~mL}$ ). The mixture was stirred at $55^{\circ} \mathrm{C}$ for $13 \mathrm{~h}$ and cooled to room temperature. The solution was adjusted to $\mathrm{pH} 3$ with $3 \mathrm{M} \mathrm{HCl}$ and extracted with ethyl acetate $(8 \times 30 \mathrm{~mL})$. The combined organic phases were washed with brine $(50 \mathrm{~mL})$, dried over $\mathrm{Na}_{2} \mathrm{SO}_{4}$ and evaporated. The crude product was purified by flash column chromatography (cHex/EtOAc 1:1 + 0.5\% acetic acid) to obtain compound $\mathbf{5}$ as a colorless solid ( $2.02 \mathrm{~g}, 84 \%$ yield). $\mathrm{R}_{\mathrm{f}}=0.27$ (cHex/EtOAc 1:1+0.5\% acetic acid). Mp: $106{ }^{\circ} \mathrm{C} .{ }^{1} \mathrm{H}-\mathrm{NMR}$ $\left(500 \mathrm{MHz}, \mathrm{D}_{2} \mathrm{O}\right) \delta=7.08$ (br. $\left.\mathrm{s}, 1 \mathrm{H}\right), 7.01$ (br. $\left.d, J=8.2 \mathrm{~Hz}, 1 \mathrm{H}\right), 6.77(\mathrm{~d}, J=8.2 \mathrm{~Hz}, 1 \mathrm{H}), 4.54(\mathrm{~s}, 2 \mathrm{H})$, $2.76(\mathrm{t}, J=7.4 \mathrm{~Hz}, 2 \mathrm{H}), 2.56(\mathrm{t}, J=7.4 \mathrm{~Hz}, 2 \mathrm{H}) \mathrm{ppm} .{ }^{13} \mathrm{C}-\mathrm{NMR}\left(126 \mathrm{MHz}, \mathrm{D}_{2} \mathrm{O}\right) \delta=178.0,152.1,132.4$, 129.2, 128.9, 126.5, 115.5, 59.5, 35.5, 29.4 ppm. MS (ESI): $m / z=195.13$ [M - $\left.\mathrm{H}^{+}\right]$. HRMS (MALDI): $\mathrm{m} / z$ $=219.06285\left[\mathrm{M}+\mathrm{Na}^{+}\right]$, calcd for $\mathrm{C}_{10} \mathrm{H}_{12} \mathrm{O}_{4}+\mathrm{Na}^{+}: 219.06333$.

\section{3-(2,2-Dimethyl-4H-benzo[d][1,3]dioxin-6-yl)-N-(2-hydroxyethyl)propanamide 6}<smiles>O=C(O)CCc1ccc(O)c(CO)c1</smiles><smiles>CC1(C)OCc2cc(CCC(=O)NCCO)ccc2O1</smiles>

To a solution of compound 5 ( $1.00 \mathrm{~g} ; 5.10 \mathrm{mmol} ; 1 \mathrm{eq}$ ) and $p$-toluenesulfonic acid monohydrate (10

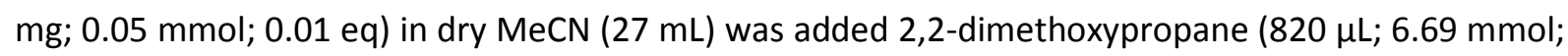
1.3 eq). After stirring for $45 \mathrm{~min}$ the solution was cooled to $0^{\circ} \mathrm{C}$ and triethylamine $(880 \mu \mathrm{L} ; 6.35$ $\mathrm{mmol} ; 1.25 \mathrm{eq})$ and ethyl chloroformate ( $540 \mu \mathrm{L} ; 5.67 \mathrm{mmol} ; 1.1 \mathrm{eq})$ were added. After additional 25 min of stirring at $0^{\circ} \mathrm{C}$ were added $\mathrm{H}_{2} \mathrm{O}(10 \mathrm{~mL})$ and ethanolamine $(340 \mu \mathrm{L} ; 5.68 \mathrm{mmol} ; 1.1$ eq). The mixture was stired for $18 \mathrm{~h}$ and the solvent removed in vacuo. The residue was purified by flash column chromatography (cHex/EtOH 8:2) to obtain acetonide 6 as a colorless solid $(0.96 \mathrm{~g}, 67 \%$ yield). $\mathrm{R}_{\mathrm{f}}=0.25$ (cHex/EtOAc/EtOH 3:3:1). Mp: $87^{\circ} \mathrm{C} .{ }^{1} \mathrm{H}$ NMR $\left(500 \mathrm{MHz}\right.$, DMSO- $\left.d_{6}\right) \delta=7.81$ (t, $J=5.5$ $\mathrm{Hz}, 1 \mathrm{H}), 6.97(\mathrm{dd}, J=1.9,8.3 \mathrm{~Hz}, 1 \mathrm{H}), 6.87(\mathrm{~d}, J=1.5 \mathrm{~Hz}, 1 \mathrm{H}), 6.68(\mathrm{~d}, J=8.3 \mathrm{~Hz}, 1 \mathrm{H}), 4.76(\mathrm{~s}, 2 \mathrm{H})$, 4.64 (br. s, 1 H), 3.36 (t, J=5.7 Hz, 2 H), 3.10 (q, J = 6.1 Hz, 2 H), 2.71 (t, J = 7.8 Hz, 2 H), 2.32 (t, J = 7.8 $\mathrm{Hz}, 2 \mathrm{H}), 1.44(\mathrm{~s}, 6 \mathrm{H}) \mathrm{ppm} .{ }^{13} \mathrm{C}$ NMR $\left(126 \mathrm{MHz}, \mathrm{DMSO}-d_{6}\right) \delta=171.5,148.9,133.1,127.8,124.5,119.2$, 116.2, 99.0, 60.1, 60.0, 41.4, 37.2, 30.4, 24.5 ppm. MS (ESI): $\mathrm{m} / z=278.14$ [M - $\mathrm{H}^{+}$]. HRMS (MALDI): $m / z=280.15444\left[\mathrm{M}+\mathrm{H}^{+}\right]$, calcd for $\mathrm{C}_{15} \mathrm{H}_{21} \mathrm{NO}_{4}+\mathrm{H}^{+}: 280.15488$. 


\section{$N$-(2-Azidoethyl)-3-(2,2-dimethyl-4H-benzo[d][1,3]dioxin-6-yl)propanamide 7}<smiles>[3H]C(=O)CCc1ccc2c(c1)COC(C)(C)O2</smiles>

To a solution of compound 6 (750 mg; $2.68 \mathrm{mmol} ; 1 \mathrm{eq})$ in dry MeCN (10 mL) were added triethylamine ( $560 \mu \mathrm{L} ; 4.04 \mathrm{mmol} ; 1.5 \mathrm{eq}$ ) and methanesulfonyl chloride ( $250 \mu \mathrm{L} ; 3.23 \mathrm{mmol} ; 1.2 \mathrm{eq}$ ) at $0^{\circ} \mathrm{C}$. The mixture was stirred for $15 \mathrm{~min}$ at RT. Then sodium azide ( $350 \mathrm{mg} ; 5.38 \mathrm{mmol} ; 2 \mathrm{eq}$ ) and tetrabutylammonium iodide (100 mg; $0.31 \mathrm{mmol} ; 0.1 \mathrm{eq}$ ) were added and the mixture was stirred at $80^{\circ} \mathrm{C}$ for $4 \mathrm{~h}$. After cooling to $\mathrm{RT} \mathrm{H}_{2} \mathrm{O}(90 \mathrm{~mL})$ was added and the aqueous phase was extracted with ethyl acetate $(5 \times 50 \mathrm{~mL})$. The combined organic phases were dried over $\mathrm{Na}_{2} \mathrm{SO}_{4}$ and evaporated. The crude product was purified by flash column chromatography (cHex/acetone 9:1 $\rightarrow$ 4:1 + 1\% TEA) to obtain title compound 7 as a yellowish solid $\left(705 \mathrm{mg}, 86 \%\right.$ yield). $R_{f}=0.75$ (cHex/EtOAc/MeOH 3:3:1). Mp: $44^{\circ} \mathrm{C} .{ }^{1} \mathrm{H}$ NMR $\left(500 \mathrm{MHz}\right.$, DMSO- $\left.d_{6}\right) \delta=8.07(\mathrm{t}, J=5.6 \mathrm{~Hz}, 1 \mathrm{H}), 6.97(\mathrm{dd}, J=2.3,8.3 \mathrm{~Hz}, 1$ H), $6.87(\mathrm{~d}, J=2.3 \mathrm{~Hz}, 1 \mathrm{H}), 6.68(\mathrm{~d}, J=8.3 \mathrm{~Hz}, 1 \mathrm{H}), 4.76(\mathrm{~s}, 2 \mathrm{H}), 3.31(\mathrm{t}, J=5.9 \mathrm{~Hz}, 2 \mathrm{H}), 3.23(\mathrm{q}, J=$ $5.6 \mathrm{~Hz}, 2 \mathrm{H}), 2.72(\mathrm{t}, J=7.8 \mathrm{~Hz}, 2 \mathrm{H}), 2.33(\mathrm{t}, J=7.8 \mathrm{~Hz}, 2 \mathrm{H}), 1.44(\mathrm{~s}, 6 \mathrm{H}) \mathrm{ppm} .{ }^{13} \mathrm{C} \mathrm{NMR}(126 \mathrm{MHz}$, DMSO- $\left.d_{6}\right) \delta=171.7,148.9,132.9,127.8,124.5,119.2,116.2,99.0,60.1,50.0,38.1,37.1,30.2,24.5$ ppm. MS (ESI): $m / z=303.11\left[\mathrm{M}-\mathrm{H}^{+}\right]$. HRMS (MALDI): $m / z=327.14267\left[\mathrm{M}+\mathrm{Na}^{+}\right]$, calcd for $\mathrm{C}_{15} \mathrm{H}_{20} \mathrm{~N}_{4} \mathrm{O}_{3}+\mathrm{Na}^{+}: 327.14276$.

\section{N-(2-Azidoethyl)-3-(4-hydroxy-3-(hydroxymethyl)phenyl)propanamide 8}<smiles>[3H]CCC(=O)NCCNC(=O)CCc1ccc(O)c(CO)c1</smiles>

Acetonide 7 (550 mg; $2.08 \mathrm{mmol} ; 1$ eq) was dissolved in a mixture of THF (10 mL) and $1 \mathrm{M} \mathrm{HCl}$ $(10 \mathrm{~mL})$, which was stirred for $3 \mathrm{~h}$ at room temperature. The reaction was quenched by addition of sat. aq. $\mathrm{NaHCO}_{3}$. The aqueous phase was extracted with ethyl acetate $(3 \times 60 \mathrm{~mL})$. The combined organic phases were washed with brine, dried over $\mathrm{MgSO}_{4}$ and evaporated to obtain the title compound 8 as a yellowish solid (705 mg, $84 \%$ yield), which was used without further purification. $R_{f}$ $=0.29(\mathrm{cHex} / \mathrm{EtOAc} / \mathrm{EtOH} 3: 3: 1) . \mathrm{Mp}: 104^{\circ} \mathrm{C} .{ }^{1} \mathrm{H}$ NMR $\left(500 \mathrm{MHz}\right.$, DMSO- $\left.d_{6}\right) \delta=9.08(\mathrm{~s}, 1 \mathrm{H}), 8.08(\mathrm{t}, J=$ $5.6 \mathrm{~Hz}, 1 \mathrm{H}), 7.11(\mathrm{~d}, J=2.0 \mathrm{~Hz}, 1 \mathrm{H}), 6.85(\mathrm{dd}, J=2.3,8.1 \mathrm{~Hz}, 1 \mathrm{H}), 6.65$ (d, J = $8.1 \mathrm{~Hz}, 1 \mathrm{H}$ ), 4.89 (br. s., $1 \mathrm{H}), 4.44(\mathrm{~s}, 2 \mathrm{H}), 3.32(\mathrm{t}, J=5.7 \mathrm{~Hz}, 2 \mathrm{H}), 3.23(\mathrm{q}, J=5.7 \mathrm{~Hz}, 2 \mathrm{H}), 2.70$ (br. t, J = 7.9 Hz, $2 \mathrm{H}$ ), 2.31 (br. $\mathrm{t}, J=7.9 \mathrm{~Hz}, 2 \mathrm{H}) \mathrm{ppm} .{ }^{13} \mathrm{C}$ NMR $\left(126 \mathrm{MHz}\right.$, DMSO-d $\left.d_{6}\right) \delta=171.9,152.3,131.1,128.2,127.1,126.8$, 
114.4, 58.3, 50.0, 38.2, 37.7, $30.6 \mathrm{ppm}$. MS (ESI'): $\mathrm{m} / \mathrm{z}=263.13\left[\mathrm{M}-\mathrm{H}^{+}\right]$. HRMS (MALDI): $\mathrm{m} / \mathrm{z}=$ $287.11165\left[\mathrm{M}+\mathrm{Na}^{+}\right]$, calcd. for $\mathrm{C}_{12} \mathrm{H}_{16} \mathrm{~N}_{4} \mathrm{O}_{3}+\mathrm{Na}^{+}: 287.11146$.

\section{N-(2-Azidoethyl)-3-(3-(hydroxymethyl)-4-((2-nitrobenzyl)oxy)phenyl)propanamide 9}<smiles>N#CCCNC(=O)CCc1ccc(O)c(CO)c1</smiles>

8<smiles>N#CCNC(=O)CCc1ccc(OCc2ccccc2[N+](=O)[O-])c(CO)c1</smiles>

To a solution of compound 8 (400 mg; $1.51 \mathrm{mmol} ; 1.0 \mathrm{eq})$ in acetone $(10 \mathrm{~mL})$ were added TBAI (55 $\mathrm{mg} ; 0.15 \mathrm{mmol} ; 0.1 \mathrm{eq}), \mathrm{K}_{2} \mathrm{CO}_{3}(417 \mathrm{mg} ; 3.02 \mathrm{mmol} ; 2.0 \mathrm{eq})$ and 2-nitrobenzylbromide (391 mg; $1.81 \mathrm{mmol} ; 1.2 \mathrm{eq})$. The mixture was heated to reflux for $5 \mathrm{~h}$ and cooled to RT. The solvent was removed and the residue was purified by flash column chromatography (cHex/EtOAc 2:3 $\rightarrow 1: 4+1 \%$ EtOH). Traces of starting material were removed by dissolving the crude product in ethyl acetate and washing with $10 \mathrm{M} \mathrm{NaOH}$. Evaporation yielded title compound 9 as a slightly yellow solid $(492 \mathrm{mg}$, $81 \%$ yield). $R_{f}=0.33$ (cHex/EtOAc/EtOH 3:3:1). Mp: $120^{\circ} \mathrm{C} .{ }^{1} \mathrm{H}$ NMR $\left(500 \mathrm{MHz}\right.$, DMSO-d $\left.d_{6}\right) \delta=8.13-$ 8.09 (m, 2 H), $7.82-7.77(m, 2$ H), $7.62-7.60(m, 1$ H), 7.26 (d, J = 2.1 Hz, 1 H), 7.01 (dd, J = 2.1, 8.3 $\mathrm{Hz}, 1 \mathrm{H}), 6.88(\mathrm{~d}, J=8.4 \mathrm{~Hz}, 1 \mathrm{H}), 5.42(\mathrm{~s}, 2 \mathrm{H}), 5.03(\mathrm{t}, J=5.5 \mathrm{~Hz}, 1 \mathrm{H}), 4.52(\mathrm{~d}, J=5.4 \mathrm{~Hz}, 2 \mathrm{H}), 3.33(\mathrm{t}$, $J=5.8 \mathrm{~Hz}, 2 \mathrm{H}$ ), $3.23(\mathrm{q}, J=5.7 \mathrm{~Hz}, 2 \mathrm{H}), 2.76$ (br. t, $J=7.9 \mathrm{~Hz}, 2 \mathrm{H}$ ), 2.35 (br. t, $J=7.9 \mathrm{~Hz}, 2 \mathrm{H}$ ) ppm. ${ }^{13} \mathrm{C}$ NMR $(126 \mathrm{MHz} \text {, DMSO-d })_{6} \delta=171.8,152.8,147.4,134.0,133.4,132.8,130.5,129.1,129.0,127.1$, 127.0, 124.8, 111.3, 66.3, 57.8, 50.0, 38.2, 37.4, 30.5 ppm. MS (ESI): $m / z=398.18\left[\mathrm{M}-\mathrm{H}^{+}\right]$. HRMS (MALDI): $m / z=422.14354\left[\mathrm{M}+\mathrm{Na}^{+}\right]$, calcd. for $\mathrm{C}_{19} \mathrm{H}_{21} \mathrm{~N}_{5} \mathrm{O}_{5}+\mathrm{Na}^{+}: 422.14349$.

\section{5-(3-(2-Azidoethylamino)-3-oxopropyl)-2-(2-nitrobenzyloxy)benzyl acetate 2}
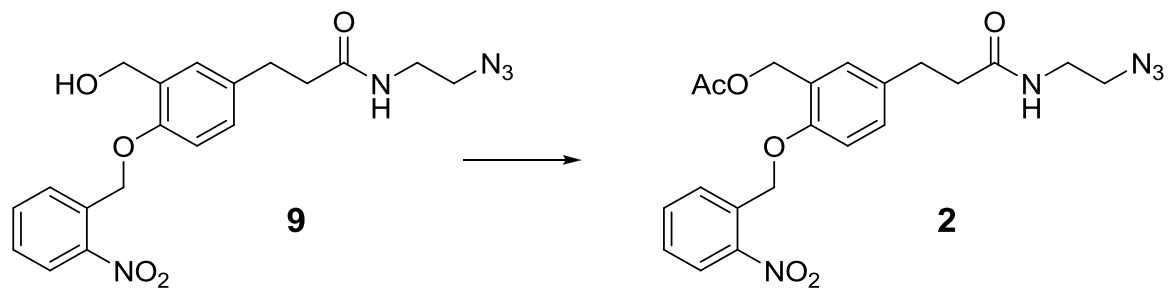

To a solution of alcohol 9 ( $202 \mathrm{mg} ; 0.51 \mathrm{mmol} ; 1.0 \mathrm{eq})$ in acetic acid anhydride (10 mL) and ethanol $(4 \mathrm{~mL})$ was added $\mathrm{FeCl}_{3}(10 \mathrm{mg} ; 0.06 \mathrm{mmol} ; 0.12 \mathrm{eq})$ at $0^{\circ} \mathrm{C}$. After stirring the mixture for $1.5 \mathrm{~h}$ at $0^{\circ} \mathrm{C}$ additional $\mathrm{FeCl}_{3}(20 \mathrm{mg} ; 0.12 \mathrm{mmol} ; 0.24 \mathrm{eq}$ ) was added and stirring was continued for $2 \mathrm{~h} .40 \mathrm{~mL}$ ethyl acetate and $30 \mathrm{ml}$ brine were added. The water phase was extracted with ethyl acetate $(2 \mathrm{x}$ 
$40 \mathrm{~mL}$ ). The organic phase was washed with brine $(2 \times 40 \mathrm{~mL})$ and sat. aq. $\mathrm{NaHCO}_{3}(2 \times 40 \mathrm{~mL})$, dried over $\mathrm{Na}_{2} \mathrm{SO}_{4}$ and evaporated. The residue was purified by flash column chromatography (cHex/EtOAc/EtOH 100:4:1 $\rightarrow$ 100:32:8) to obtain quinone methide precursor 2 as a yellow solid (197 mg, $89 \%$ yield). $R_{f}=0.34$ (cHex/EtOAc/EtOH 3:3:1). Mp: 87 ${ }^{\circ} \mathrm{C} .{ }^{1} \mathrm{H}$ NMR (500 MHz, DMSO-d ${ }_{6}$ ) $\delta=$ $8.13(\mathrm{~d}, J=8.1 \mathrm{~Hz}, 1 \mathrm{H}), 8.08(\mathrm{t}, J=5.5 \mathrm{~Hz}, 1 \mathrm{H}), 7.81-7.78(\mathrm{~m}, 2 \mathrm{H}), 7.65-7.59(\mathrm{~m}, 1 \mathrm{H}), 7.17(\mathrm{~d}, J=2.0$ $\mathrm{Hz}, 1 \mathrm{H}), 7.14(\mathrm{dd}, J=2.1,8.4 \mathrm{~Hz}, 1 \mathrm{H}), 6.99(\mathrm{~d}, J=8.4 \mathrm{~Hz}, 1 \mathrm{H}), 5.47(\mathrm{~s}, 2 \mathrm{H}), 5.06(\mathrm{~s}, 2 \mathrm{H}), 3.32(\mathrm{t}, J=$ $5.7 \mathrm{~Hz}, 2 \mathrm{H}), 3.23(\mathrm{q}, J=5.6 \mathrm{~Hz}, 2 \mathrm{H}), 2.76(\mathrm{t}, J=7.7 \mathrm{~Hz}, 2 \mathrm{H}), 2.35(\mathrm{t}, J=7.8 \mathrm{~Hz}, 2 \mathrm{H}), 2.04(\mathrm{~s}, 3 \mathrm{H}) \mathrm{ppm}$. ${ }^{13} \mathrm{C}$ NMR $\left(126 \mathrm{MHz}, \mathrm{DMSO}-d_{6}\right) \delta=171.7,170.2,154.0,147.3,134.0,133.7,132.6,129.7,129.2,129.1$, $128.9,124.8,123.9,112.1,66.5,61.1,50.0,38.1,37.1,30.1,20.7$ ppm. MS (ESI) : $\mathrm{m} / z=440.10[\mathrm{M}-$ $\left.\mathrm{H}^{+}\right]$. HRMS (MALDI): $m / z=464.15332\left[\mathrm{M}+\mathrm{Na}^{+}\right]$, calcd. for $\mathrm{C}_{21} \mathrm{H}_{23} \mathrm{~N}_{5} \mathrm{O}_{6}+\mathrm{Na}^{+}: 464.15405$.

\section{Synthesis of quinone methide precursor 3}

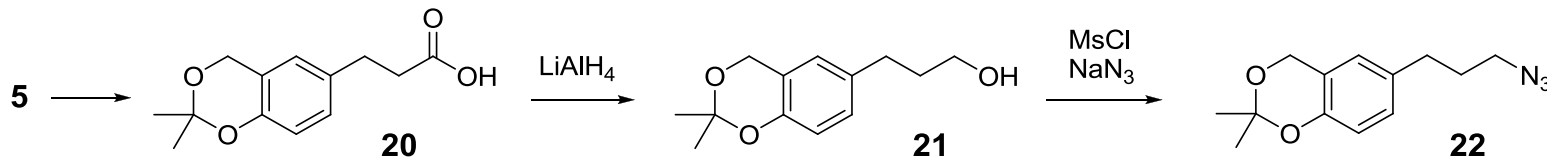

21<smiles>CC(=O)OCc1cc(CCCCN)ccc1OCc1ccccc1[N+](=O)[O-]</smiles>

\section{3-(2,2-Dimethyl-4H-benzo[d][1,3]dioxin-6-yl)propanoic acid 20}<smiles>O=C(O)CCc1ccc(O)c(CO)c1</smiles><smiles>CC1(C)OCc2cc(CCC(=O)O)ccc2O1</smiles>

To a solution of compound 5 (1.20 g; $6.12 \mathrm{mmol} ; 1 \mathrm{eq})$ and $p$-toluenesulfonic acid monohydrate (11 mg; $0.06 \mathrm{mmol} ; 0.01 \mathrm{eq})$ in dry DMF (10 mL) was added 2,2-dimethoxypropane (1.41 mL; 11.4 $\mathrm{mmol} ; 1.9 \mathrm{eq}$ ). After stirring for $2 \mathrm{~h}$ the solution was poured into $100 \mathrm{~mL}$ brine and extracted with ethyl acetate $(4 \times 60 \mathrm{~mL})$. The combined organic phases were washed with brine $(2 \times 40 \mathrm{~mL})$, dried over $\mathrm{Na}_{2} \mathrm{SO}_{4}$ and evaporated. The residue was purified by flash column chromatography (cHex/EtOAc $4: 1+0.5 \%$ acetic acid) to obtain 20 as colorless crystals ( $1.15 \mathrm{~g}, 80 \%$ yield). $R_{f}=0.45$ (cHex/EtOAc 2:1 + $0.5 \%$ acetic acid). Mp: $88^{\circ} \mathrm{C} .{ }^{1} \mathrm{H}$ NMR $\left(500 \mathrm{MHz}, \mathrm{CDCl}_{3}\right) \delta=11.41$ (br. s., $1 \mathrm{H}$ ), 7.00 (dd, $J=1.5,8.3$ 
$\mathrm{Hz}, 1 \mathrm{H}), 6.80(\mathrm{~d}, J=1.5 \mathrm{~Hz}, 1 \mathrm{H}), 6.75(\mathrm{~d}, J=8.4 \mathrm{~Hz}, 1 \mathrm{H}), 4.82(\mathrm{~s}, 2 \mathrm{H}), 2.87(\mathrm{t}, J=7.7 \mathrm{~Hz}, 2 \mathrm{H}), 2.64(\mathrm{t}$, $J=7.8 \mathrm{~Hz}, 2 \mathrm{H}$ ), $1.53(\mathrm{~s}, 6 \mathrm{H}) \mathrm{ppm} .{ }^{13} \mathrm{C} \mathrm{NMR}\left(126 \mathrm{MHz}, \mathrm{CDCl}_{3}\right) \delta=179.0,149.8,132.1,128.1,124.4$, 119.5, 117.3, 99.6, 61.0, 35.9, 30.0, 24.9 ppm. MS (ESI'): $m / z=235.13\left[\mathrm{M}-\mathrm{H}^{+}\right]$. HRMS (MALDI): $\mathrm{m} / \mathrm{z}=$ $275.06741\left[\mathrm{M}+\mathrm{K}^{+}\right]$, calcd. for $\mathrm{C}_{13} \mathrm{H}_{16} \mathrm{O}_{4}+\mathrm{K}^{+}: 275.06802$.

\section{3-(2,2-Dimethyl-4H-benzo[d][1,3]dioxin-6-yl)propan-1-ol 21}<smiles>CC1(C)OCc2cc(CCC(=O)O)ccc2O1</smiles><smiles>CCCCc1ccc2c(c1)COC(C)(C)O2</smiles>

Compound 20 (1.00 g; $4.23 \mathrm{mmol} ; 1 \mathrm{eq})$ was dissolved in dry THF $(20 \mathrm{~mL})$ and cooled to $0^{\circ} \mathrm{C}$. A $1 \mathrm{M}$ solution of $\mathrm{LiAlH}_{4}$ in THF was added dropwise ( $8.6 \mathrm{~mL} ; 8.6 \mathrm{mmol} ; 2$ eq). The solution was brought to room temperature and stirred for $2.5 \mathrm{~h}$. After cooling to $0^{\circ} \mathrm{C}$ was added successively $\mathrm{H}_{2} \mathrm{O}(0.35 \mathrm{~mL})$, $15 \% \mathrm{NaOH}(0.35 \mathrm{~mL}), \mathrm{H}_{2} \mathrm{O}(1 \mathrm{~mL})$ and acetic acid $(0.8 \mathrm{~mL})$. Celite ${ }^{\circledR} 535$ was added and the solvents were evaporated. The absorbed crude product was purified by flash column chromatography (cHex/EtOAc 3:1 $\rightarrow 1: 3$ ) to obtain 21 as a colorless oil (0.80 g, $85 \%$ yield). $R_{f}=0.19$ (cHex/EtOAc 3:1). ${ }^{1} \mathrm{H} \mathrm{NMR}\left(500 \mathrm{MHz}, \mathrm{CDCl}_{3}\right) \delta=6.98(\mathrm{dd}, J=1.7,8.3 \mathrm{~Hz}, 1 \mathrm{H}), 6.79(\mathrm{~d}, J=1.7 \mathrm{~Hz}, 1 \mathrm{H}), 6.74(\mathrm{~d}, J=8.3 \mathrm{~Hz}$, $1 \mathrm{H}), 4.82(\mathrm{~s}, 2 \mathrm{H}), 3.65(\mathrm{t}, J=6.4 \mathrm{~Hz}, 2 \mathrm{H}), 2.62(\mathrm{t}, J=7.9 \mathrm{~Hz}, 2 \mathrm{H}), 1.84(\mathrm{~m}, 6.4 \mathrm{~Hz}, 2 \mathrm{H}), 1.53(\mathrm{~s}, 6 \mathrm{H})$ ppm. ${ }^{13} \mathrm{C}$ NMR $\left(126 \mathrm{MHz}, \mathrm{CDCl}_{3}\right) \delta=149.4,133.7,128.2,124.4,119.3,117.1,99.5,62.3,61.1,34.5$, 31.4, 24.9 ppm. HRMS (MALDI): $m / z=222.12471$ [M], calcd. for $\mathrm{C}_{13} \mathrm{H}_{18} \mathrm{O}_{3}: 222.12505$.

\section{6-(3-Azidopropyl)-2,2-dimethyl-4H-benzo[d][1,3]dioxine 22}<smiles>[Z1]CCCc1ccc2c(c1)COC(C)(C)O2</smiles>

To a solution of compound 21 (470 g; $2.11 \mathrm{mmol} ; 1 \mathrm{eq})$ in dry DMF (15 mL) were added triethylamine $(440 \mu \mathrm{L} ; 3.17 \mathrm{mmol} ; 1.5 \mathrm{eq}$ ) and methanesulfonyl chloride (182 $\mu \mathrm{L} ; 2.35 \mathrm{mmol} ; 1.1 \mathrm{eq})$ at $0^{\circ} \mathrm{C}$. The mixture was stirred for $15 \mathrm{~min}$ at room temperature. Then sodium azide ( $280 \mathrm{mg}$; $4.23 \mathrm{mmol}$; $2 \mathrm{eq}$ ) and tetrabutylammonium iodide ( $80 \mathrm{mg} ; 0.21 \mathrm{mmol} ; 0.1 \mathrm{eq}$ ) were added and the mixture was stirred at $80^{\circ} \mathrm{C}$ for $2.5 \mathrm{~h}$. After cooling to room temperature $\mathrm{H}_{2} \mathrm{O}(90 \mathrm{~mL})$ was added and the aqueous phase was extracted with ethyl acetate $(3 \times 70 \mathrm{~mL})$. The combined organic phases were dried over $\mathrm{Na}_{2} \mathrm{SO}_{4}$ and evaporated. The crude product was purified by flash column chromatography (cHex/EtOAc 19:1 $\rightarrow 9: 1$ ) to obtain title compound 22 as a yellowish oil ( $457 \mathrm{mg}, 87 \%$ yield). $R_{f}=0.73$ (cHex/EtOAc 3:1). ${ }^{1} \mathrm{H} \mathrm{NMR}\left(500 \mathrm{MHz}, \mathrm{CDCl}_{3}\right) \delta=6.97(\mathrm{dd}, J=1.7,8.3 \mathrm{~Hz}, 1 \mathrm{H}), 6.78(\mathrm{~d}, J=1.7 \mathrm{~Hz}, 1 \mathrm{H}), 6.75(\mathrm{~d}, J=8.3 \mathrm{~Hz}$, 
$1 \mathrm{H}), 4.82(\mathrm{~s}, 2 \mathrm{H}$ ), $3.27(\mathrm{t}, J=6.8 \mathrm{~Hz}, 2 \mathrm{H}), 2.62(\mathrm{t}, J=7.5 \mathrm{~Hz}, 2 \mathrm{H}$ ), 1.87 (quin, $J=7.2 \mathrm{~Hz}, 2 \mathrm{H}), 1.54(\mathrm{~s}, 6$ H) ppm. ${ }^{13} \mathrm{C}$ NMR $\left(126 \mathrm{MHz}, \mathrm{CDCl}_{3}\right) \delta=149.6,132.8,128.2,124.5,119.5,117.2,99.6,61.0,50.7$, 32.1, 30.7, 24.9 ppm. HRMS (MALDI): $m / z=270.12126\left[\mathrm{M}+\mathrm{Na}^{+}\right]$, calcd. for $\mathrm{C}_{13} \mathrm{H}_{17} \mathrm{~N}_{3} \mathrm{O}_{2}+\mathrm{Na}^{+}$: 270.12130.

\section{4-(3-Azidopropyl)-2-(hydroxymethyl)phenol 23}<smiles>CC1(C)OCc2cc(CCCN)ccc2O1</smiles>

Acetonide 22 (300 mg; $1.21 \mathrm{mmol} ; 1 \mathrm{eq}$ ) was dissolved in a mixture of THF (10 mL) and $1 \mathrm{M} \mathrm{HCl}$ $(10 \mathrm{~mL})$, which was stirred for $2 \mathrm{~h}$ at room temperature. The reaction was quenched by addition of sat. aq. $\mathrm{NaHCO}_{3}$. The aqueous phase was extracted with ethyl acetate $(3 \times 60 \mathrm{~mL})$. The combined organic phases were washed with brine, dried over $\mathrm{NaSO}_{4}$ and evaporated. The crude product was purified by flash column chromatography (cHex/EtOAc 9:1 $\rightarrow$ 1:1) to obtain title compound 23 as yellowish crystals $\left(219 \mathrm{mg}, 87 \%\right.$ yield). $\mathrm{R}_{\mathrm{f}}=0.20$ (cHex/EtOAc 3:1). Mp: $40^{\circ} \mathrm{C} .{ }^{1} \mathrm{H}$ NMR $(500 \mathrm{MHz}$, $\left.\mathrm{CDCl}_{3}\right) \delta=7.20(\mathrm{~s}, 1 \mathrm{H}), 7.01(\mathrm{dd}, J=2.0,8.2 \mathrm{~Hz}, 1 \mathrm{H}), 6.85(\mathrm{~d}, J=1.8 \mathrm{~Hz}, 1 \mathrm{H}), 6.81(\mathrm{~d}, J=8.2 \mathrm{~Hz}, 1 \mathrm{H})$, $4.82(\mathrm{~d}, J=3.7 \mathrm{~Hz}, 2 \mathrm{H}$ ), $3.26(\mathrm{t}, J=6.8 \mathrm{~Hz}, 2 \mathrm{H}$ ), 2.61 (t, $J=7.5 \mathrm{~Hz}, 2 \mathrm{H}$ ), 2.48 (br. s., $1 \mathrm{H}$ ), 1.86 (quin, $J=$ $7.2 \mathrm{~Hz}, 2 \mathrm{H}) \mathrm{ppm} .{ }^{13} \mathrm{C} \mathrm{NMR}\left(126 \mathrm{MHz}, \mathrm{CDCl}_{3}\right) \delta=154.3,132.5,129.4,128.0,124.8,116.6,64.7,50.7$, 31.9, 30.7 ppm. MS (ESI) $): m / z=206.35\left[\mathrm{M}-\mathrm{H}^{+}\right]$. HRMS (MALDI): $m / z=230.09031\left[\mathrm{M}+\mathrm{Na}^{+}\right]$, calcd. for $\mathrm{C}_{10} \mathrm{H}_{13} \mathrm{~N}_{3} \mathrm{O}_{2}+\mathrm{Na}^{+}: 230.09000$.

\section{(5-(3-Azidopropyl)-2-(2-nitrobenzyloxy)phenyl)methanol 24}

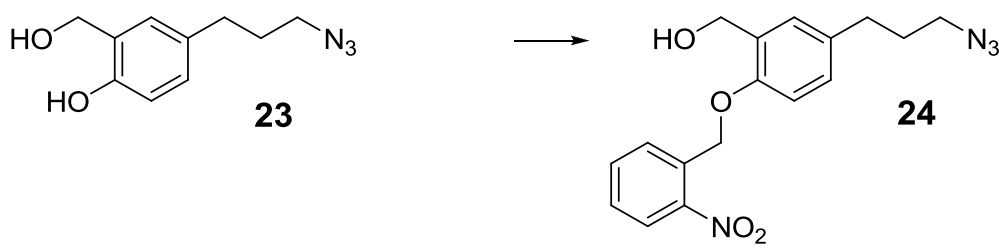

To a solution of compound 23 (150 mg; $0.72 \mathrm{mmol} ; 1.0 \mathrm{eq})$ in acetone (10 mL) were added TBAI ( $26 \mathrm{mg} ; 0.08 \mathrm{mmol} ; 0.1 \mathrm{eq}$ ), $\mathrm{K}_{2} \mathrm{CO}_{3}$ (200 mg; $1.45 \mathrm{mmol} ; 2.0 \mathrm{eq}$ ) and 2-nitrobenzylbromide (185 mg; $0.86 \mathrm{mmol} ; 1.2 \mathrm{eq})$. The mixture was heated to reflux for $1.5 \mathrm{~h}$ and cooled to room temperature. The solvent was removed and the residue was purified by flash column chromatography (cHex/EtOAc 9:1 $\rightarrow 1: 1$ ) to obtain title compound $\mathbf{2 4}$ as yellow crystals ( $231 \mathrm{mg}, 94 \%$ yield). $\mathrm{R}_{\mathrm{f}}=0.21$ (cHex/EtOAc 3:1). Mp: $50^{\circ} \mathrm{C} .{ }^{1} \mathrm{H} N M R\left(500 \mathrm{MHz}, \mathrm{CDCl}_{3}\right) \delta=8.17(\mathrm{~d}, J=8.0 \mathrm{~Hz}, 1 \mathrm{H}), 7.84(\mathrm{~d}, J=7.8 \mathrm{~Hz}, 1 \mathrm{H}), 7.70(\mathrm{t}$, $J=7.5 \mathrm{~Hz}, 1 \mathrm{H}), 7.51(\mathrm{t}, J=7.7 \mathrm{~Hz}, 1 \mathrm{H}), 7.20(\mathrm{~d}, J=2.0 \mathrm{~Hz}, 1 \mathrm{H}), 7.07(\mathrm{dd}, J=2.1,8.3 \mathrm{~Hz}, 1 \mathrm{H}), 6.84(\mathrm{~d}, J$ 
$=8.3 \mathrm{~Hz}, 1 \mathrm{H}), 5.51(\mathrm{~s}, 2 \mathrm{H}), 4.79(\mathrm{~s}, 2 \mathrm{H}), 3.28(\mathrm{t}, J=6.8 \mathrm{~Hz}, 2 \mathrm{H}), 2.66(\mathrm{t}, J=7.5 \mathrm{~Hz}, 2 \mathrm{H}), 2.14$ (br. s., 1 H), 1.89 (quin, $J=7.2 \mathrm{~Hz}, 2 \mathrm{H}$ ) ppm. ${ }^{13} \mathrm{C}$ NMR $\left(126 \mathrm{MHz}, \mathrm{CDCl}_{3}\right) \delta=154.3,147.1,134.3,134.0,133.7$, $129.5,129.1,128.9,128.7,128.5,125.2,111.9,67.2,61.8,50.7,32.0,30.7$ ppm. MS (ESI) $): m / z=$ $341.23\left[\mathrm{M}-\mathrm{H}^{+}\right]$. HRMS (MALDI): $m / z=365.12219\left[\mathrm{M}+\mathrm{Na}^{+}\right]$, calcd. for $\mathrm{C}_{17} \mathrm{H}_{18} \mathrm{~N}_{4} \mathrm{O}_{4}+\mathrm{Na}^{+}: 365.12203$.

\section{5-(3-Azidopropyl)-2-(2-nitrobenzyloxy)benzyl acetate 3}<smiles>CC(C)OCc1cc(CCCN)ccc1OCc1ccccc1[N+](=O)[O-]</smiles>

To a solution of alcohol 24 (50 mg; $0.15 \mathrm{mmol} ; 1.0 \mathrm{eq}$ ) in acetic acid anhydride ( $4 \mathrm{~mL}$ ) was added DMAP ( $5 \mathrm{mg} ; 0.04 \mathrm{mmol} ; 0.3 \mathrm{eq}$ ). The mixture was stirred at room temperature for $1 \mathrm{~h}$, quenched by addition of sat. aq. $\mathrm{NaHCO}_{3}(20 \mathrm{~mL})$ and stirred for an additional $15 \mathrm{~min}$. The aqueous phase was extracted with ethyl acetate $(4 \times 40 \mathrm{~mL})$. The combined organic phases were washed with brine, dried over $\mathrm{NaSO}_{4}$ and evaporated. The crude product was purified by flash column chromatography (cHex/EtOAc 9:1 $\rightarrow$ 1:1) to obtain title compound 3 as a yellow oil $\left(42 \mathrm{mg}, 73 \%\right.$ yield). $R_{f}=0.51$ (cHex/EtOAc 3:1). ${ }^{1} \mathrm{H}$ NMR $\left(500 \mathrm{MHz}, \mathrm{CDCl}_{3}\right) \delta=8.18(\mathrm{~d}, J=8.2 \mathrm{~Hz}, 1 \mathrm{H}), 7.90(\mathrm{~d}, J=7.8 \mathrm{~Hz}, 1 \mathrm{H}), 7.71$ (t, $J=7.6 \mathrm{~Hz}, 1 \mathrm{H}$ ), 7.50 (t, J=7.8 Hz, $1 \mathrm{H}$ ), 7.20 (d, J = 1.8 Hz, 1 H), 7.12 (dd, J = 2.0, 8.3 Hz, $1 \mathrm{H}$ ), 6.88 $(\mathrm{d}, J=8.3 \mathrm{~Hz}, 1 \mathrm{H}), 5.51(\mathrm{~s}, 2 \mathrm{H}), 5.25(\mathrm{~s}, 2 \mathrm{H}), 3.29(\mathrm{t}, J=6.7 \mathrm{~Hz}, 2 \mathrm{H}), 2.67(\mathrm{t}, J=7.5 \mathrm{~Hz}, 2 \mathrm{H}), 2.11(\mathrm{~s}, 3$ H), 1.89 (quin, $J=7.2 \mathrm{~Hz}, 2 \mathrm{H}$ ) ppm. ${ }^{13} \mathrm{C} \mathrm{NMR}\left(126 \mathrm{MHz}, \mathrm{CDCl}_{3}\right) \delta=171.1,154.6,146.9,134.3,134.0$, $133.8,130.4,129.7,128.5,128.4,125.2,124.7,112.2,67.1,62.0,50.7,32.0,30.7,21.2$ ppm. MS $\left(\mathrm{ESI}^{+}\right): m / z=407.10\left[\mathrm{M}+\mathrm{Na}^{+}\right]$. HRMS (MALDI): $m / z=407.13226\left[\mathrm{M}+\mathrm{Na}^{+}\right]$, calcd. for $\mathrm{C}_{19} \mathrm{H}_{20} \mathrm{~N}_{4} \mathrm{O}_{5}+\mathrm{Na}^{+}$: 407.13259.

\section{Synthesis of linker 10 and linker 11}<smiles>C#CC(=O)NCCCCCC(=O)NOCC(=O)NCCCCCNC(=O)CONCOO</smiles>

After the assembly of PNA chains on solid support, Fmoc-protected 6-aminohexanoic acid (Danneberg et al. Beilstein J. Org. Chem. 2015, 11, 493-498) was coupled by the methods shown under PNA synthesis. After removal of Fmoc, propiolic acid was attached in the presence of DIC and HOBt. 


\section{2-((2-((((9H-Fluoren-9-yl)methoxy)carbonyl)amino)ethyl)(prop-2-yn-1-yl)amino)acetic acid 11}

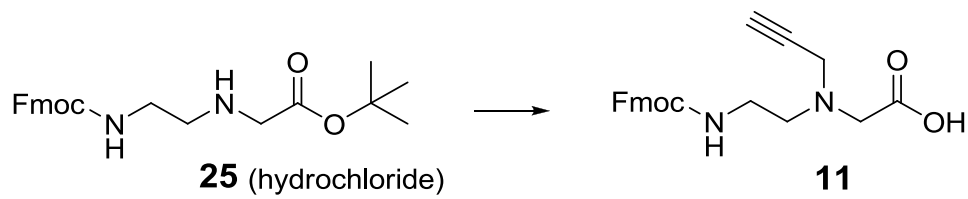

Compound 25 was synthesized by the method of Thomson et al. Tetrahedron 1995, 51, 6179-6194.

To a solution of 25 (430 mg; $1 \mathrm{mmol} ; 1.0 \mathrm{eq})$ in dry DCM (10 mL) was added successively DIPEA (350 $\mu \mathrm{L} ; 2 \mathrm{mmol} ; 2 \mathrm{eq}$ ) and propargyl bromide ( $80 \%$ in toluene; $130 \mu \mathrm{L} ; 1.2 \mathrm{mmol} ; 1.2 \mathrm{eq}$ ) dropwise at $0^{\circ} \mathrm{C}$. The mixture was stirred for $18 \mathrm{~h}$ after which it was evaporated to dryness. The residue was dissolved in a mixture of DCM $(4 \mathrm{~mL})$ and TFA $(4 \mathrm{~mL})$ and stirred for $1 \mathrm{~h}$ at room temperature. It was again evaporated to dryness and the residue was purified by flash column chromatography (DCM:MeOH + $0.5 \% \mathrm{AcOH}$ 99:1 $\rightarrow$ 90:10). The resulting yellow oil was dissolved in $\mathrm{DCM}(40 \mathrm{~mL})$, washed with $\mathrm{H}_{2} \mathrm{O}(2$ x $20 \mathrm{~mL}$ ) and brine $(20 \mathrm{~mL})$, , dried over $\mathrm{NaSO}_{4}$ and evaporated to obtain linker $\mathbf{1 1}$ as off-white foam (220 mg, $54 \%$ yield). $R_{f}=0.42$ (DCM:MeOH 9:1 + 0.5\% AcOH). ${ }^{1} H$ NMR $\left(250 \mathrm{MHz}\right.$, DMSO-d $\left.\mathrm{d}_{6}\right) \delta=7.88$ (d, J = 7.3 Hz, $2 \mathrm{H}), 7.68(\mathrm{~d}, J=7.2 \mathrm{~Hz}, 2 \mathrm{H}), 7.41(\mathrm{t}, J=7.2 \mathrm{~Hz}, 2 \mathrm{H}), 7.33(\mathrm{t}, J=7.2 \mathrm{~Hz}, 2 \mathrm{H}), 7.20(\mathrm{t}, J=$ $5.1 \mathrm{~Hz}, 1 \mathrm{H}), 4.33$ - 4.15 (m, 3 H), 3.48 (br. s, 2 H), 3.28 (s, 2 H), $3.17-3.02(\mathrm{~m}, 3 \mathrm{H}), 2.59$ (t, J = $6.4 \mathrm{~Hz}$, $2 \mathrm{H}) \mathrm{ppm}$. The presence of rotamers has caused considerable line broadening. ${ }^{13} \mathrm{C} \mathrm{NMR}(126 \mathrm{MHz}$, DMSO-d $\left.\mathrm{d}_{6}\right) \delta=172.0,156.2,144.0,140.8,127.7,127.2,125.3,120.2,79.1,76.0,65.4,54.2,52.6,46.8$, 42.0, 38.5 ppm. MS $\left(\mathrm{ESI}^{+}\right): \mathrm{m} / z=379.16\left[\mathrm{M}+\mathrm{H}^{+}\right]$. HRMS (MALDI): $m / z=379.16484\left[\mathrm{M}+\mathrm{H}^{+}\right]$, calcd. for $\mathrm{C}_{22} \mathrm{H}_{22} \mathrm{~N}_{2} \mathrm{O}_{4}+\mathrm{H}^{+}: 379.16523$.

\section{Synthesis and purification of PNA}

10mer PNA was synthesized manually on solid support (Rink Amide MBHA resin purchased from Novabiochem, now incorporated into Merck Millipore, Darmstadt, Germany) in a $2 \mathrm{~mL}$ polyethylene syringe reactor equipped with a fritted disc. A typical procedure is as follows: $43.6 \mathrm{mg}$ resin was swollen for $2 \mathrm{~h}$ in DCM. After washing with DMF $(3 \times 1 \mathrm{~mL})$ the coupling was performed with $\mathrm{HOBt}$ (17.0 mg; $111.2 \mu \mathrm{mol} ; 5$ eq), DIC (17.4 $\mu \mathrm{L} ; 111.2 \mu \mathrm{mol} ; 5$ eq), and Fmoc-Lys(Boc)-OH (52.1 mg; $111.2 \mu \mathrm{mol} ; 5 \mathrm{eq})$ in $350 \mu \mathrm{L}$ DMF. After shaking the syringe for $1 \mathrm{~h}$ at RT the resin was washed with DMF $(3 \times 1 \mathrm{~mL})$ and DCM $(3 \times 1 \mathrm{~mL})$. A Kaiser test was performed to show complete coupling, otherwise coupling was repeated. After washing with DMF ( $3 \times 1 \mathrm{~mL})$ deprotection was achieved by shaking the resin with $20 \%$ piperidine in DMF 3 times $(20 \mathrm{~min}, 7 \mathrm{~min}$ and $2 \mathrm{~min}$ ). The resin was washed with DMF ( $3 \times 1 \mathrm{~mL})$ and DCM $(3 \times 1 \mathrm{~mL})$ and a Kaiser test performed to show successful deprotection. After washing with DMF $(3 \times 1 \mathrm{~mL})$ the next monomer $(5$ eq) was coupled using the same conditions as before. The coupling and deprotection cycle was continued until the full 
sequence was assembled. The resin was then dried in vacuum after a final washing with DCM $(3 \mathrm{x}$ $1 \mathrm{~mL}$ ). Cleavage of the PNA from the resin was performed with $1.5 \mathrm{~mL}$ of a mixture of TFA, water and TIPS (9.5:0.25:0.25) twice $(2 \times 1 \mathrm{~h})$. The solvent was evaporated by a stream of air and the crude product dissolved in water purified by a Barnstead ${ }^{\mathrm{TM}}$ Smart2Pure ${ }^{\mathrm{TM}}$ Water Purification System.

For synthesis of 15mer PNA see Dogandzhiyski et al. Bioconjugate Chem. 2015, 26, 2514-2519.

\section{Click reaction}

Linkaging of PNA and QMP was accomplished by CuAAC in solution. The crude PNA (typically $300 \mu \mathrm{L}$ of a $400 \mu \mathrm{M}$ solution) was incubated with 2.5 eq QMP-azide 2 or 3 in a DMSO: $\mathrm{H}_{2} \mathrm{O}$ 1:1 solution containing $500 \mu \mathrm{M} \mathrm{Cu}$ "TBTA complex and $5 \mathrm{mM}$ sodium ascorbate for $2 \mathrm{~h}$ at $37^{\circ} \mathrm{C}$. (TBTA: Tris[(1benzyl-1H-1,2,3-triazol-4-yl)methyl]amine).

\section{HPLC purification}

PNA-conjugates were purified by RP-HPLC on a JASCO PU-980 with a JASCO UV-975 UV/VIS or a JASCO MD-2010 diode array detector. A mass spectrum (MALDI) of each conjugate was recorded. Since the nitrobenzyl group is photolabile the spectra show many degradation fragments.

$[\mathrm{M}+\mathrm{H}-16]$ Loss of oxygen

$[\mathrm{M}+\mathrm{H}-136]$ Loss of the nitrobenzyl group

[M+H-195] Formation of the quinone methide / self-adduct 


\section{PNA 13b}

MS (MALDI) $\mathrm{m} / \mathrm{z}=3408.4[\mathrm{M}+\mathrm{H}]^{+}$, calcd for $\mathrm{C}_{142} \mathrm{H}_{181} \mathrm{~N}_{65} \mathrm{O}_{38}+\mathrm{H}^{+}: 3405.4$

HPLC conditions: preparative: Phenomenex Gemini C18, $250 \times 10,10 \mu \mathrm{m}$, linear gradient of $10-$ $32.2 \% \mathrm{MeCN}$ in $0.1 \%$ TFA for $30 \mathrm{~min}, 4.0 \mathrm{~mL} / \mathrm{min}, 50^{\circ} \mathrm{C}, 254 \mathrm{~nm} . \mathrm{t}_{\mathrm{R}}=17.3 \mathrm{~min}$; analytical: Phenomenex Gemini C18, $150 \times$ 4.6, $5 \mu \mathrm{m}, 2$ min hold $5 \%$ MeCN, linear gradient of $5-60 \%$ MeCN in $0.1 \%$ TFA for $15 \mathrm{~min}, 1 \mathrm{~mL} / \mathrm{min}, 260 \mathrm{~nm}, \mathrm{t}_{\mathrm{R}}=11.0 \mathrm{~min}$.

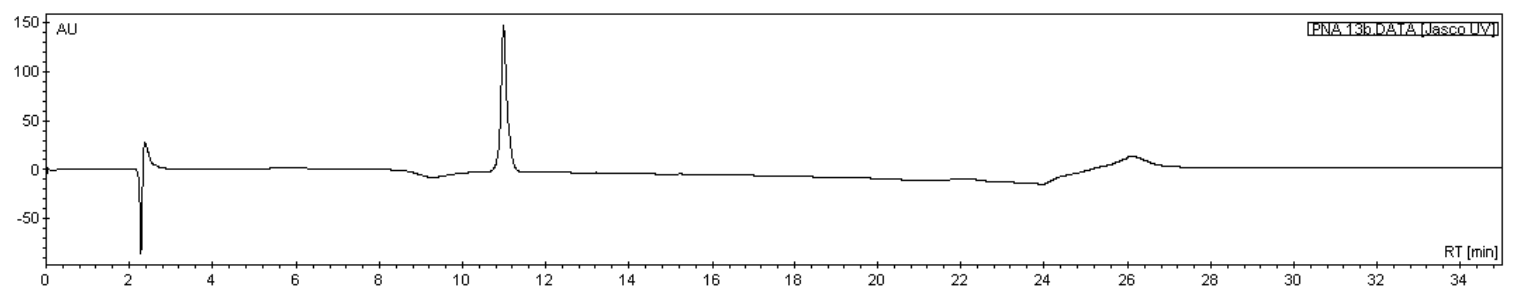

Voyager Spec \#1[BP = 3393.4, 21264]

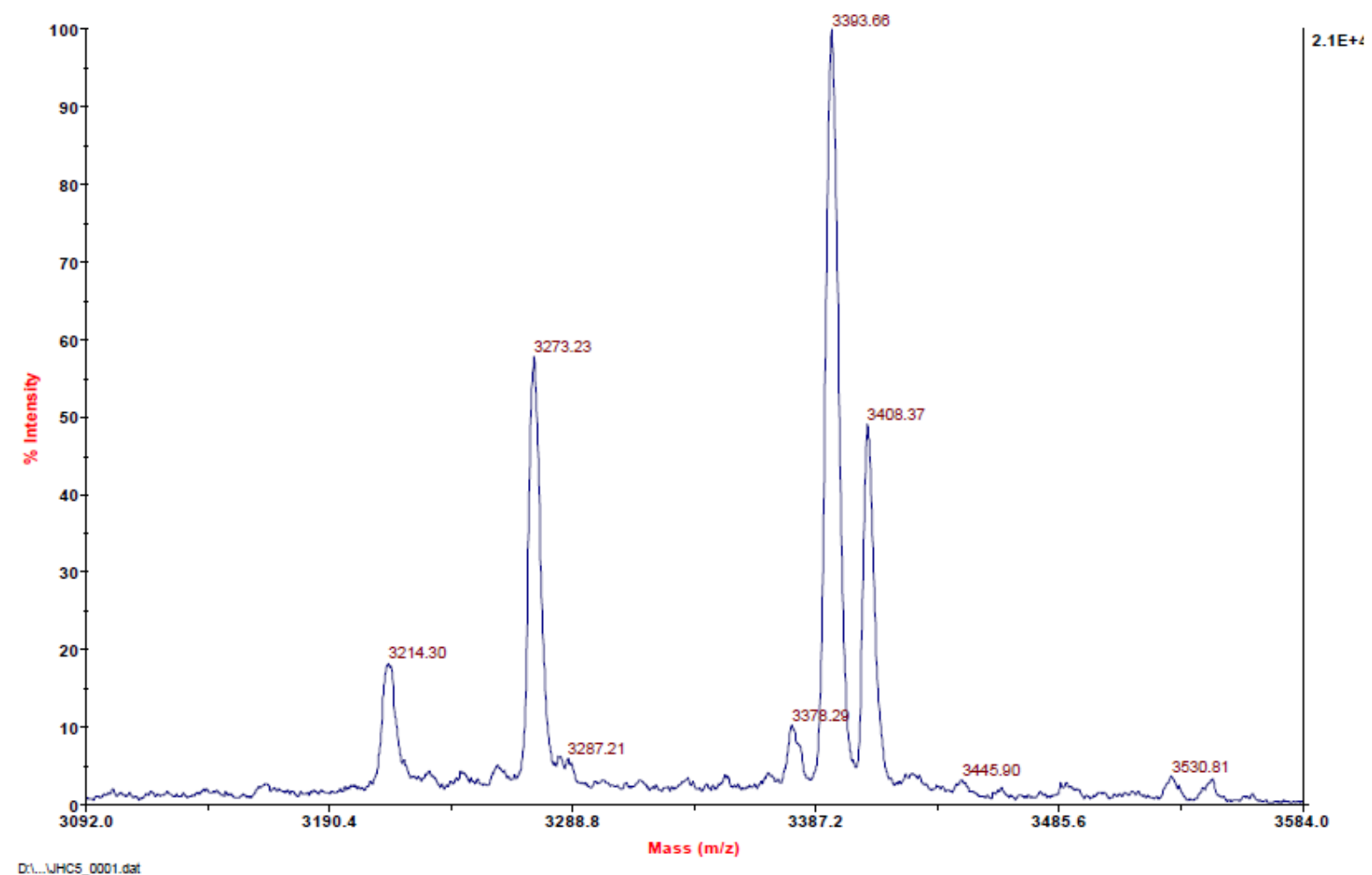




\section{PNA 15b}

MS (MALDI) $\mathrm{m} / \mathrm{z}=3404.1[\mathrm{M}+\mathrm{H}]^{+}$, calcd for $\mathrm{C}_{142} \mathrm{H}_{181} \mathrm{~N}_{65} \mathrm{O}_{38}+\mathrm{H}^{+}: 3405.4$

HPLC conditions: preparative: Phenomenex Gemini C18, $250 \times 10,10 \mu \mathrm{m}$, linear gradient of $6-50 \%$ $\mathrm{MeCN}$ in $0.1 \%$ TFA for $40 \mathrm{~min}, 4.0 \mathrm{~mL} / \mathrm{min}, 50^{\circ} \mathrm{C}, 254 \mathrm{~nm} . \mathrm{t}_{\mathrm{R}}=18.2 \mathrm{~min}$; analytical: Phenomenex Gemini $\mathrm{C} 18,150 \times 4.6,5 \mu \mathrm{m}, 2$ min hold $5 \% \mathrm{MeCN}$, linear gradient of $5-60 \% \mathrm{MeCN}$ in $0.1 \%$ TFA for $15 \mathrm{~min}, 1 \mathrm{~mL} / \mathrm{min}, 260 \mathrm{~nm}, \mathrm{t}_{\mathrm{R}}=11.2 \mathrm{~min}$.
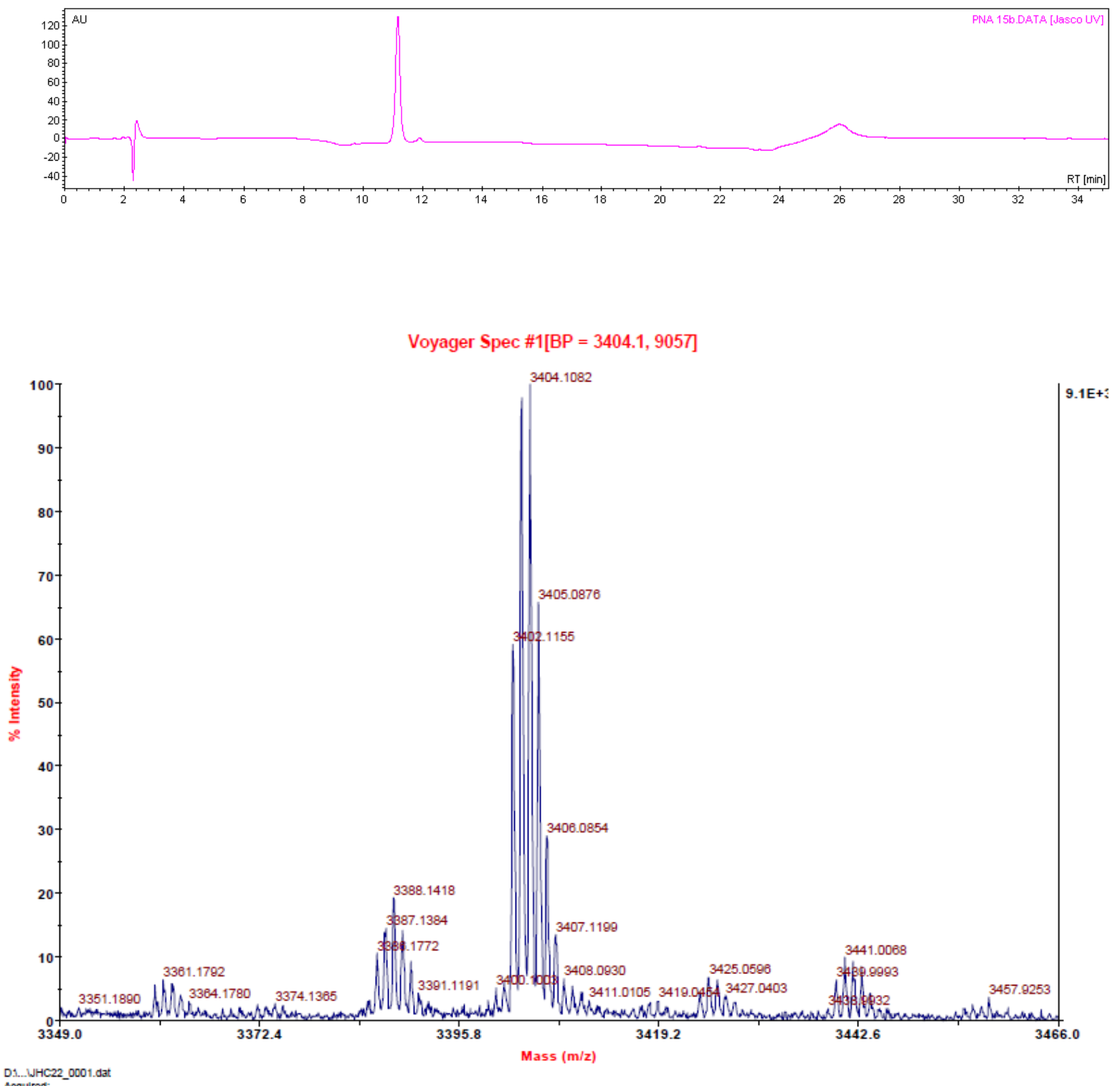

D1. UHC22_0001.dat 


\section{PNA 17b}

MS (MALDI) $\mathrm{m} / \mathrm{z}=3443.80[\mathrm{M}+\mathrm{H}]^{+}$, calcd for $\mathrm{C}_{144} \mathrm{H}_{182} \mathrm{~N}_{66} \mathrm{O}_{38}+\mathrm{H}^{+}$: 3444.4; analytical: Phenomenex Gemini C18, $150 \times$ 4.6, $5 \mu \mathrm{m}, 2$ min hold $5 \% \mathrm{MeCN}$, linear gradient of $5-60 \% \mathrm{MeCN}$ in $0.1 \%$ TFA for $15 \mathrm{~min}, 1 \mathrm{~mL} / \mathrm{min}, 260 \mathrm{~nm}, \mathrm{t}_{\mathrm{R}}=11.2 \mathrm{~min}$.

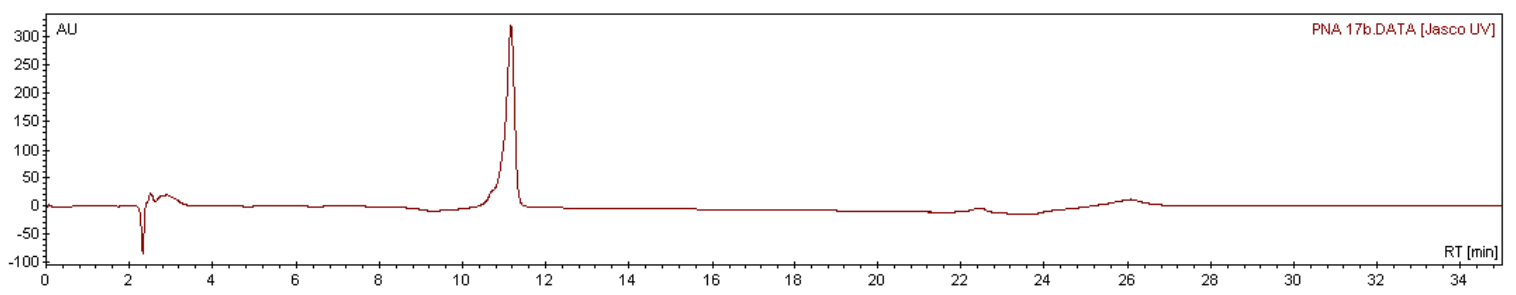

Voyager Spec \#1 $=>$ SM11[BP = 3306.6, 30003]

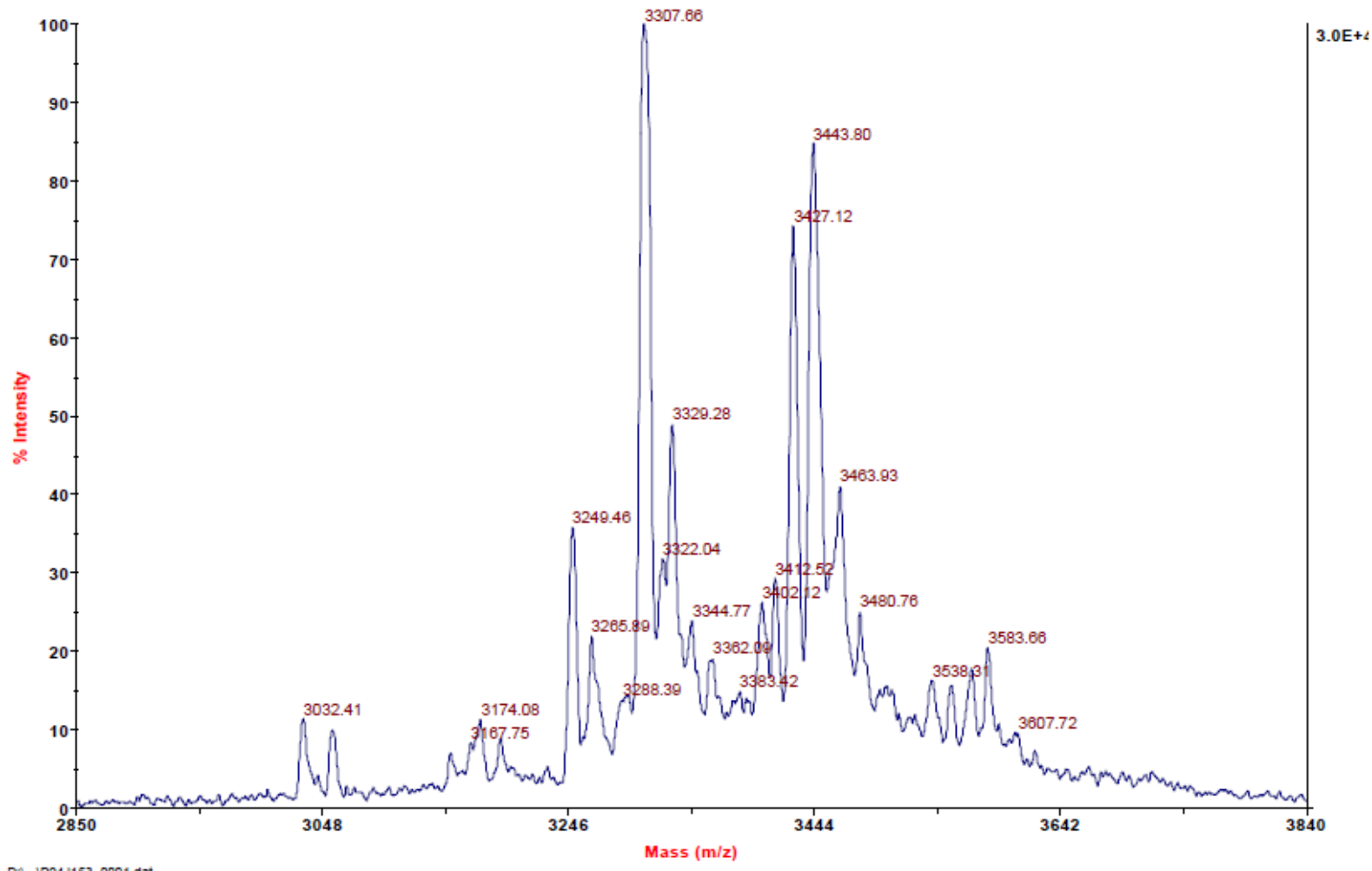

D.L.IP24J153_0001.dat: 


\section{PNA 18b}

MS (MALDI) $\mathrm{m} / \mathrm{z}=4902.6[\mathrm{M}+\mathrm{H}]^{+}$, calcd for $\mathrm{C}_{204} \mathrm{H}_{261} \mathrm{~N}_{95} \mathrm{O}_{54}+\mathrm{H}^{+}: 4906.1$

HPLC conditions: analytical: Phenomenex Gemini C18, $150 \times$ 4.6, $5 \mu \mathrm{m}, 2$ min hold $5 \%$ MeCN, linear gradient of $5-60 \% \mathrm{MeCN}$ in $0.1 \%$ TFA for $15 \mathrm{~min}, 1 \mathrm{~mL} / \mathrm{min}, 260 \mathrm{~nm}, \mathrm{t}_{\mathrm{R}}=10.9 \mathrm{~min}$; preparative: Phenomenex Gemini C18, $250 \times 10,10 \mu \mathrm{m}$, linear gradient of $10-32.2 \%$ MeCN in $0.1 \%$ TFA for 30 $\min , 4.0 \mathrm{~mL} / \mathrm{min}, 50^{\circ} \mathrm{C}, 254 \mathrm{~nm}, \mathrm{t}_{\mathrm{R}}=17.4 \mathrm{~min}$.
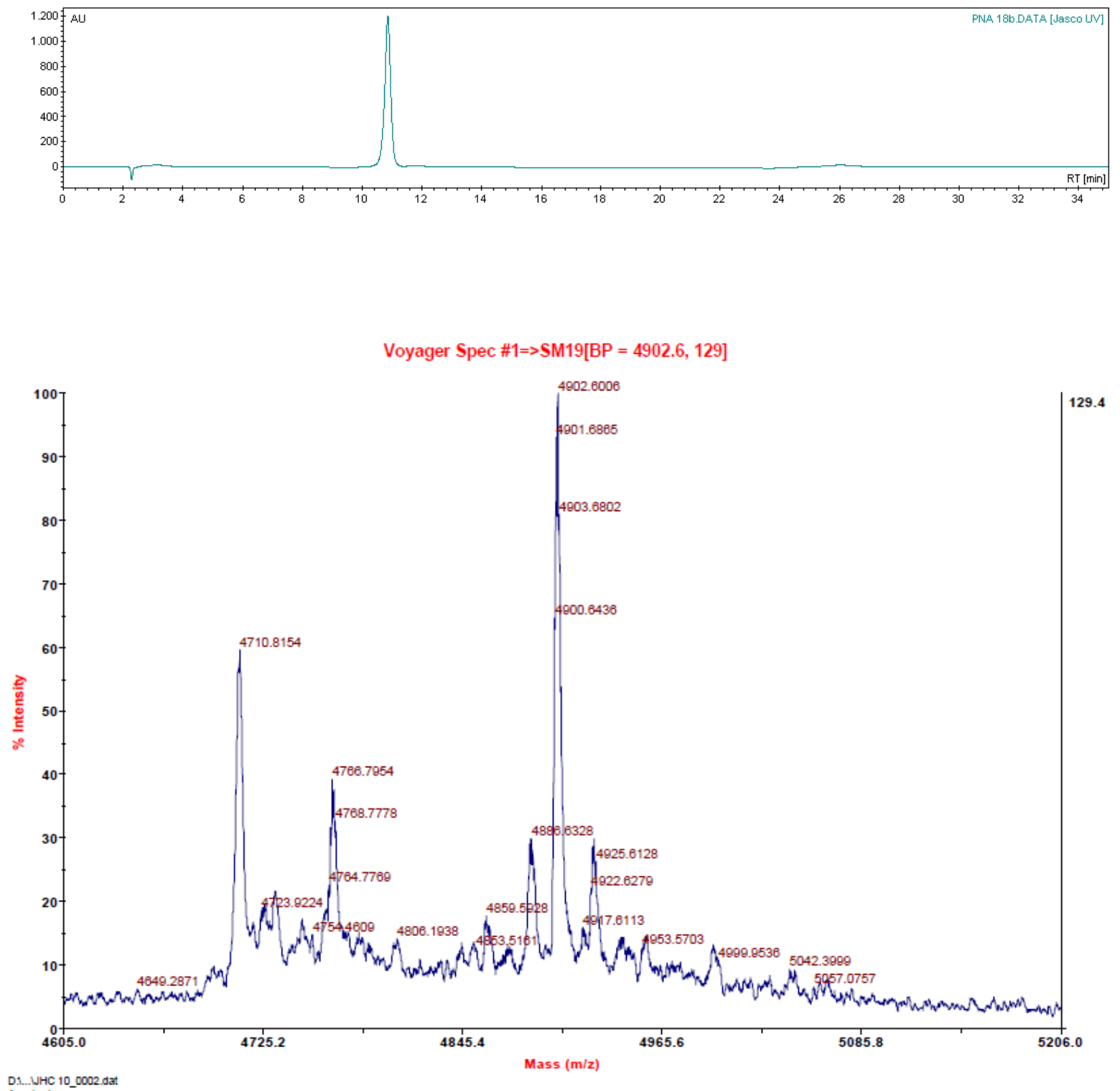


\section{PNA 19b}

MS (MALDI) m/z = $3095.8[\mathrm{M}+\mathrm{H}]^{+}$, calcd for $\mathrm{C}_{129} \mathrm{H}_{164} \mathrm{~N}_{62} \mathrm{O}_{32}+\mathrm{H}^{+}: 3094.3$

HPLC conditions: analytical \& preparative: Phenomenex Gemini C18, $150 \times 4.6,5 \mu \mathrm{m}, 2$ min hold $5 \%$ MeCN, linear gradient of $5-60 \% \mathrm{MeCN}$ in $0.1 \%$ TFA for $15 \mathrm{~min}, 1 \mathrm{~mL} / \mathrm{min}, 260 \mathrm{~nm}, \mathrm{t}_{\mathrm{R}}=10.0 \mathrm{~min}$.

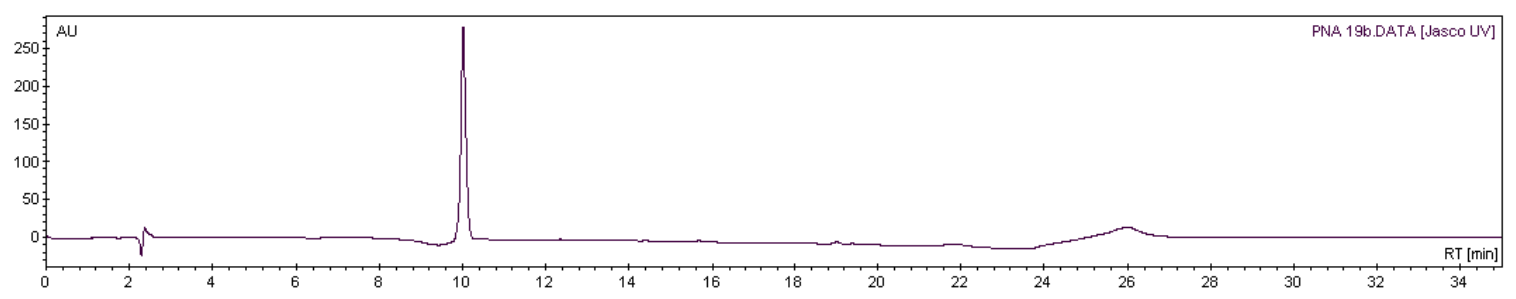

Voyager Spec \#1[BP = 3080.9, 4381]

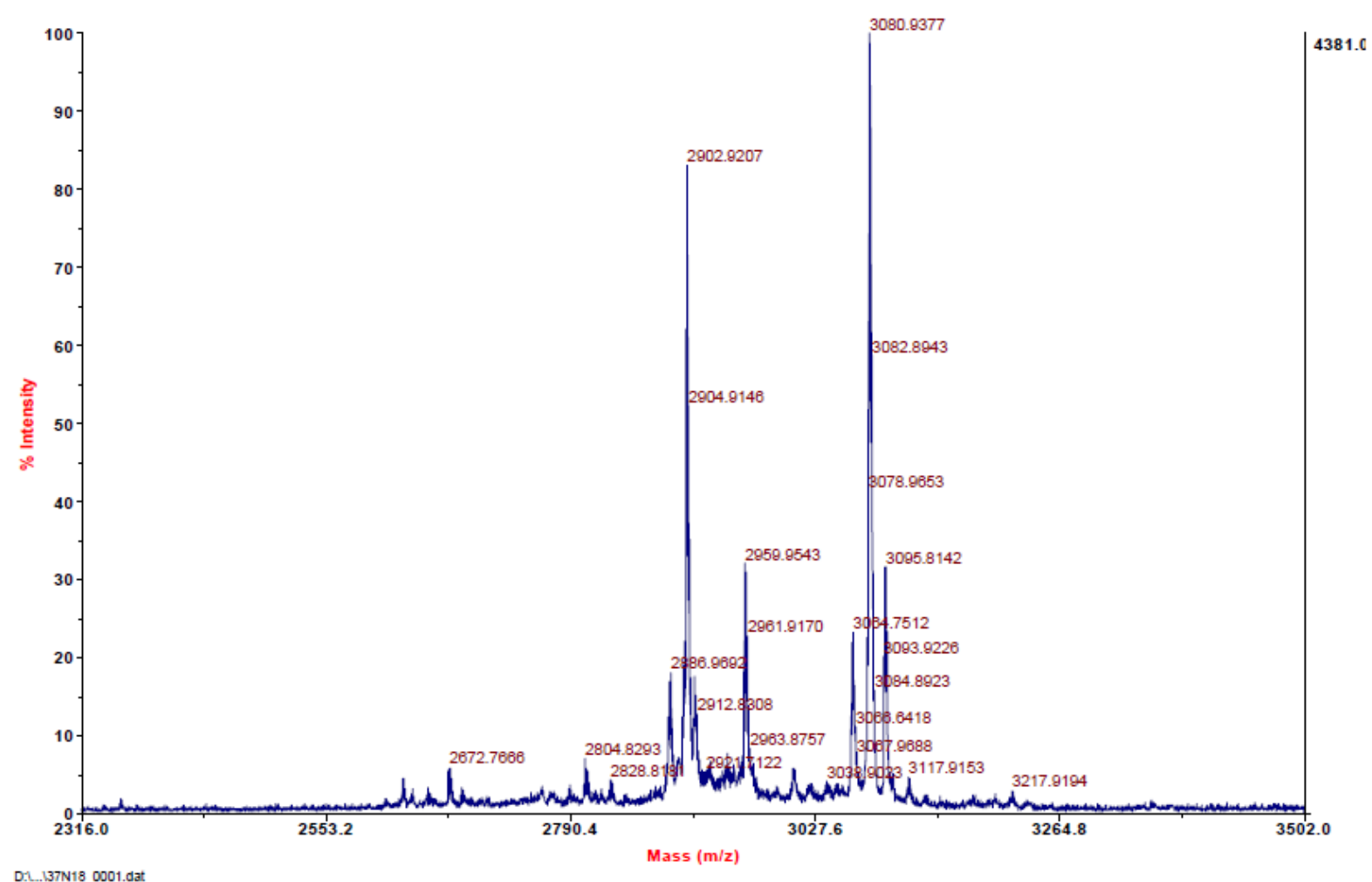




\section{Inactivation of RNases}

All experimental steps were performed under sterile conditions. Plasticware, tubes and most solutions were treated with diethylpyrocarbonate (DEPC). Solutions which are not compatible with DEPC treatment were prepared by mixing molecular biology grade powdered reagents up in DEPCtreated ultrapure water. All glassware was baked at $180^{\circ} \mathrm{C}$ for six hours.

\section{Polyacrylamide Gel Electrophoresis}

The samples were analyzed by denaturing PAGE (16\% acrylamide, $7 \mathrm{M}$ urea, $150 \times 310 \mathrm{~mm}, 80 \mathrm{~mm}$ separation distance) on a DNA sequencing device (ALFexpress, GE Healthcare/Amersham Bioscience). Prior to electrophoresis each sample was diluted to $150 \mathrm{nM}$ RNA and 1.5 equivalents of loading buffer ( $8 \mathrm{M}$ Urea, $20 \mathrm{mM}$ EDTA and $0.2 \%$ Crocein Orange in DEPC water) were added. $5 \mu \mathrm{L}$ were loaded on the gel. Electrophoresis was performed with the following settings: $1500 \mathrm{~V}$ (maximum), $60 \mathrm{~mA}$ (maximum), $25 \mathrm{~W}$ (constant), 25 or $57^{\circ} \mathrm{C}, 2 \mathrm{~s}$ sampling interval. The electropherogram was further analyzed with the AlleleLinks 1.01 software package (Amersham Biosciences, Uppsala, Sweden). Peak areas of educt and alkyation product were integrated to determine the degree of alkylation. Graphing and curve fitting of the results was performed in OriginPro (OriginLab, Northampton, MA).

\section{Photochemical deprotection of quinone methide precursors}

Irradiation was performed in a custom build apparatus. Two LZ1-10UV00 (LED Engin Inc.) 365 nm UVLEDs were mounted on heatsink. A holder for two glass tubes (Carl Roth $50 \times \emptyset 10 \mathrm{~mm}$ ) was mounted on top in a way that the tubes were irradiated from the bottom.

A lab bench power supply was configured to drive the LEDs with a constant current of $0.4 \mathrm{~A}$ corresponding to a radiant flux of $550 \mathrm{~mW}$.

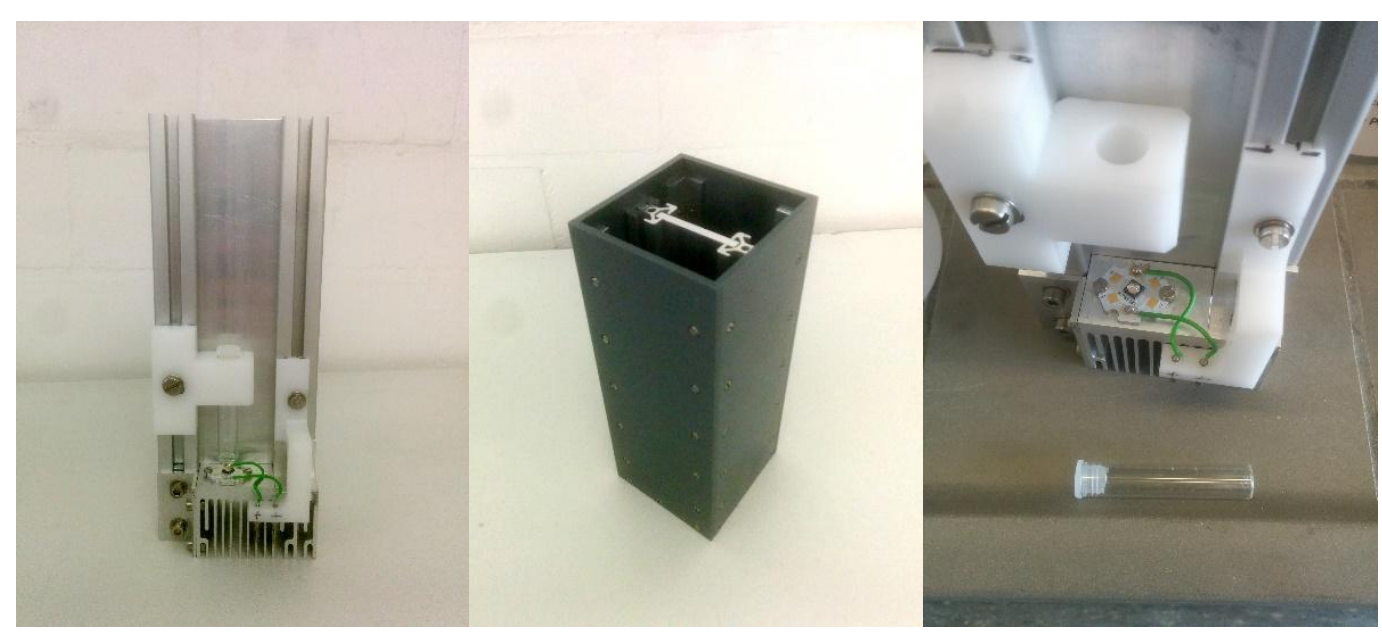

Figure S1: Apparatus used for the light induced activation of the quinone methide precursors. 


\section{Irradiation of PNA and measuring self-alkylation kinetics}

A solution containing $30 \mu \mathrm{M}$ PNA, $130 \mathrm{mM}$ MES buffer $(\mathrm{pH}$ 7) and $130 \mathrm{mM} \mathrm{NaCl}$ was mixed in Eppendorf tubes to reach a final volume of $140 \mu \mathrm{L}$. The solution was irradiated for $2 \mathrm{~min}$ in the Eppendorf tube and incubated at $37^{\circ} \mathrm{C} .20 \mu \mathrm{L}$ samples were taken after the indicated time intervals and analyzed by HPLC. To determine the amount of self-alkylation the ratio between initial peak area (corresponding to the acetal ester) and the emerging peaks (corresponding to the self-adducts) was calculated.

HPLC conditions: Phenomenex Gemini C18, $150 \times$ 4.6, $5 \mu \mathrm{m}$, linear gradient of $7-40 \% \mathrm{MeCN}$ in $0.1 \mathrm{M}$ TEAA buffer (pH 7) for $10 \mathrm{~min}, 2 \mathrm{~mL} / \mathrm{min}, 254 \mathrm{~nm}, 50^{\circ} \mathrm{C}$.

\section{Isolation of the unstable photolysis product 13c}

PNA conjugate 13b was irradiated as described above. Immediately after photolysis, the sample was separated by HPLC using the given conditions. A new faster running peak (see Figure $1 \mathrm{~b}$ ) was isolated and lyophilized. The MALDI spectrum (Figure S2, see below) shows a predominant peak corresponding to the calculated mass of 13c. For the self-adducts, a mass of 3210.38 is expected (Figure S3), for the hydrolysis product a mass of 3228.39 .

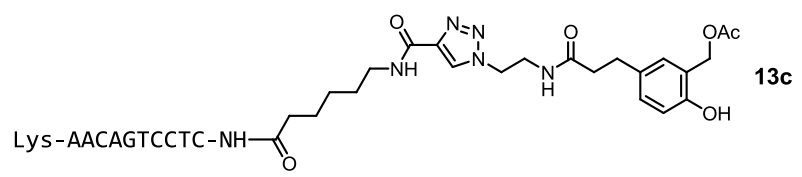

Voyager Spec \#1=>SM21[BP = 3273.1, 10057]

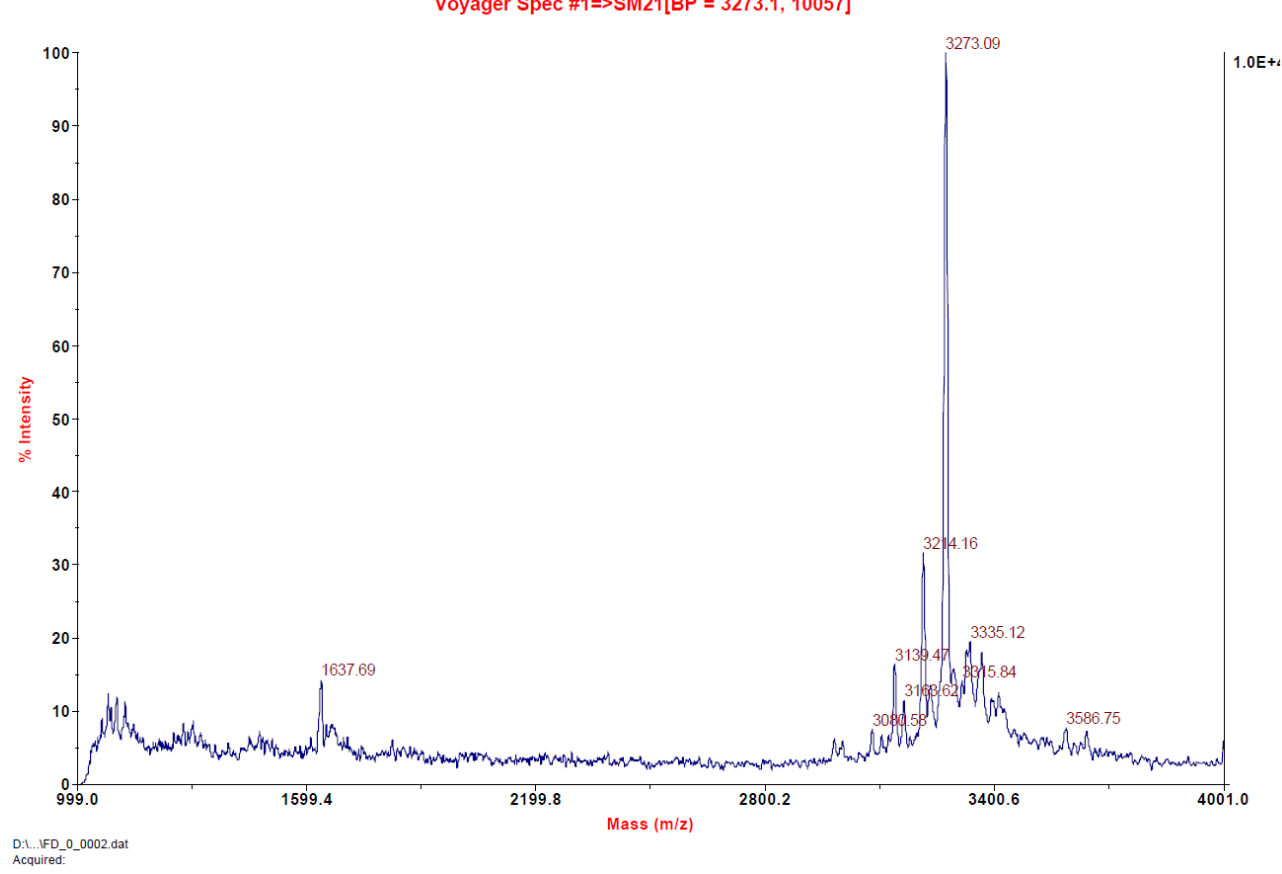

Figure S2: Mass spectrum of compound 13c (MALDI). $\mathrm{m} / \mathrm{z}=3273.1[\mathrm{M}+\mathrm{H}]^{+}$, calcd for $\mathrm{C}_{135} \mathrm{H}_{176} \mathrm{~N}_{64} \mathrm{O}_{36}+\mathrm{H}^{+}: 3270.40$ 


\section{Mass spectrometric characterization of self-alkylation products}

PNA conjugates $\mathbf{1 3 b}, \mathbf{1 7 b}$, and $\mathbf{1 9 b}$ were irradiated as described above. After $2 \mathrm{~h}$ of incubation at $37^{\circ} \mathrm{C}$, the samples were separated by HPLC. The faster running group of peaks (e.g. Figure $1 \mathrm{~d}$ ) was isolated and evaporated to dryness in a SpeedVac.

Voyager Spec \#1[BP = 3211.6, 2333]

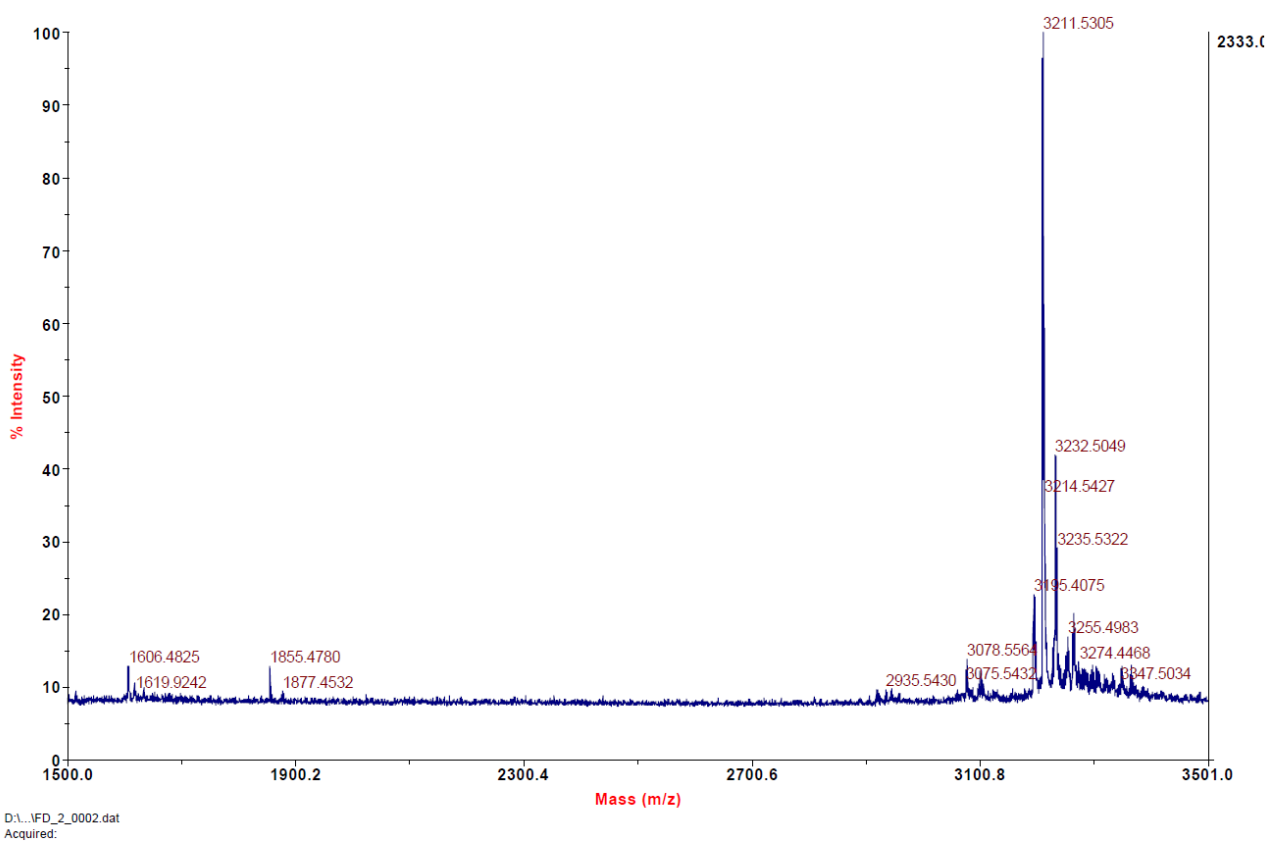

Voyager Spec \#1 [BP = 3211.6, 2333]

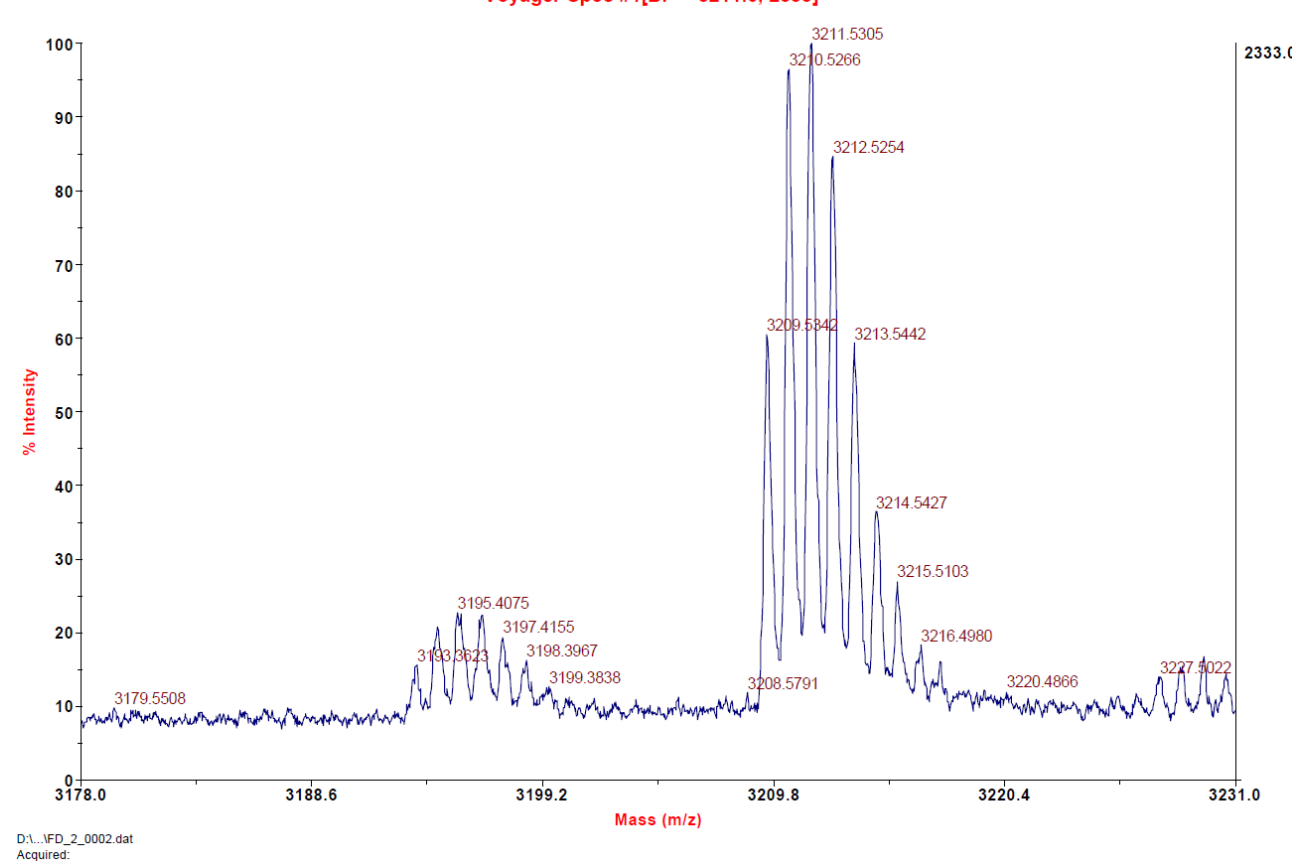

Figure S3: Mass spectrum of compound 13b after irradiation, elimination of HOAC and selfalkylation (MALDI). Top: Overview. Bottom: Detail. $\mathrm{m} / \mathrm{z}=3211.5[\mathrm{M}+\mathrm{H}]^{+}$, calcd for $\mathrm{C}_{133} \mathrm{H}_{172} \mathrm{~N}_{64} \mathrm{O}_{34}+\mathrm{H}^{+}$: 3210.38 
Voyager Spec \#1 [BP = 3250.7, 4261]

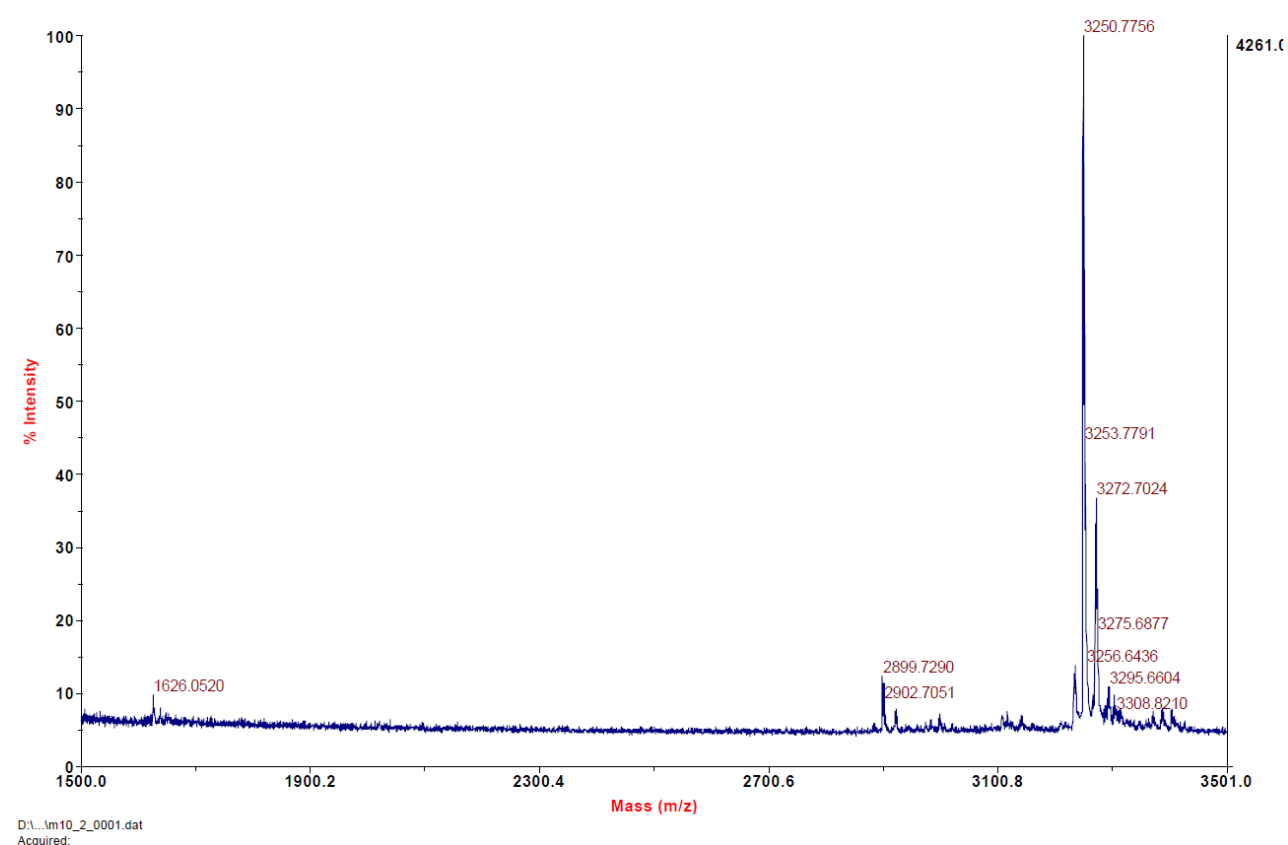

Figure S4: Mass spectrum of compound 17b after irradiation, elimination of HOAC and selfalkylation (MALDI). $\mathrm{m} / \mathrm{z}=3250.7[\mathrm{M}+\mathrm{H}]^{+}$, calcd for $\mathrm{C}_{135} \mathrm{H}_{173} \mathrm{~N}_{65} \mathrm{O}_{34}+\mathrm{H}^{+}: 3249.39$

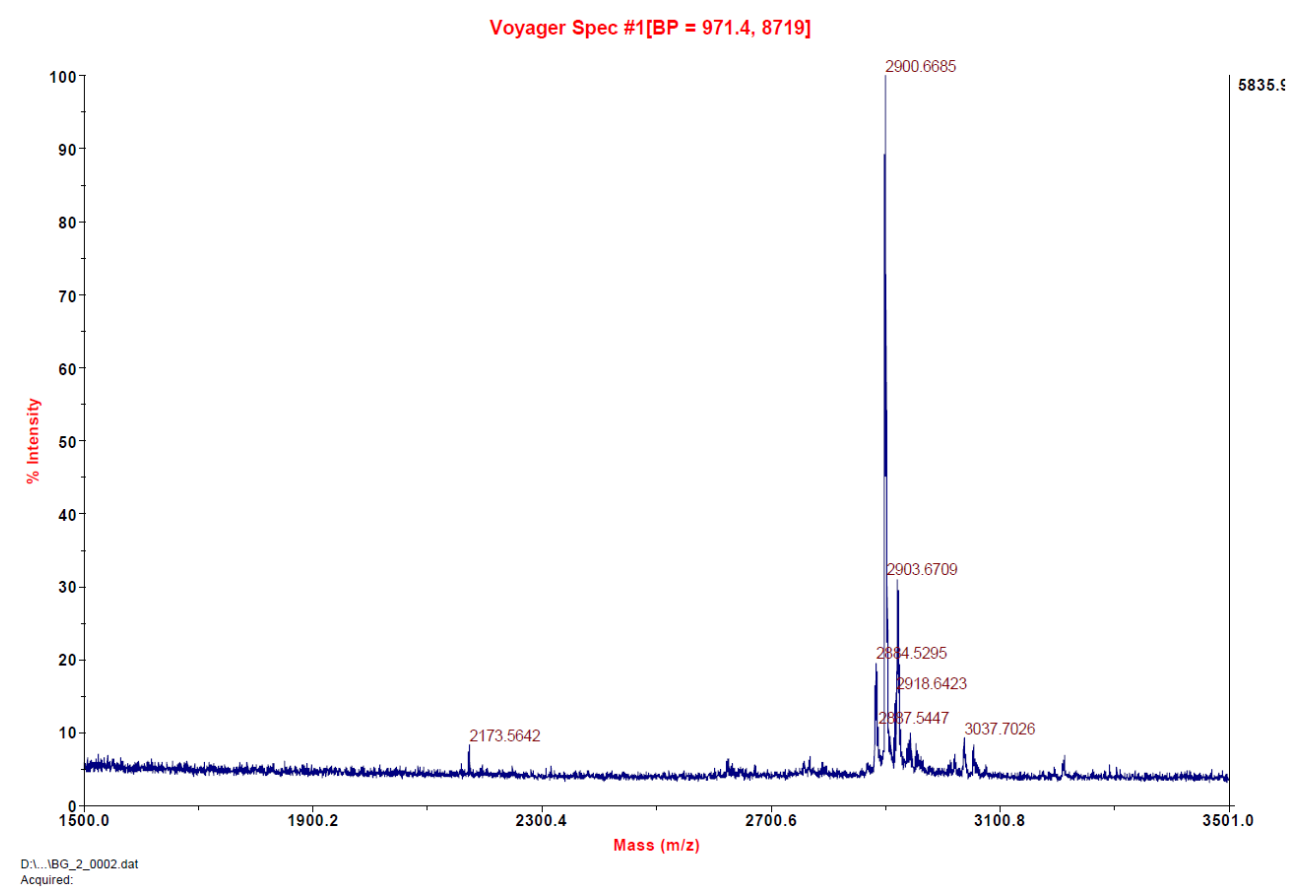

Figure S5: Mass spectrum of compound 19b after irradiation, elimination of HOAc and selfalkylation (MALDI). $\mathrm{m} / \mathrm{z}=2900.67[\mathrm{M}+\mathrm{H}]^{+}$, calcd for $\mathrm{C}_{120} \mathrm{H}_{155} \mathrm{~N}_{61} \mathrm{O}_{28}+\mathrm{H}^{+}: 2899.27$ 


\section{Irradiation and Incubation of PNA with RNA}

A solution containing $6 \mu \mathrm{M}$ PNA, $3 \mu \mathrm{M}$ RNA (Cy5 labeled), $130 \mathrm{mM}$ MES buffer ( $\mathrm{pH}$ 7) and $130 \mathrm{mM}$ $\mathrm{NaCl}$ were mixed in Eppendorf tubes (DNA LoBind Tubes) to reach a final volume of $20 \mu \mathrm{L}$. This solution was transferred into a $50 \times \varnothing 10 \mathrm{~mm}$ glass tube and irradiated for $2 \mathrm{~min}$ with the above described apparatus. Afterwards a $1 \mu \mathrm{L}$ sample was taken and the solution transferred into a DNA low bind Eppendorf tube. The tube was kept in an incubator at $37^{\circ} \mathrm{C}$. Further samples of $1 \mu \mathrm{L}$ were drawn after indicated time intervals. The samples were diluted to a total volume of $10 \mu \mathrm{L}$ with DEPC water and stored in a freezer at $-20^{\circ} \mathrm{C}$.

\section{Analysis of RNA alkylation using the ALFexpress sequencer}

The ALFexpress sequencer basically runs a denaturing polyacrylamide gel under well controlled electrophoresis conditions. The picture shows the open apparatus with the gel cassette removed. Cy5-labeled samples are loaded into 40 lanes on the top of the gel. Upon electrophoresis, dye labeled oligos, fragments, or extension products move in the gel downwards with different speeds until they cross a horizontal laser beam at the bottom of the sequencer. Fluorescent emission of Cy5 is then registered independently for each lane by 40 avalanche photodiodes (shiny oval spots down in Figure S6). As long as the dye-labeled oligonucleotides do not contain quenching chromophores, the signal is proportional to the absolute concentration of Cy5 moving through the laser beam. Due

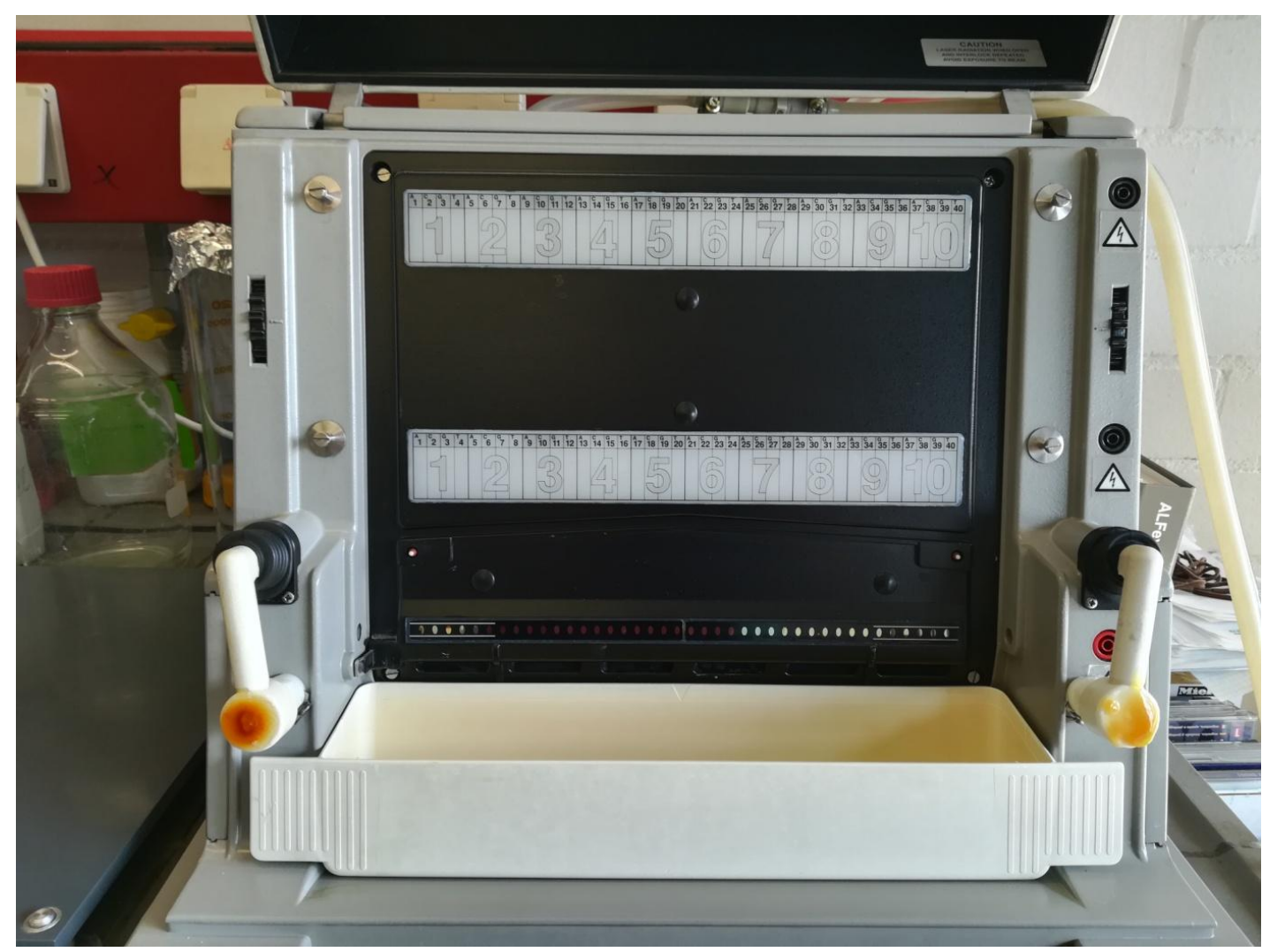

Figure S6: ALFexpress sequencer (gel chamber removed) used to quantify the crosslinking yields. 
to attenuation of the beam by the gel matrix, identical samples may generate stronger signals in lane 1 compared to lane 40 . Within a single lane, however, integrals of the fluorescent signals represent the relative concentration of each Cy5-labeled species present in that lane. Thus, although the method is denaturing polyacrylamide gel electrophoresis, the plotted data look like HPL chromatograms and can be interpreted in the same way. The original data shown in Figures 3, 5, and 8 were obtained in this way.

\section{RNA alkylation requires irradiation of the PNA-QMP conjugates}

To demonstrate that photochemical removal of the nitrobenzyl group is a precondition for RNA alkylation, RNA 12 and PNA 13b were incubated as described above for $72 \mathrm{~h}$. The irradiation step, however, was omitted (Figure S7).

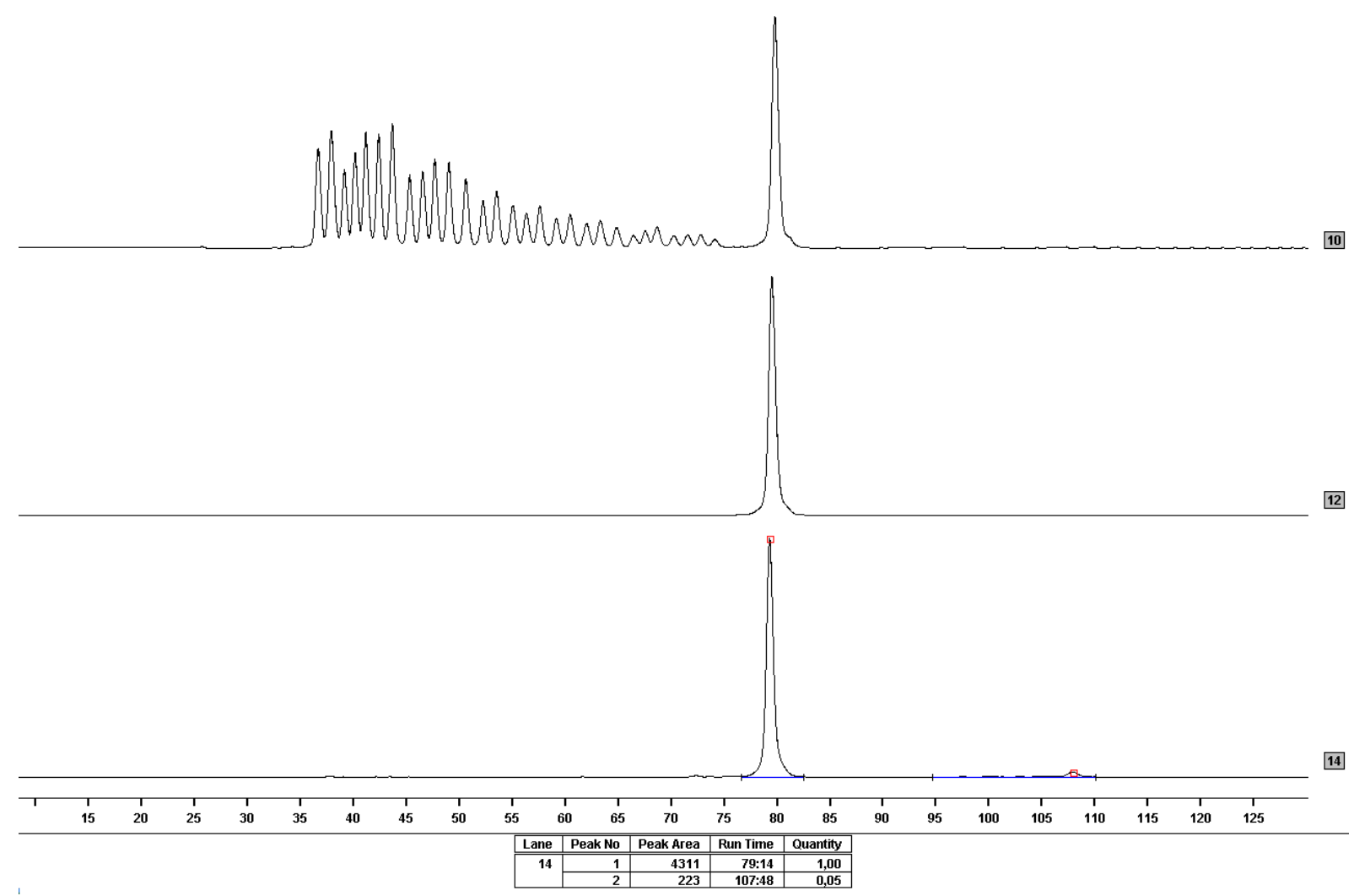

Figure S7. Top: The base ladder of 29mer RNA 12 obtained by partial hydrolysis and analyzed with the ALFexpress sequencer as described above shows 29 well separated fragments. Middle: RNA 12 before incubation with PNA 13b. Bottom: RNA 12 after incubation with PNA 13b for $72 \mathrm{~h}$ in the dark. The amount of crosslinks (108 $\mathrm{min}$ ) is reduced to a minimum. The handling of the sample was done under dimmed daylight. This may have caused a few percent of deprotection. 


\section{Correspondence of HPLC peaks and signals in the sequencer}

The experiments was conducted almost as described under "Irradiation and Incubation of PNA with RNA" but concentrations were increased: RNA $14(10 \mu \mathrm{M})$ was incubated with PNA 15b $(20 \mu \mathrm{M})$, irradiated and incubated for some hours at $37^{\circ} \mathrm{C}$. The reaction mixture was then separated by HPLC Figure S8, b and c). Three fractions (A, B, C) were isolated, evaporated to dryness in a SpeedVac and subsequently analyzed in the sequencer (Figure S9). HPLC conditions: Phenomenex Synergi $10 \mu \mathrm{m}$ Hydro-RP 80A HPLC column $250 \times 4.6$ mm, 4 min hold $10 \%$ MeCN, linear gradient of $10-50 \%$ MeCN in $0.1 \mathrm{M}$ TEAA buffer ( $\mathrm{pH}$ 7) for $36 \mathrm{~min}, 1 \mathrm{~mL} / \mathrm{min}, 50^{\circ} \mathrm{C}$.

RNA 14: ${ }^{\prime}$ Cy5-T 10 - AUACCUUGUGCGAGAAAGAGAGGCCGUUA-T ${ }_{4}{ }^{3}$

PNA 15b: Lys-AACACGCTCT-NH-Linker-QMP 2

a)

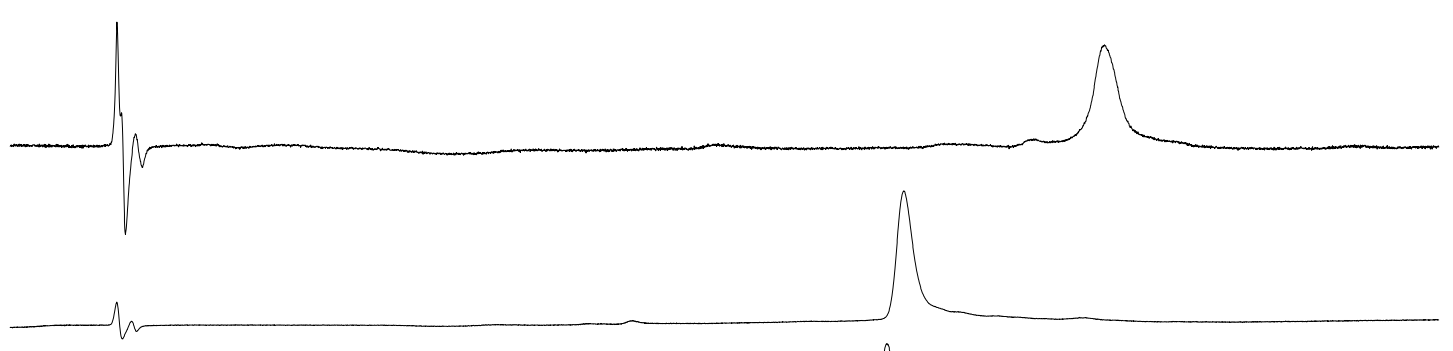

c)

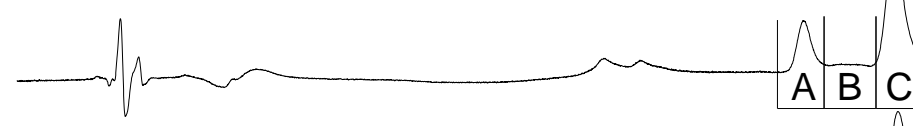

d)

e)

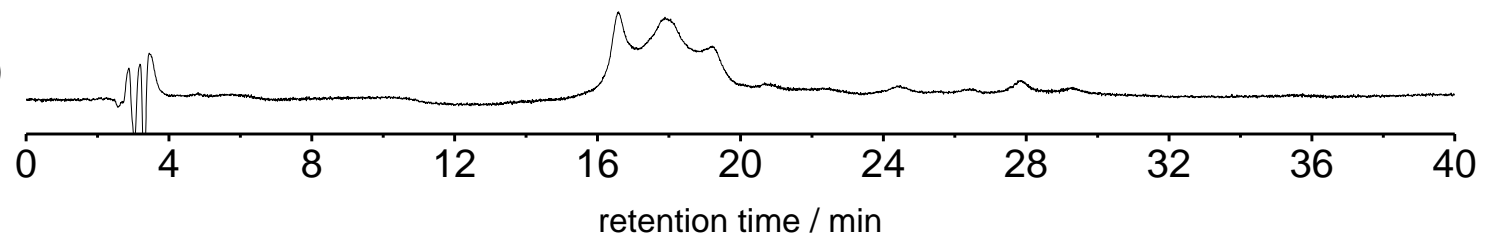

Figure S8. Alkylation of the dye labeled RNA 14 analysed by HPLC. a) PNA 15b before irradiation, detection by UV absorbance at $260 \mathrm{~nm}$. b) Untreated RNA 14, detection by UV absorbance at $260 \mathrm{~nm}$. c) Reaction mixture of RNA 14 and irradiated PNA 15b, detection by UV absorbance at $260 \mathrm{~nm} ; \mathrm{PNA}, \mathrm{RNA}$ and alkylation products are all visible. The boundaries of fractions A, B, and C are shown. ALFexpress analysis of these fractions is shown below in Figure S9. d) Same run but detection by fluorescence; excitation at $600 \mathrm{~nm}$, detection at $650 \mathrm{~nm}$; only the Cy5-labeled RNA and crosslinked products are visible. e) Pure PNA 15b 40 min after irradiation; detection by UV absorbance at $260 \mathrm{~nm}$; the PNA is mainly converted into self-alkylation products. 
a)

b)

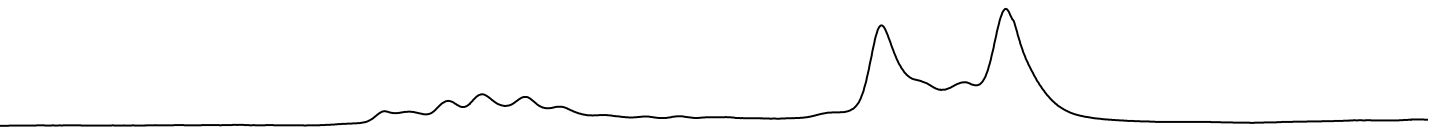

c)

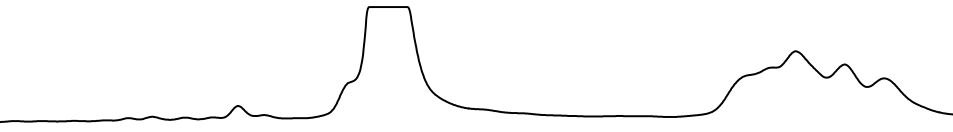

d)

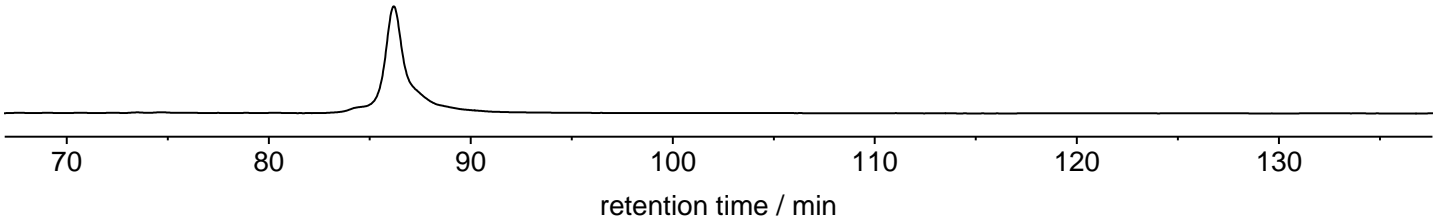

Figure S9. Alkylation of the dye labeled RNA 14 analysed with the sequencer. a) HPLC fraction A (see Figure S8) contains crosslinked RNA exclusively. The corresponding mass spectrum is shown in Figure S10. b) HPLC fraction B: Different types of crosslinked RNA. c) HPLC fraction C: Free RNA 14 and some crosslinked material. d) Untreated RNA 14 as a reference. Gel temperature: $57^{\circ} \mathrm{C}$.

\section{Mass spectrometric detection of PNA-RNA crosslinks}

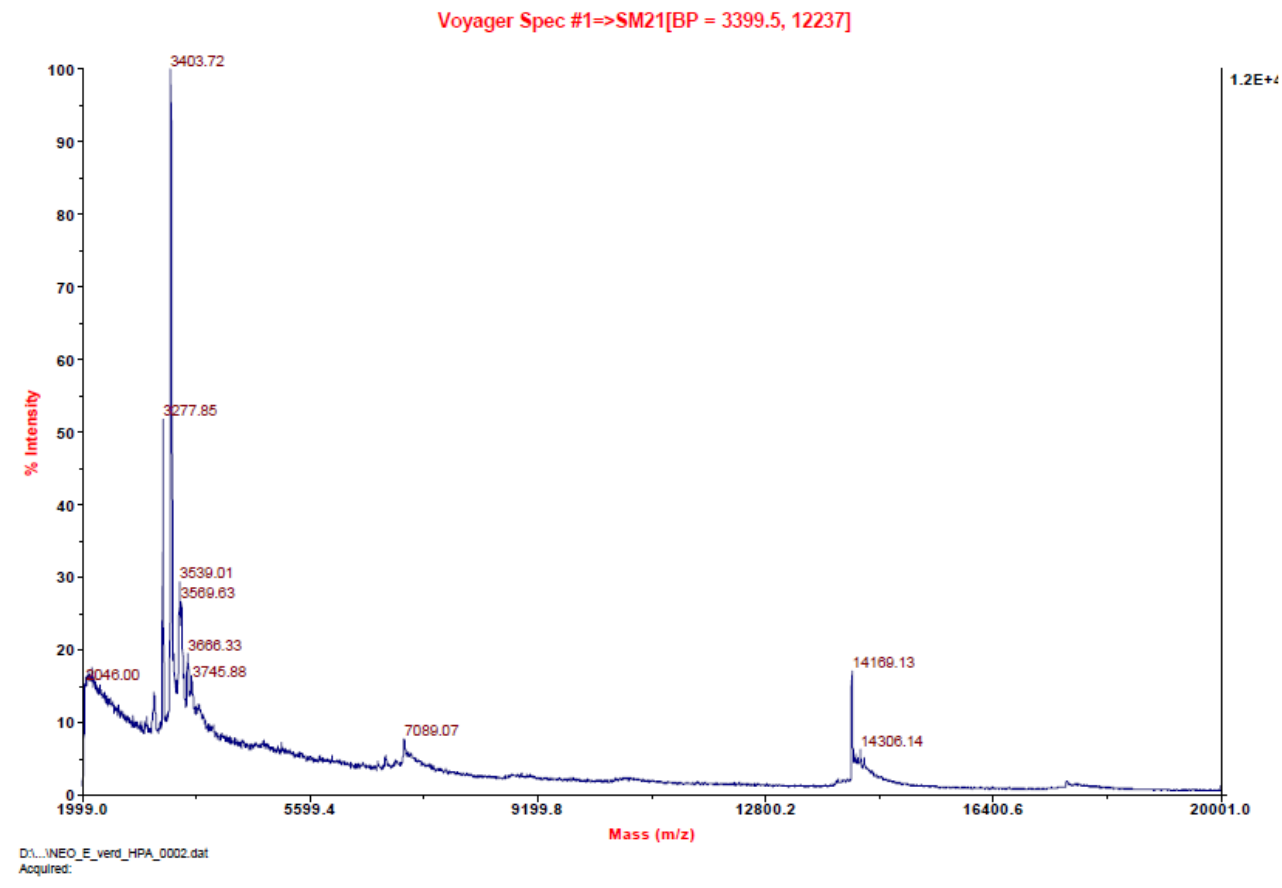

Figure S10a. Mass spectrometric detection of PNA-RNA crosslinks (MALDI), control experiment. RNA $14(20 \mu \mathrm{M})$ was incubated with PNA 15b $(40 \mu \mathrm{M})$ without irradiation in DEPC water. Mass spectrometric analysis (matrix: HPA, 3-hydroxypicolinic acid) showed 
peaks of the non-irradiated PNA 15b (calcd for $\mathrm{C}_{142} \mathrm{H}_{181} \mathrm{~N}_{65} \mathrm{O}_{38}+\mathrm{H}^{+}$: 3405.4) and of RNA 14 (calcd for $\mathrm{C}_{450} \mathrm{H}_{563} \mathrm{~N}_{147} \mathrm{O}_{300} \mathrm{P}_{43}+\mathrm{H}^{+}$: 14163.97) but no significant signal of duplexes or crosslinked products. Duplexes of $\mathbf{1 4}$ and $\mathbf{1 5 b}$, bound to each other by base pairing only, are well separated under these conditions.

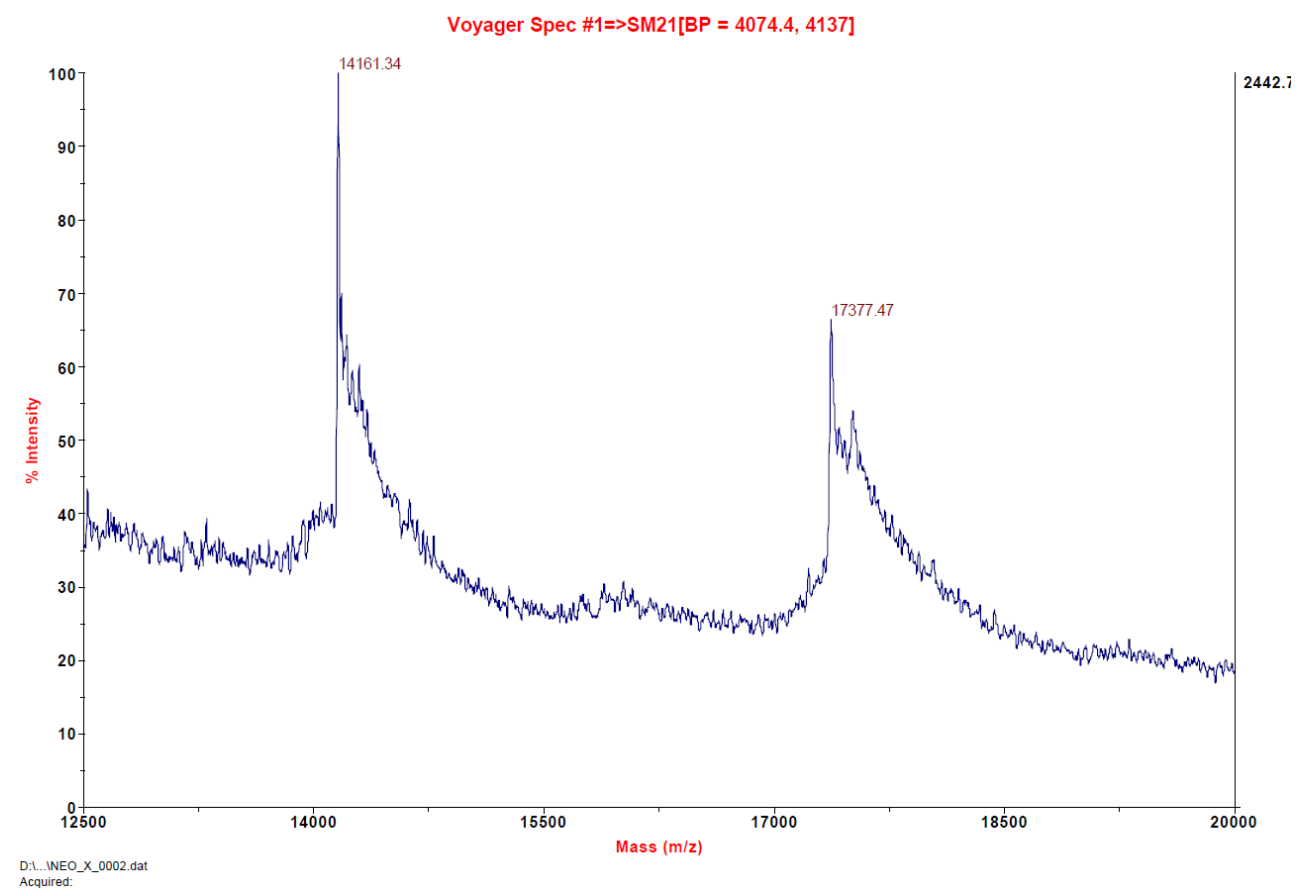

Figure S10b. Mass spectrometric detection of PNA-RNA crosslinks (MALDI). RNA 14 (23 $\mu$ M) was incubated with PNA 15b (46 $\mu \mathrm{M})$ as described above in "Irradiation and Incubation of PNA with RNA" irradiated and kept for several hours. The reaction mixture was then separated by HPLC as described in "Correspondance of HPLC peaks and signals in the sequencer". Peaks corresponding to fractions A and B (Figure S8) were collected and desalted by a second HPLC run (Phenomenex Gemini C18, $150 \times$ 4.6, $5 \mu \mathrm{m}, 4$ min hold $0 \%$ MeCN, linear gradient of $0-70 \% \operatorname{MeCN}$ in DEPC water $(\mathrm{pH} 7)$ for 2 min, 4 min hold $70 \%$ $\mathrm{MeCN}, 2 \mathrm{~mL} / \mathrm{min}, 254 \mathrm{~nm}, 30^{\circ} \mathrm{C}$.) and concentrated to dryness in a SpeedVac. Mass spectrometric analysis (matrix: HPA, 3-hydroxypicolinic acid) showed the peak of RNA 14 (calcd for $\mathrm{C}_{450} \mathrm{H}_{563} \mathrm{~N}_{147} \mathrm{O}_{300} \mathrm{P}_{43}+\mathrm{H}^{+}$: 14163.97) but also a new signal ( $\mathrm{m} / \mathrm{z}=17377$ ) corresponding to the mass of the crosslinked product (calcd for $\mathrm{C}_{583} \mathrm{H}_{735} \mathrm{~N}_{211} \mathrm{O}_{334} \mathrm{P}_{43}+\mathrm{H}^{+}$: exact mass 17366.58, molecular weight 17375.17). Because noncovalent complexes of $\mathbf{1 4}$ and $\mathbf{1 5 b}$, are separated under these conditions (Figure S10a), this signal can be assigned to a covalently connected molecule. 


\section{Comparison of integration modes}

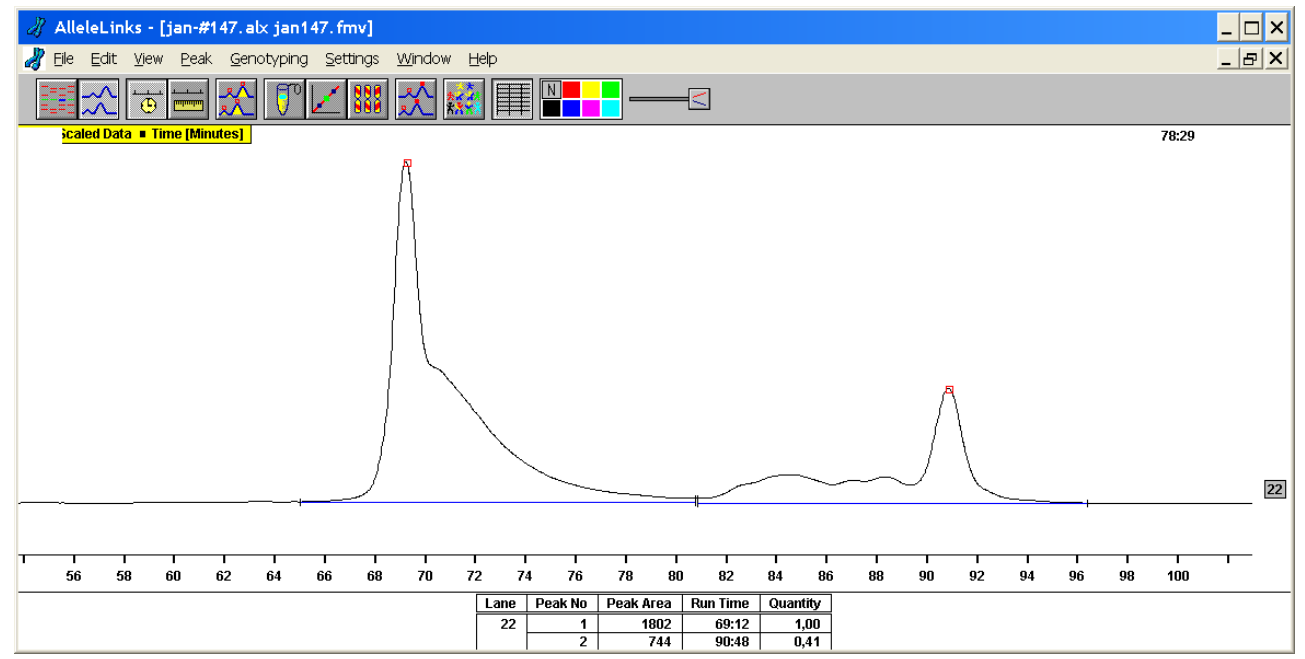

Figure S11: Comparison of integration modes. An irradiated sample of conjugate $13 \mathbf{b}$ was incubated with RNA 12 for $2 \mathrm{~h}$ and analyzed at a gel temperature of $57^{\circ} \mathrm{C}$ (details see above). The identical experiment is depicted in Figure 3c. Here, in addition, the boundaries for integration are shown. If the broad tail ranging from $70-81 \mathrm{~min}$ is calculated as part of the RNA peak, all peaks from 81 - 96 min are considered as crosslinks, suggesting a crosslinking yield of $29.2 \%(744$ / (744 + 1802)).

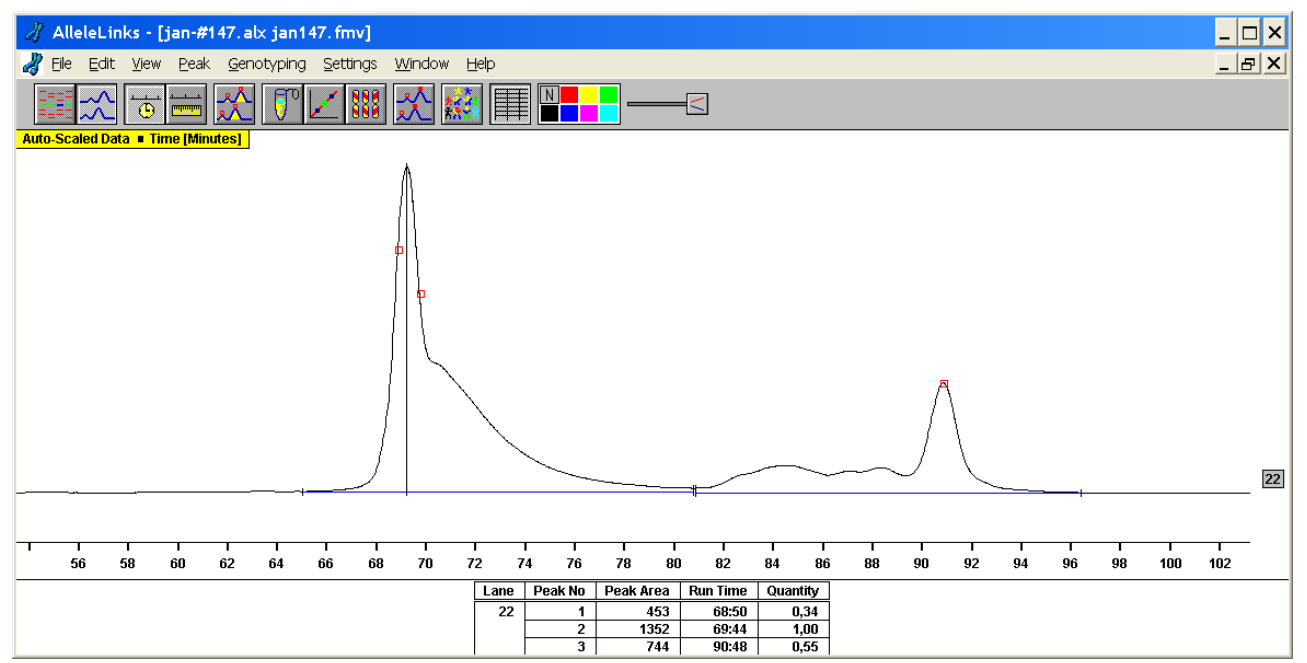

Figure S12: Comparison of integration modes. Note, however, that the pure RNA peak is highly symmetrical (Figures 3a and S7). This indicates that the tailing belongs to different chemical species. Since it is well documented in literature that quinone methides reversibly form labile covalent bonds with nucleotides, we assign the "tailing" to this type of crosslinks that are expected to compose quickly in the gel at $57^{\circ} \mathrm{C}$ and thus only induce a minor bandshift. Crosslinks involving stable bonds do not decompose during gel electrophoresis and appear in the bands from 81 - 96 min. If the peak of the unreacted RNA $\mathbf{1 2}$ is assumed to be symmetric, the integral of $\mathbf{1 2}$ should be twice the area from 65 minutes to the top $(2 \times 453)$. In this calculation, the integral of crosslinks is $1352+744-453$ $=1643$, corresponding to a crosslinking yield of $64.5 \%$. 


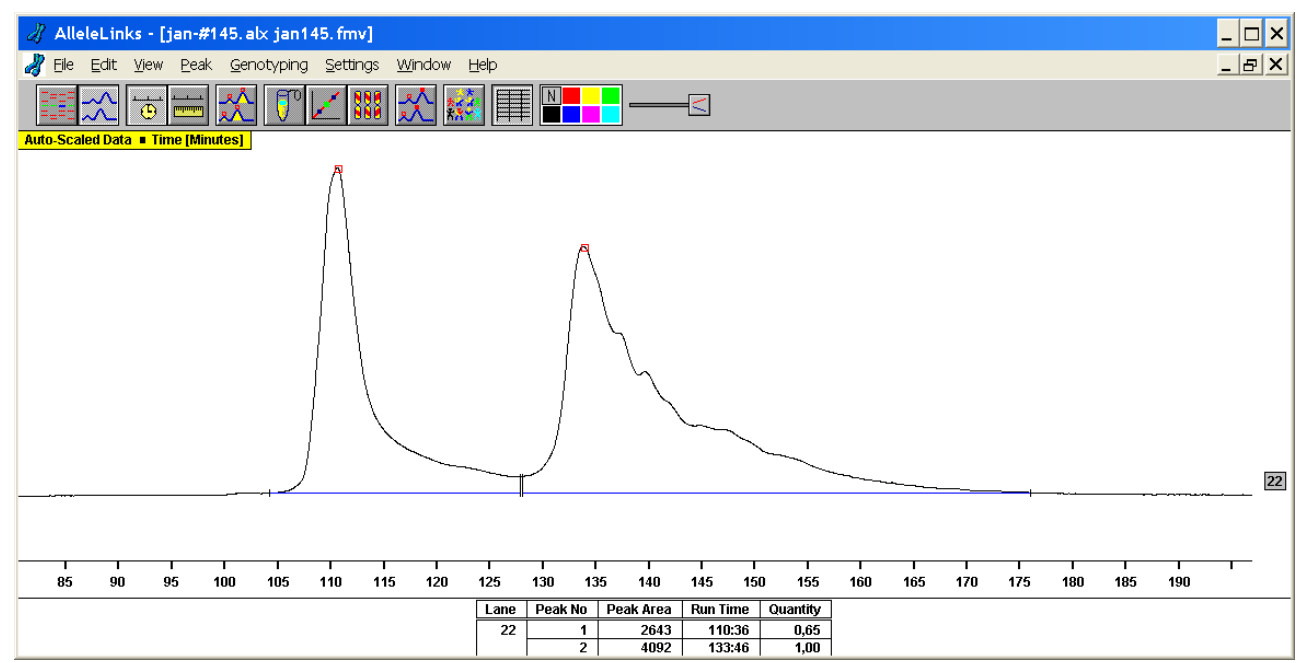

Figure S13: Comparison of integration modes. An aliquot of the identical sample as shown in Figures S11 and S12 was also analyzed at a gel temperature of $25^{\circ} \mathrm{C}$. The tailing of the RNA peak (105-128 $\mathrm{min}$ ) is now largely reduced. Almost all crosslinked species survive gel electrophoresis at $25^{\circ} \mathrm{C}$ and appear in the second group of peaks. When analyzed as in Figure S11, the crosslinking yield is $60.8 \%$ $(4092 /(2643+4092))$.

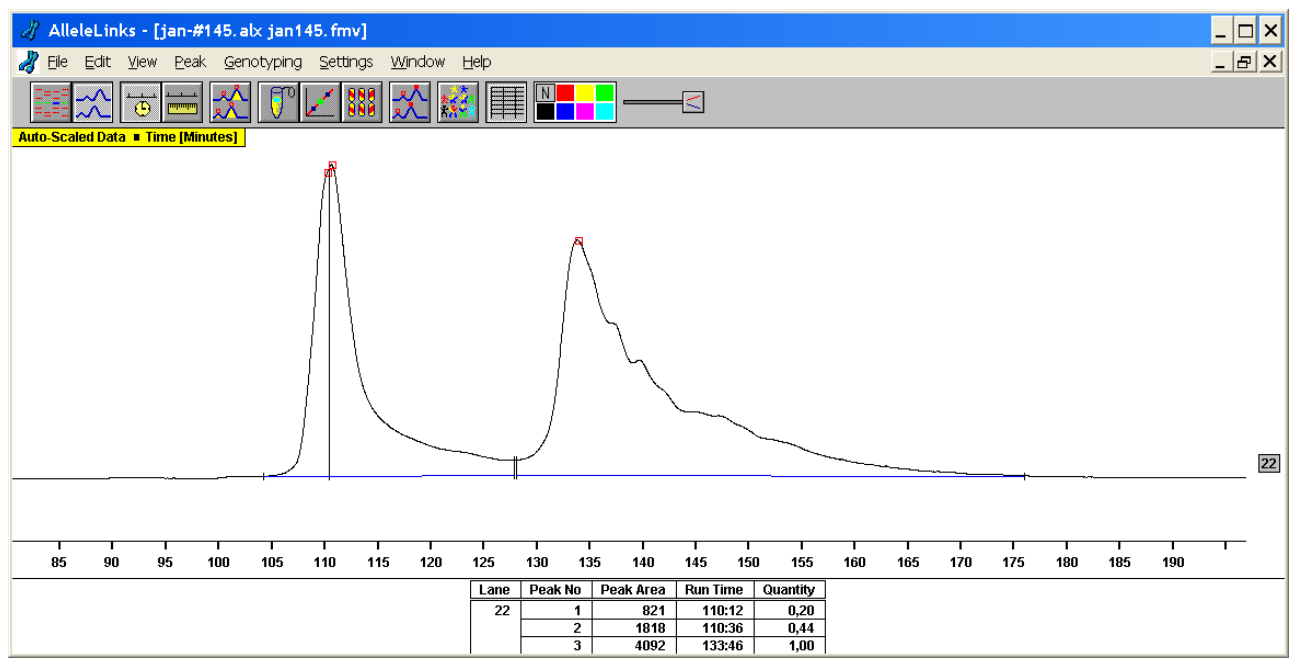

Figure S14: Comparison of integration modes. Using the same type of calculation as in Figure S12, the area of crosslinks is $1818+4092-821=5089$, corresponding to a crosslinking yield of even 75.6 $\%$. 


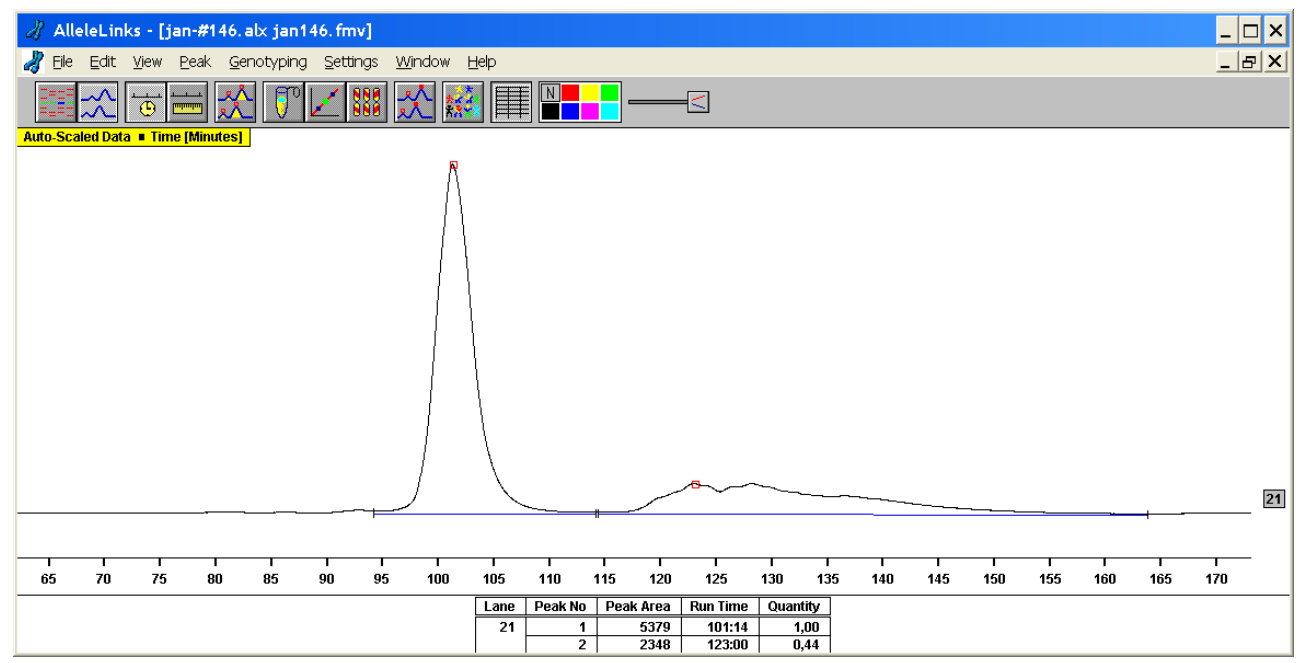

Figure S15: Comparison of integration modes. A third aliquot of the same sample was first heated to a temperature of $57^{\circ} \mathrm{C}$ for $2 \mathrm{~h}$ (corresponding to the conditions of high gel temperature; splits labile crosslinks) and then analyzed at a gel temperature of $25^{\circ} \mathrm{C}$. Note the the peak of RNA 12 (integrated from $95-115 \mathrm{~min})$ is now symmetric. The crosslinking yield obtained is $30.4 \%(2348 /(5379+2348))$ and corresponds very well to the result shown in Figure S11. 
This report was created by ACD/NMR Processor Academic Edition. For more information go to www.acdlabs.com/nmrproc/ 1H 500MHZ_2.ESP
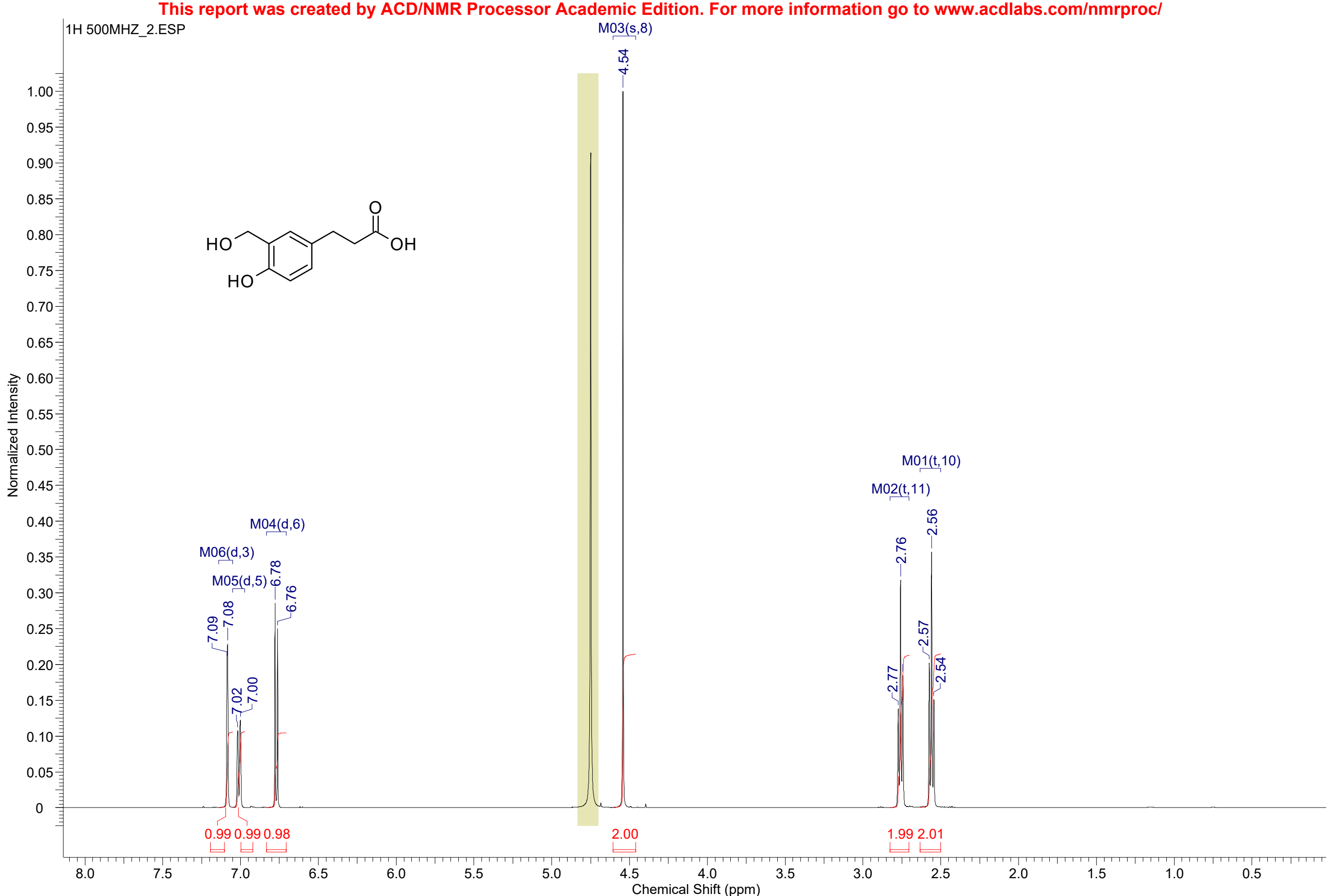
This report was created by ACD/NMR Processor Academic Edition. For more information go to www.acdlabs.com/nmrproc/

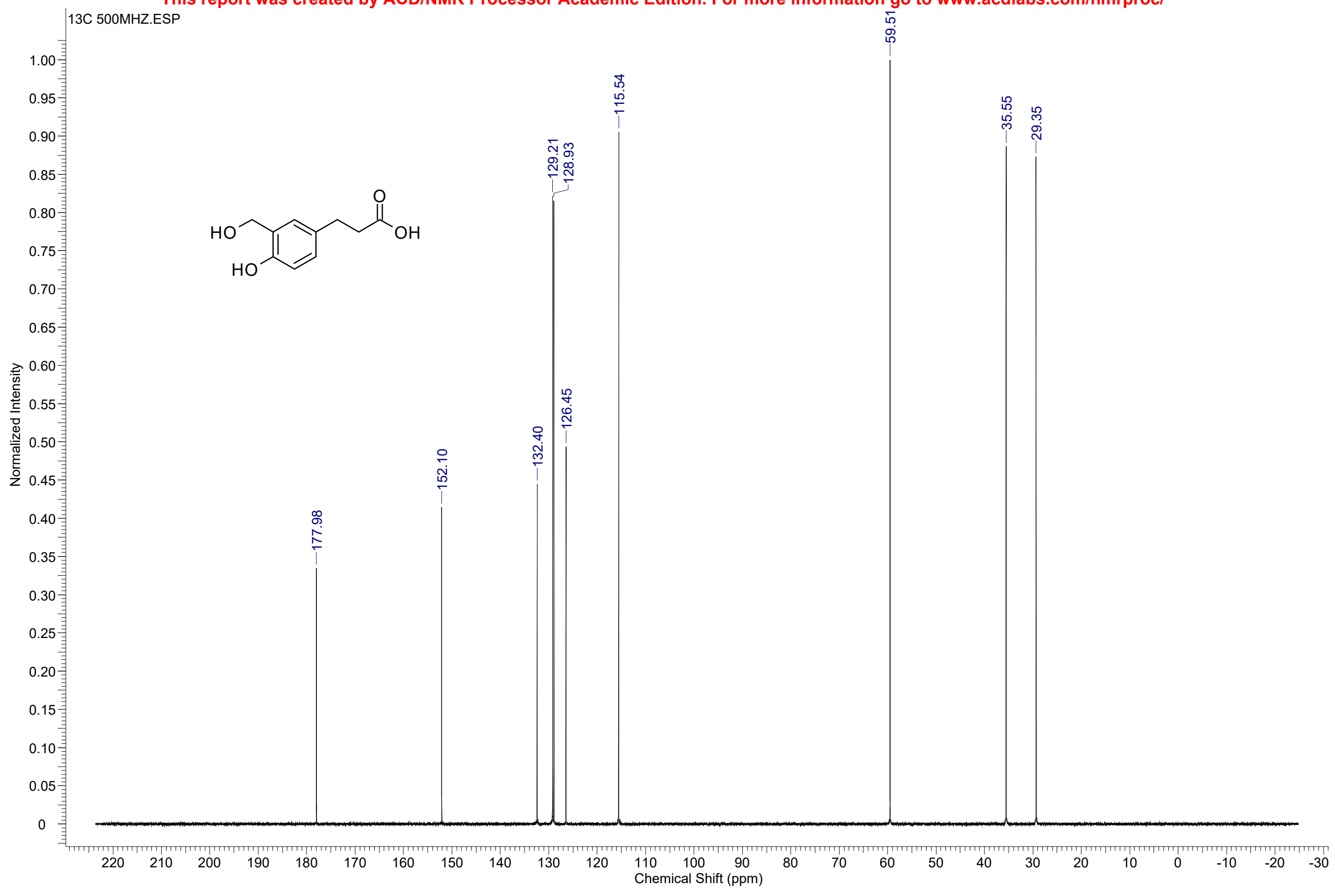


This report was created by ACD/NMR Processor Academic Edition. For more information go to www.acdlabs.com/nmrprocl $1 \mathrm{H} 500 \mathrm{MHZ}$.ESP

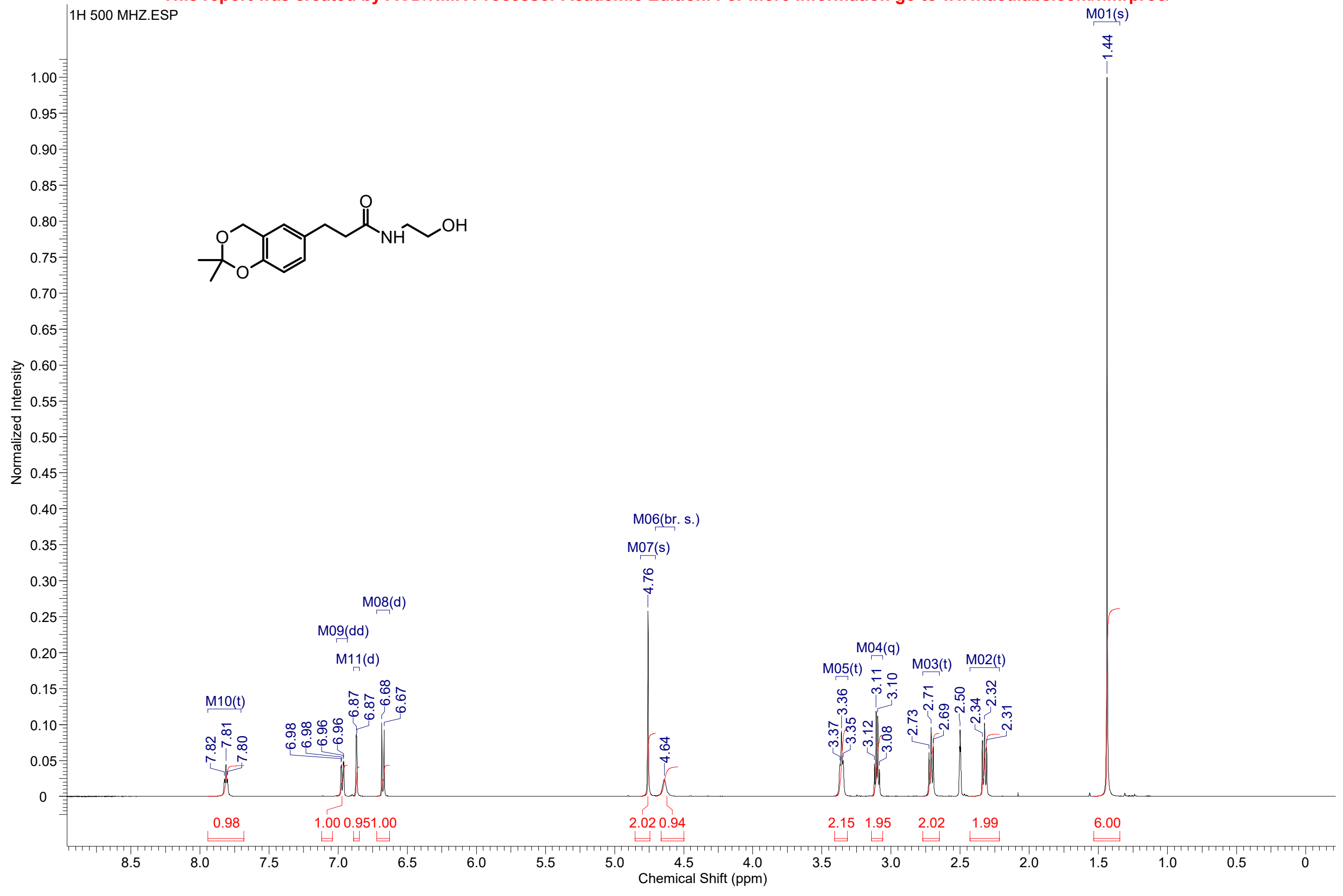


This report was created by ACD/NMR Processor Academic Edition. For more information go to www.acdlabs.com/nmrproc/ 13C 500 MHZ.ESP

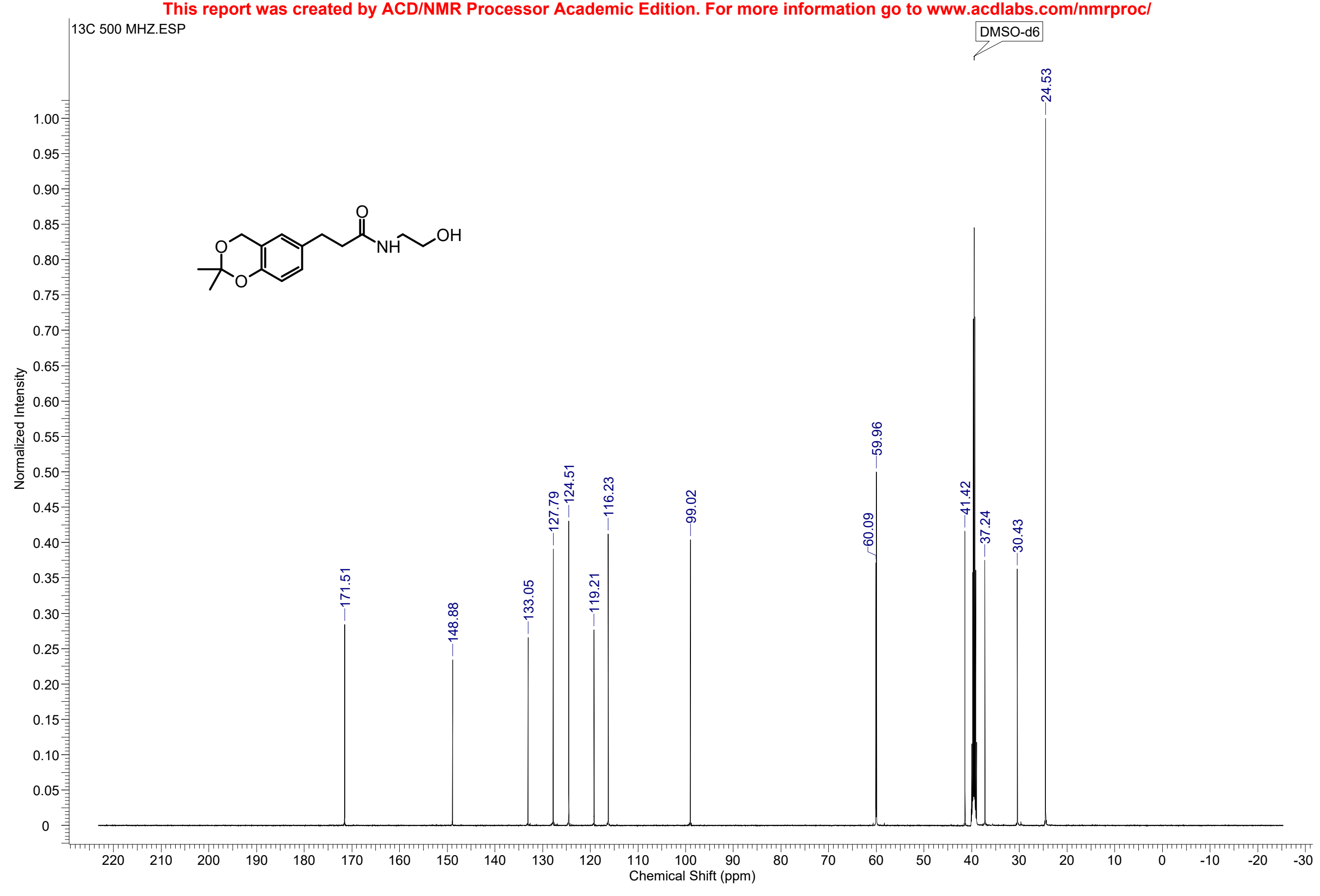


This report was created by ACD/NMR Processor Academic Edition. For more information go to www.acdlabs.com/nmrproc/

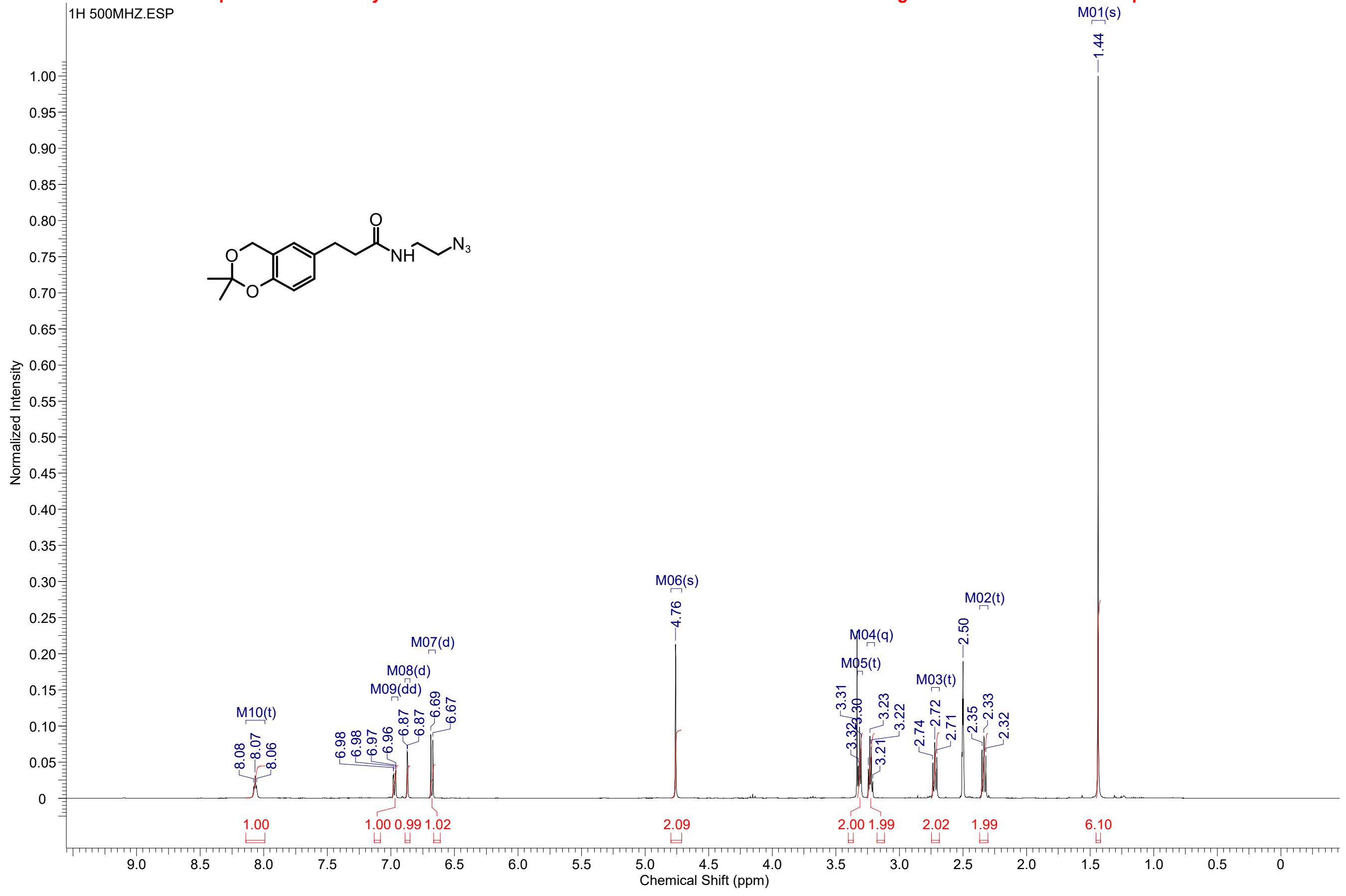


This report was created by ACD/NMR Processor Academic Edition. For more information go to www.acdlabs.com/nmrproc/ 13C 500MHZ.ESP

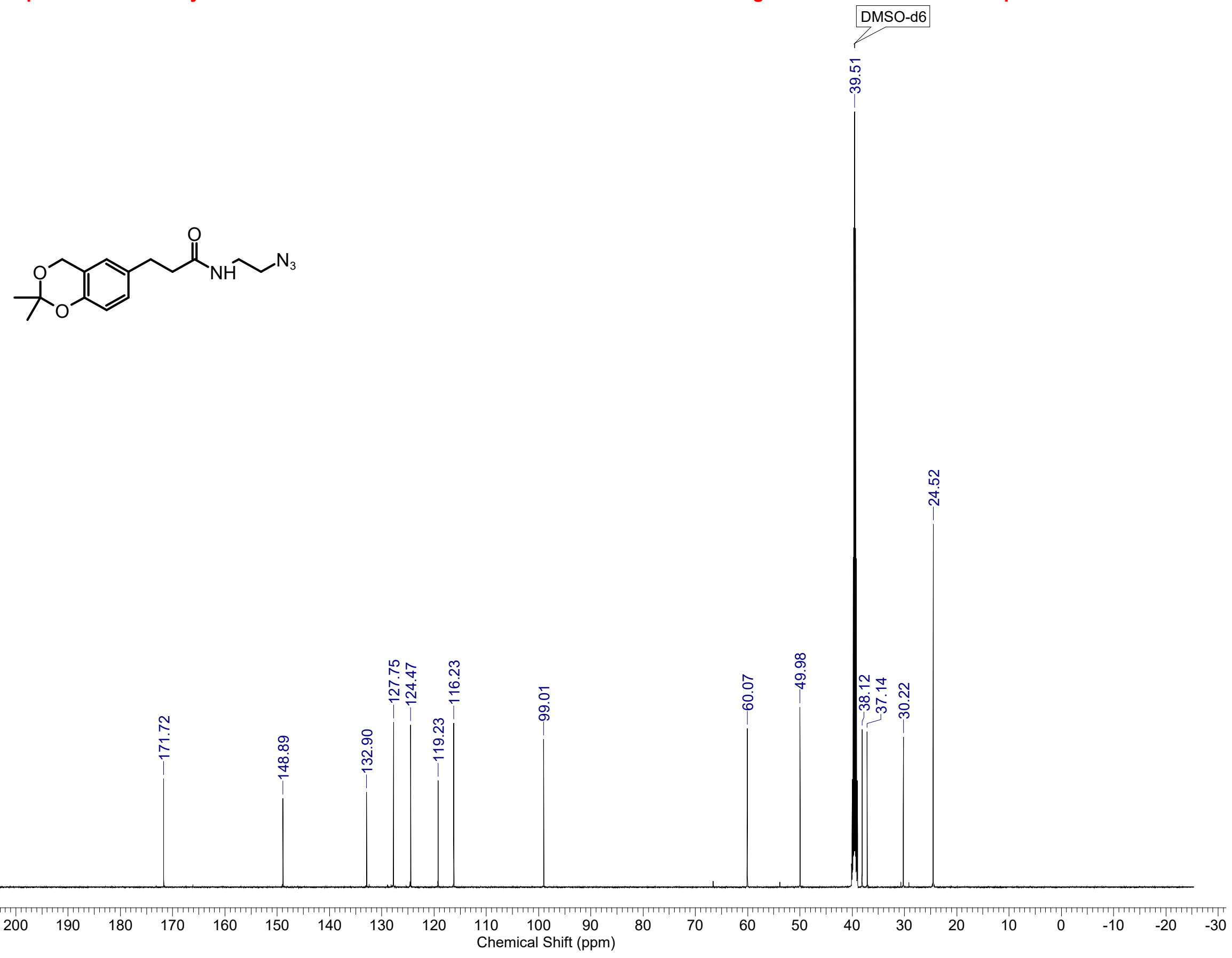


This report was created by ACD/NMR Processor Academic Edition. For more information go to www.acdlabs.com/nmrproc/ 1H 500 MHZ.ESP

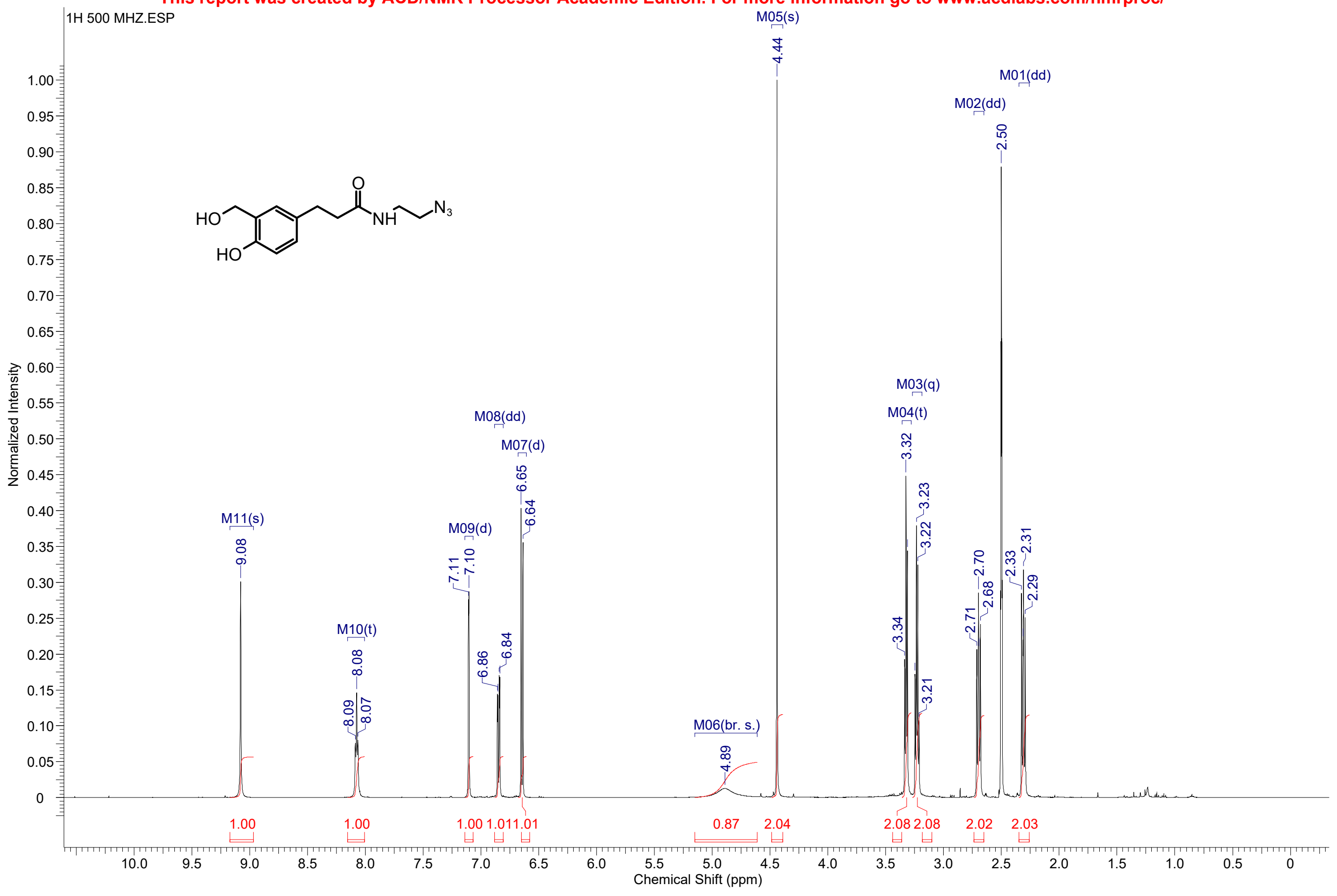


This report was created by ACD/NMR Processor Academic Edition. For more information go to www.acdlabs.com/nmrproc/ 13C 500MHZ.ESP

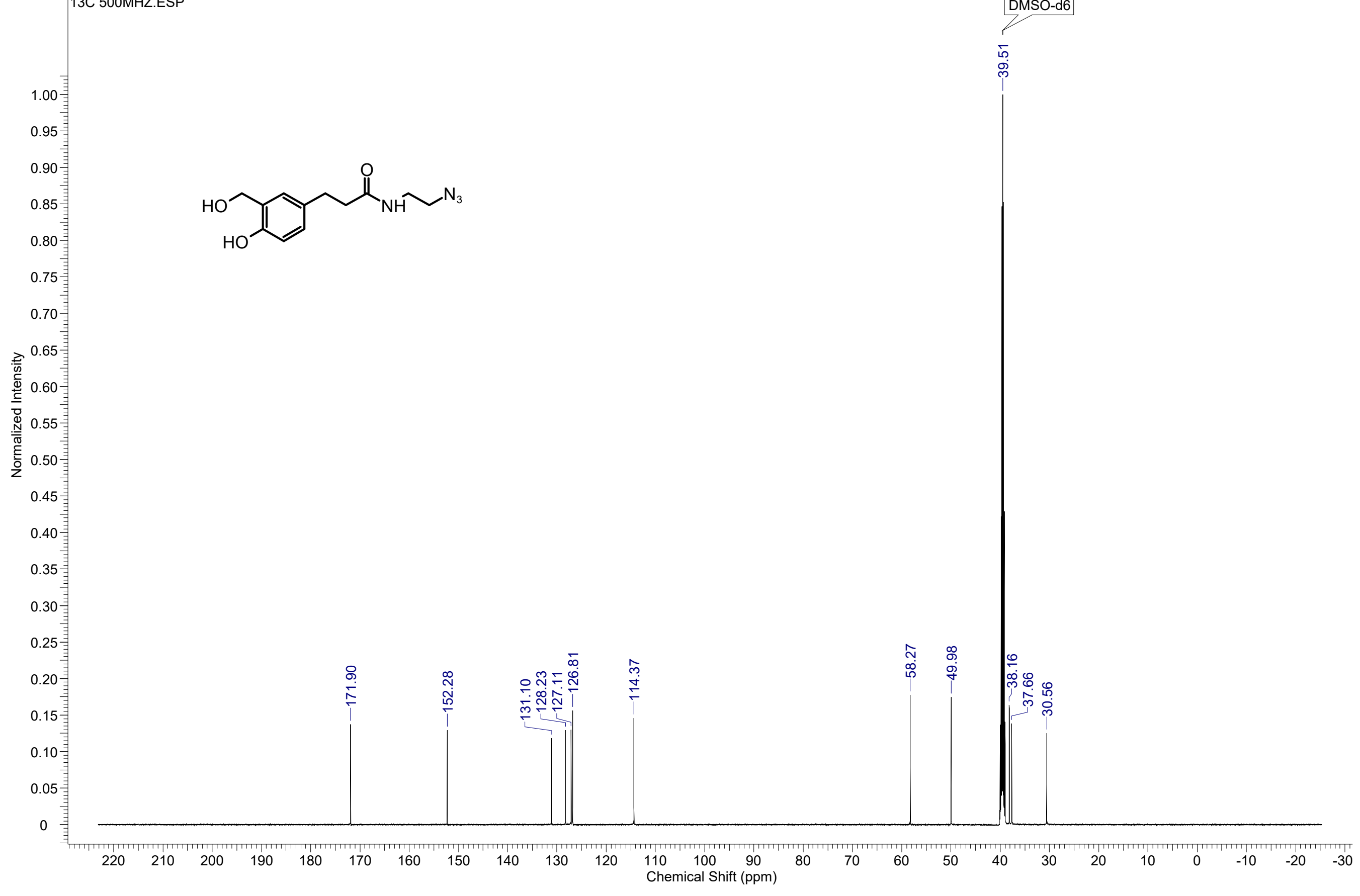


This report was created by ACD/NMR Processor Academic Edition. For more information go to www.acdlabs.com/nmrproc/ $1 \mathrm{H} 500 \mathrm{MHZ} . \mathrm{ESP}$

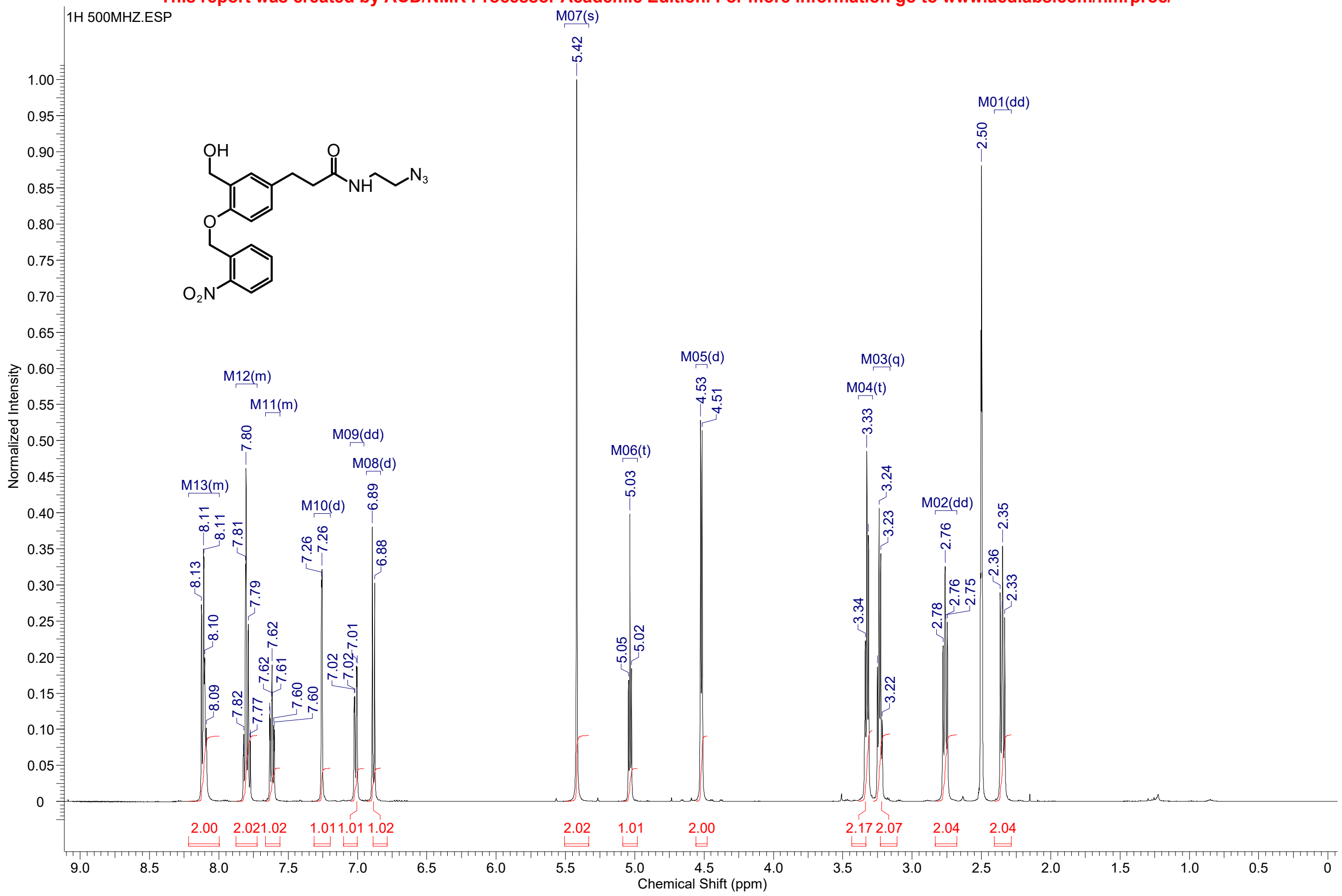


This report was created by ACD/NMR Processor Academic Edition. For more information go to www.acdlabs.com/nmrproc/ 13C 500MHZ.ESP

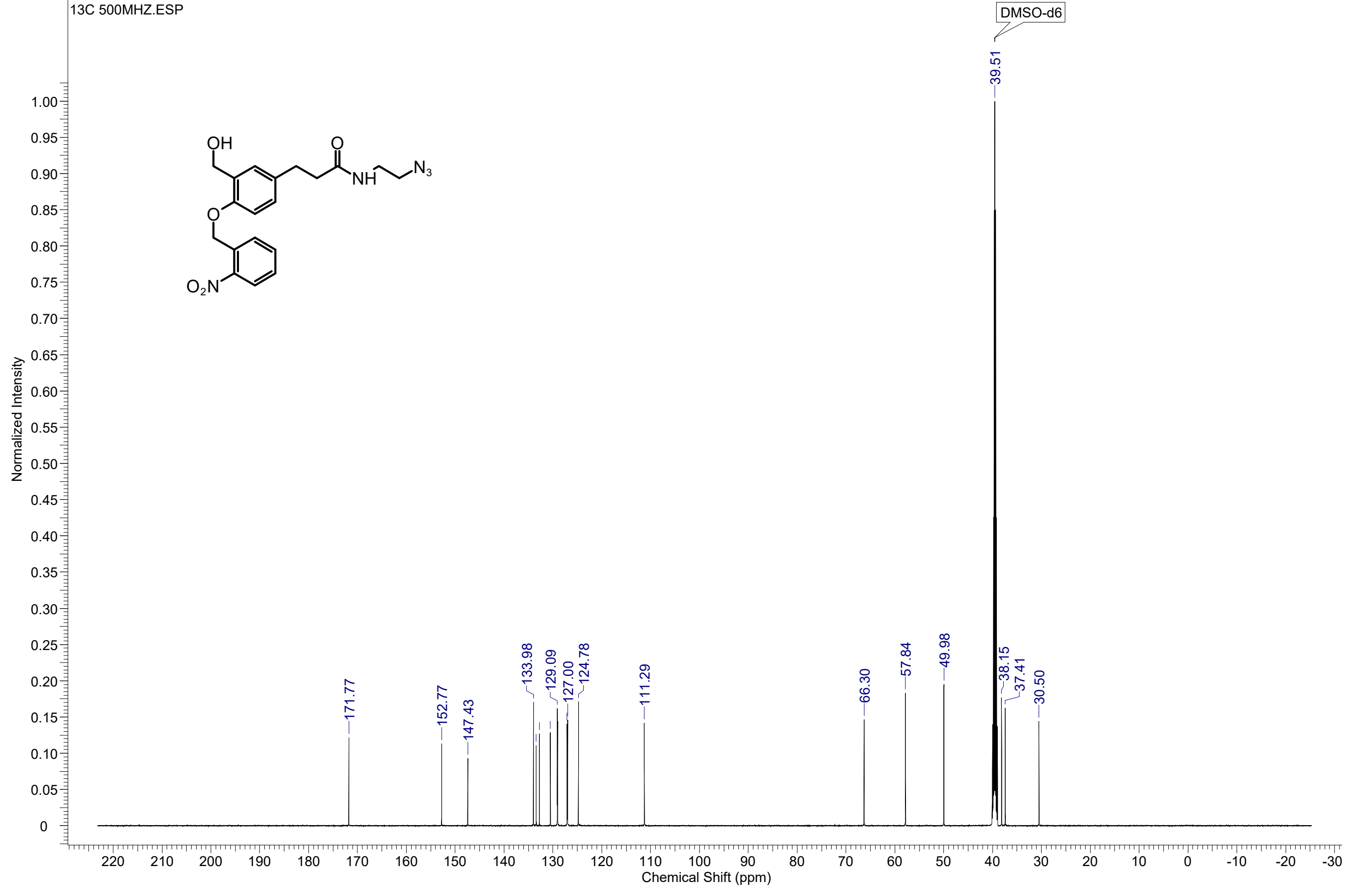


This report was created by ACD/NMR Processor Academic Edition. For more information go to www.acdlabs.com/nmrproc/

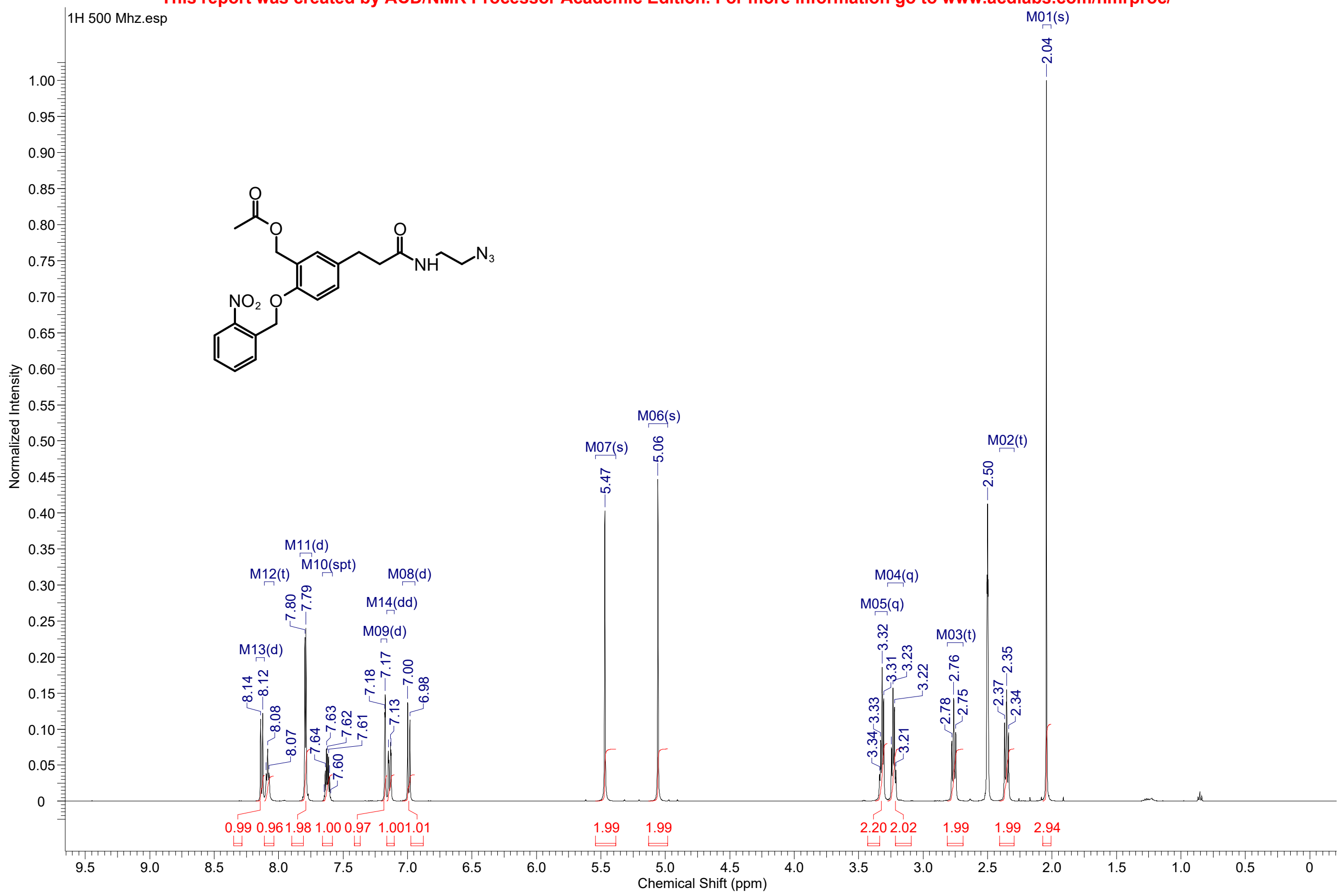


This report was created by ACD/NMR Processor Academic Edition. For more information go to www.acdlabs.com/nmrproc/

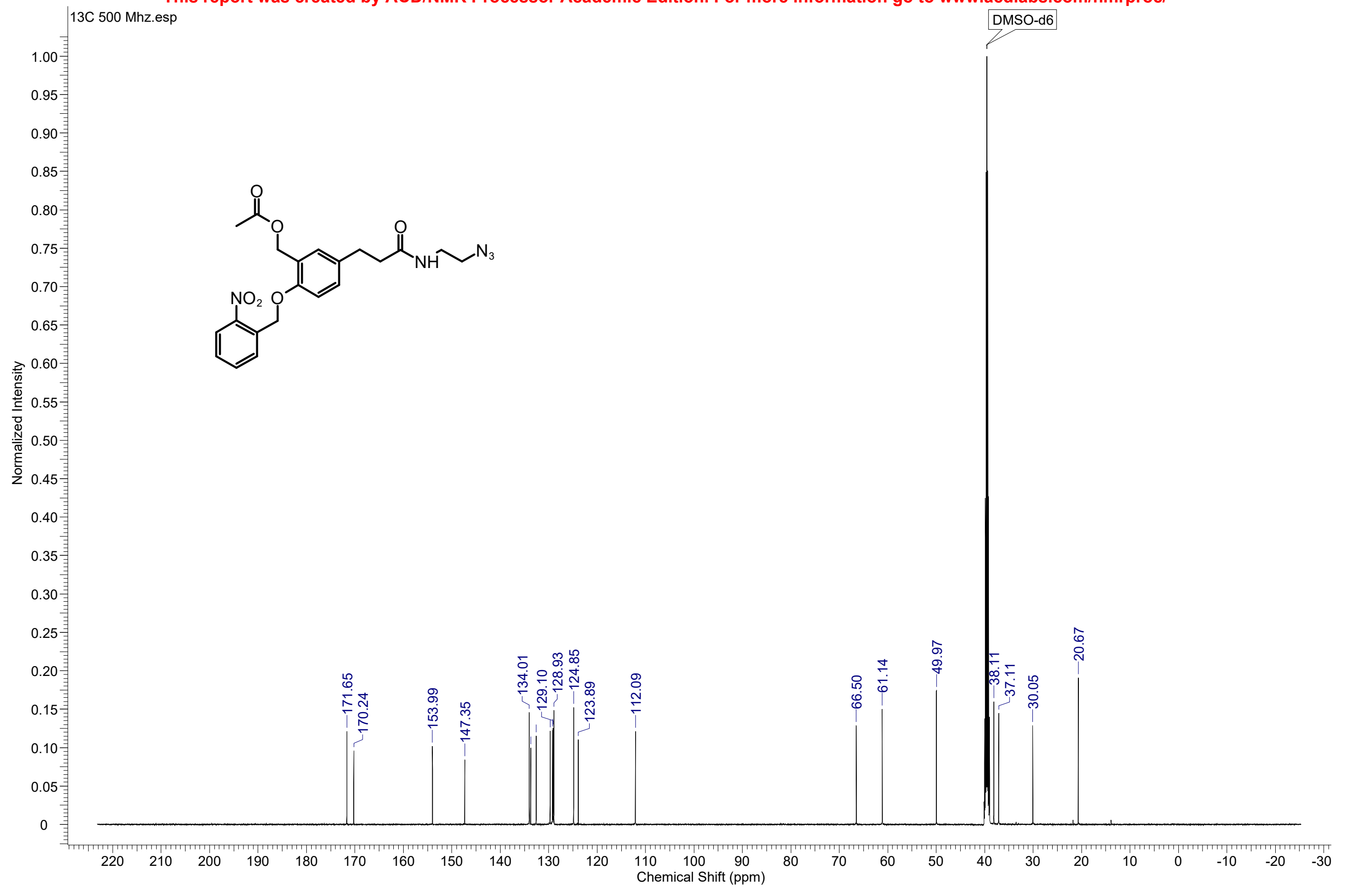




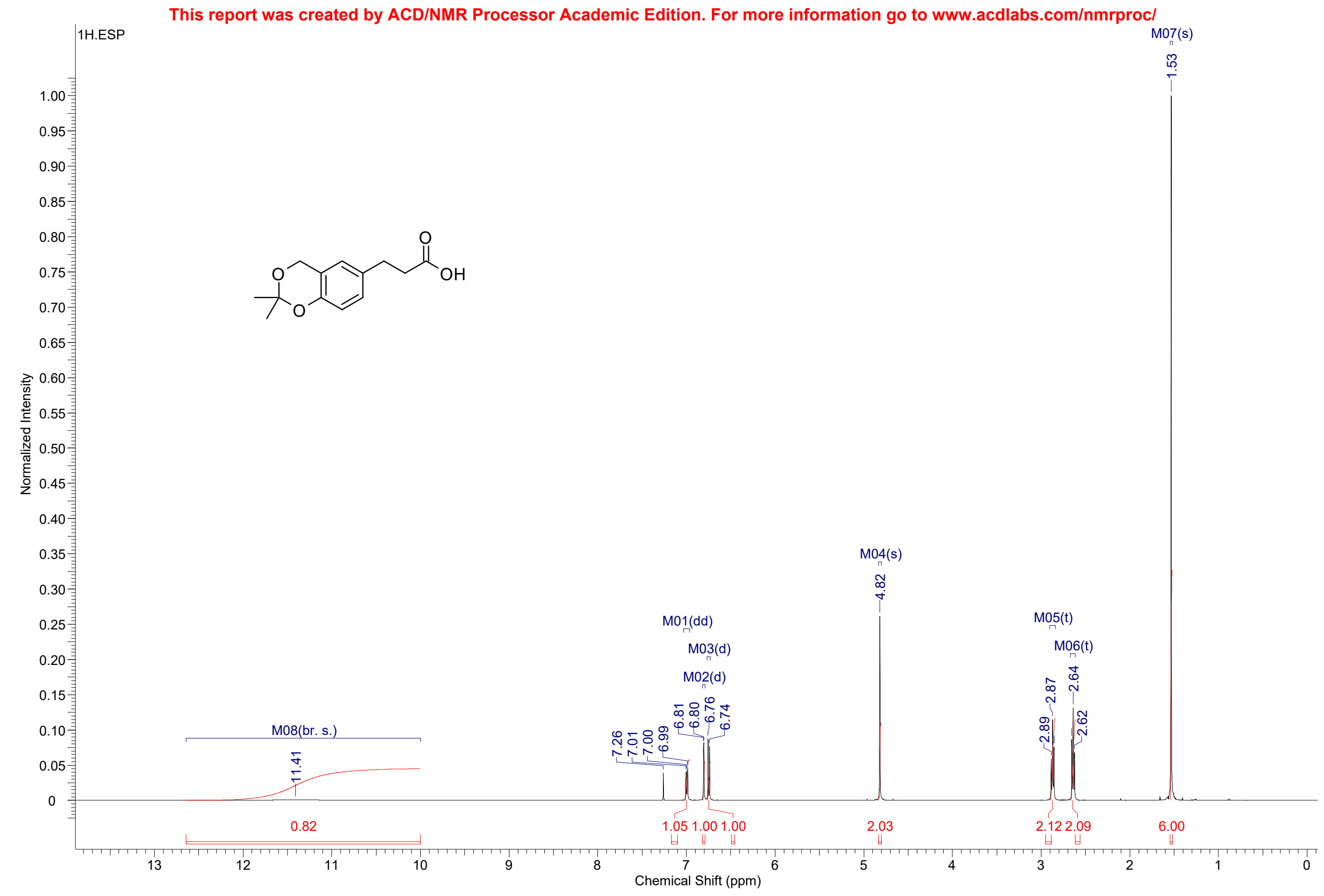




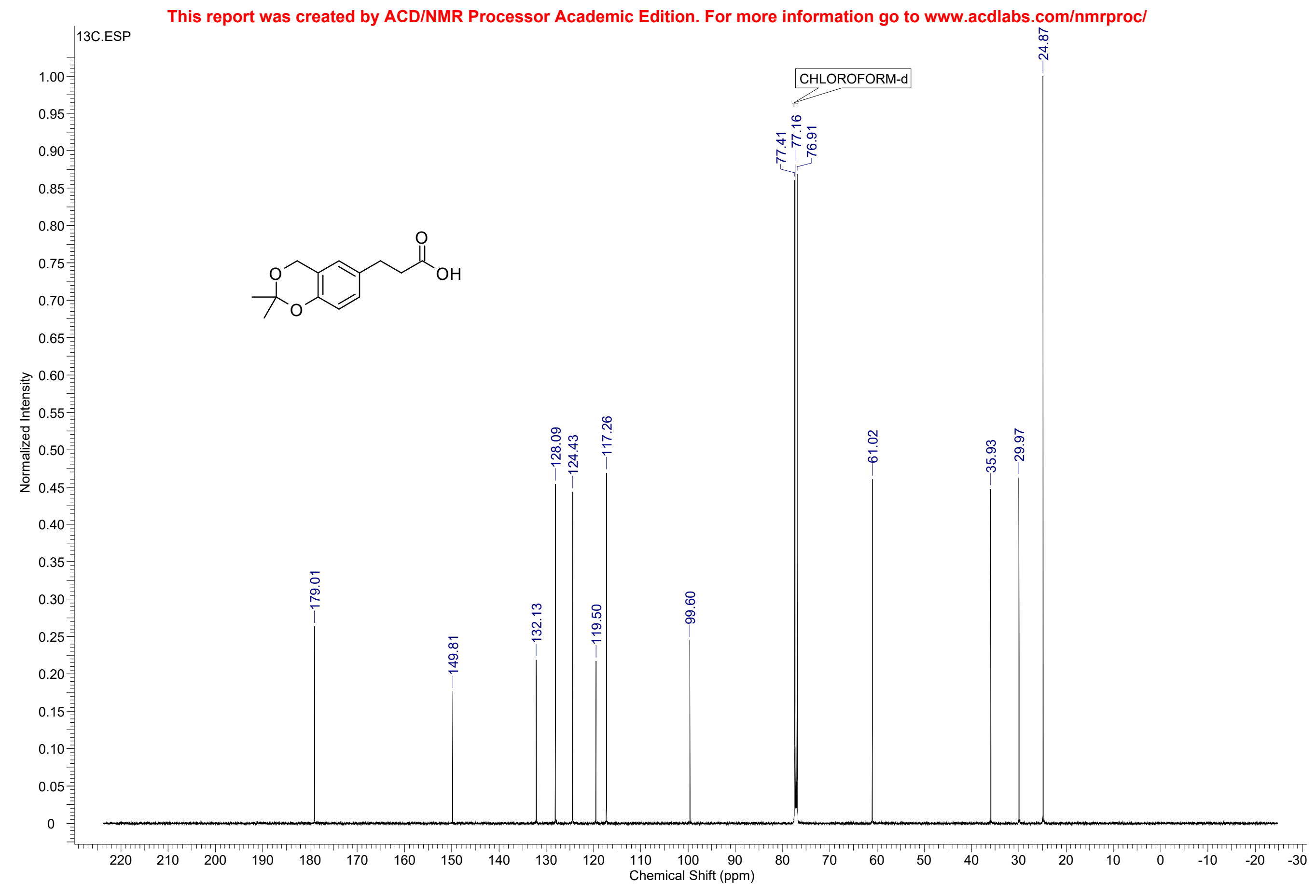




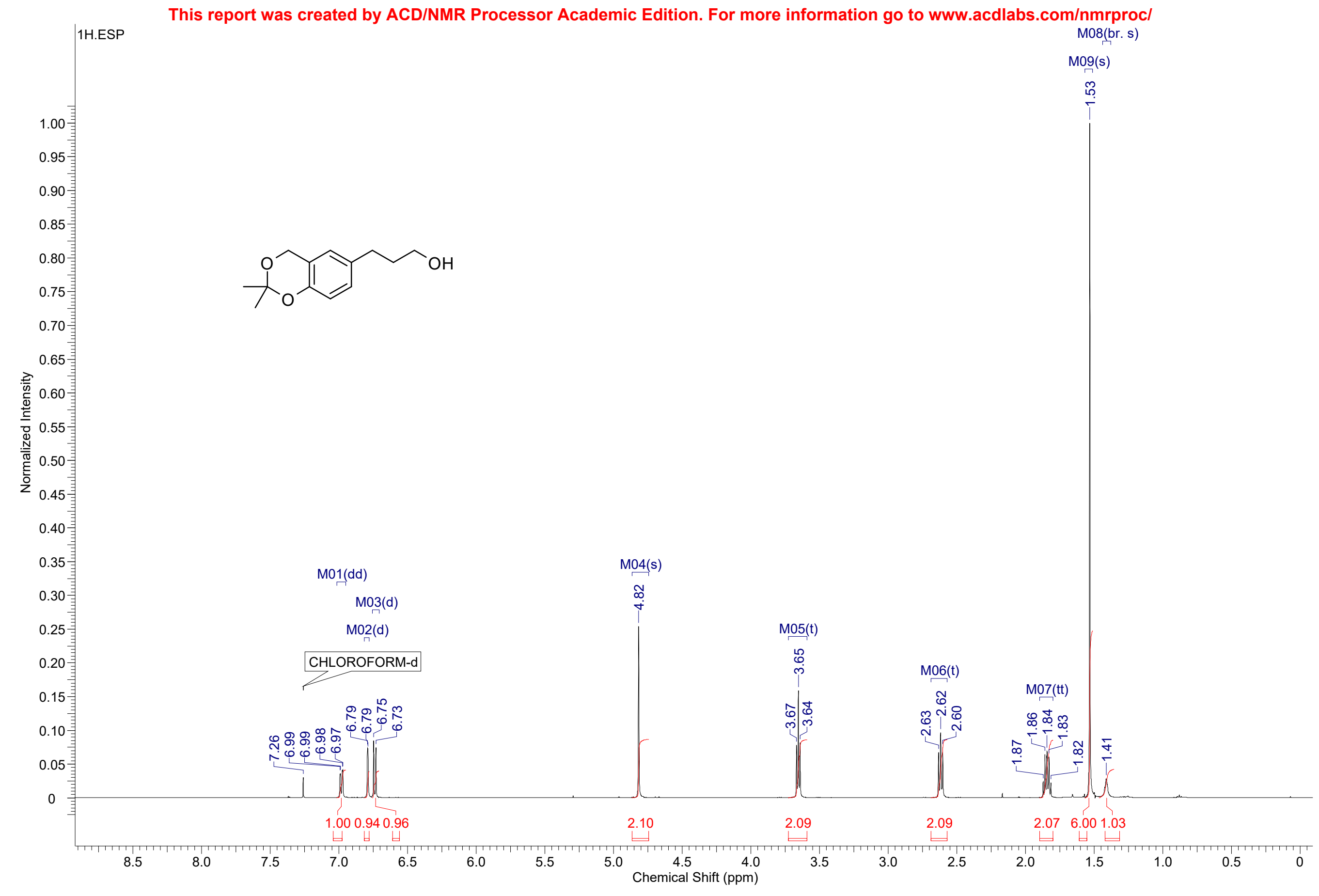




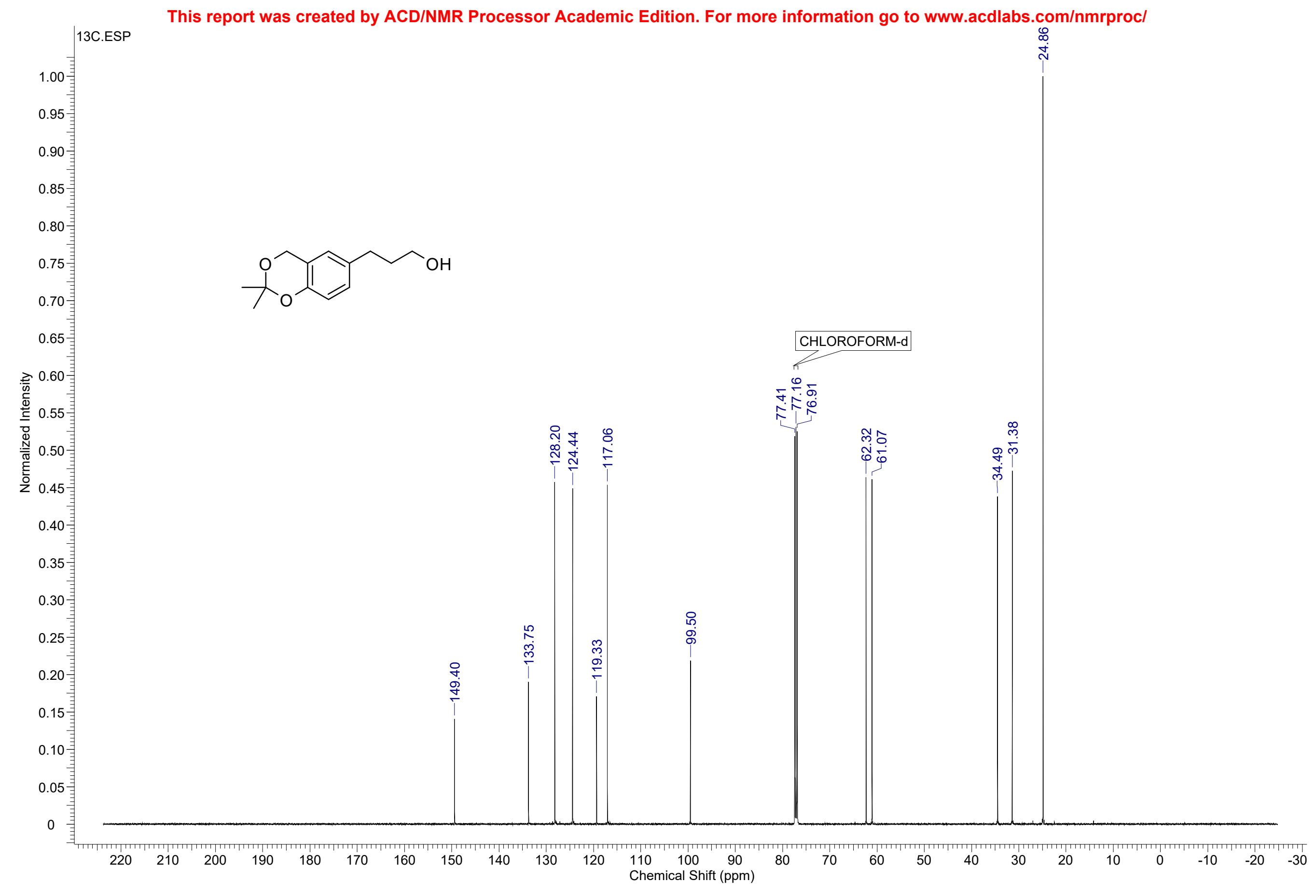




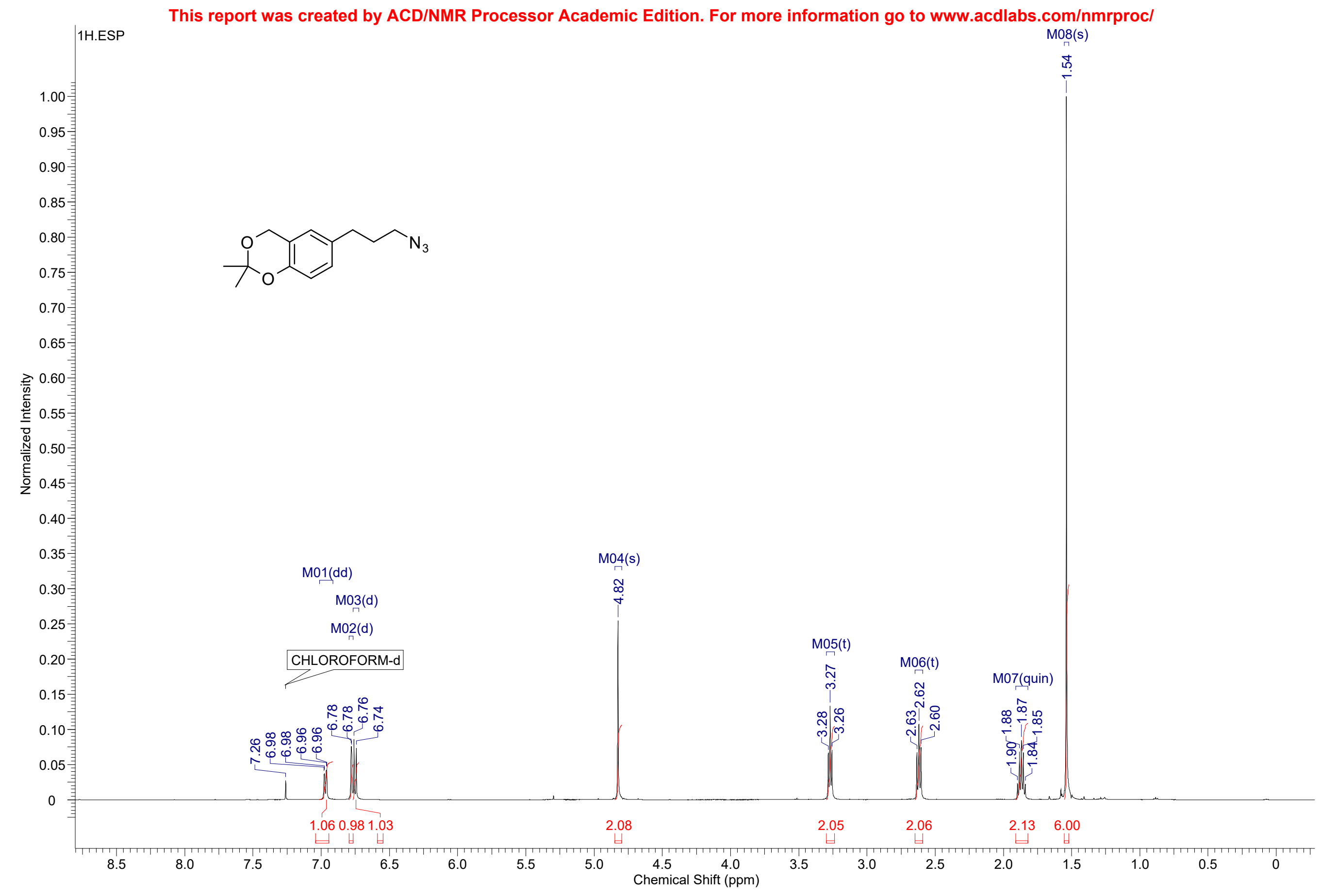




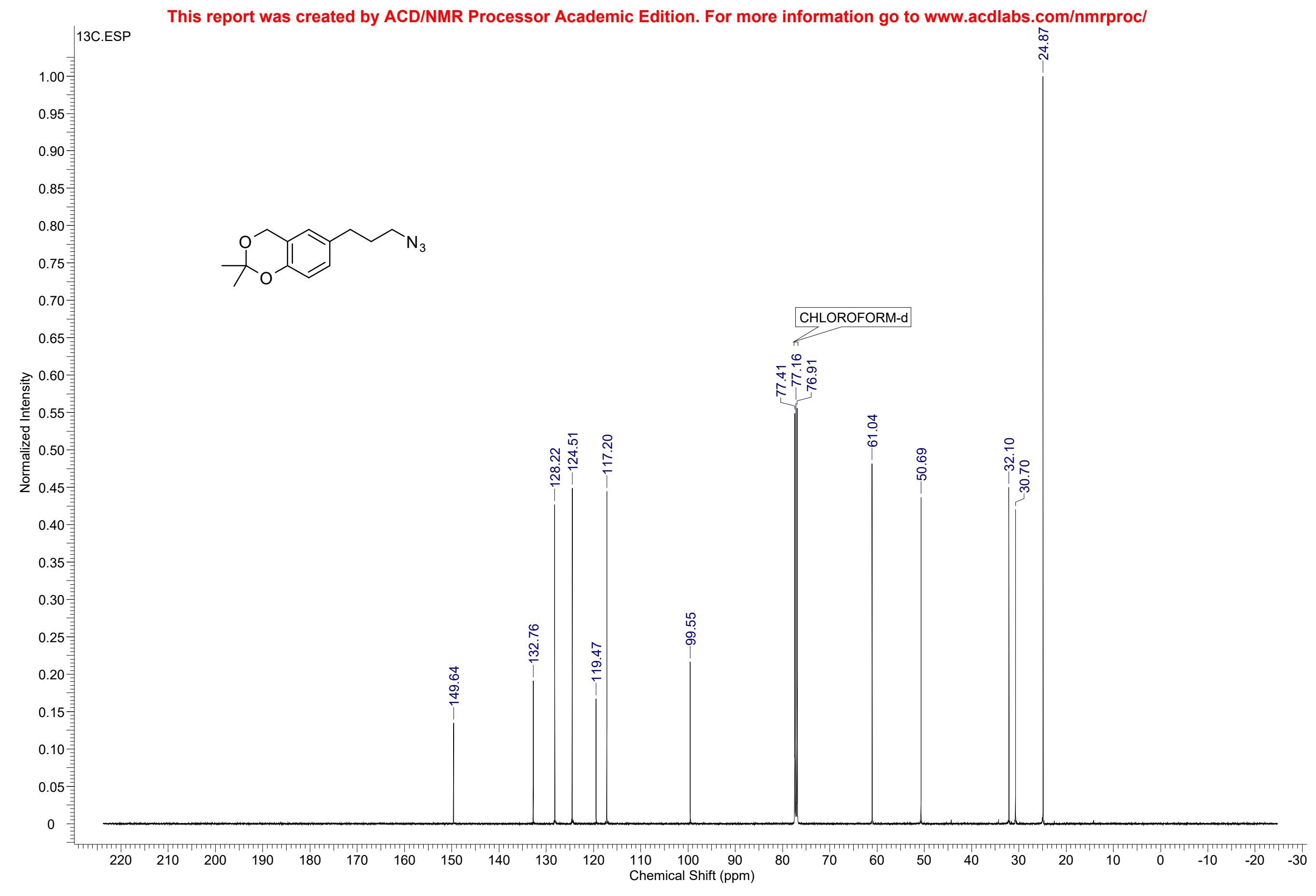




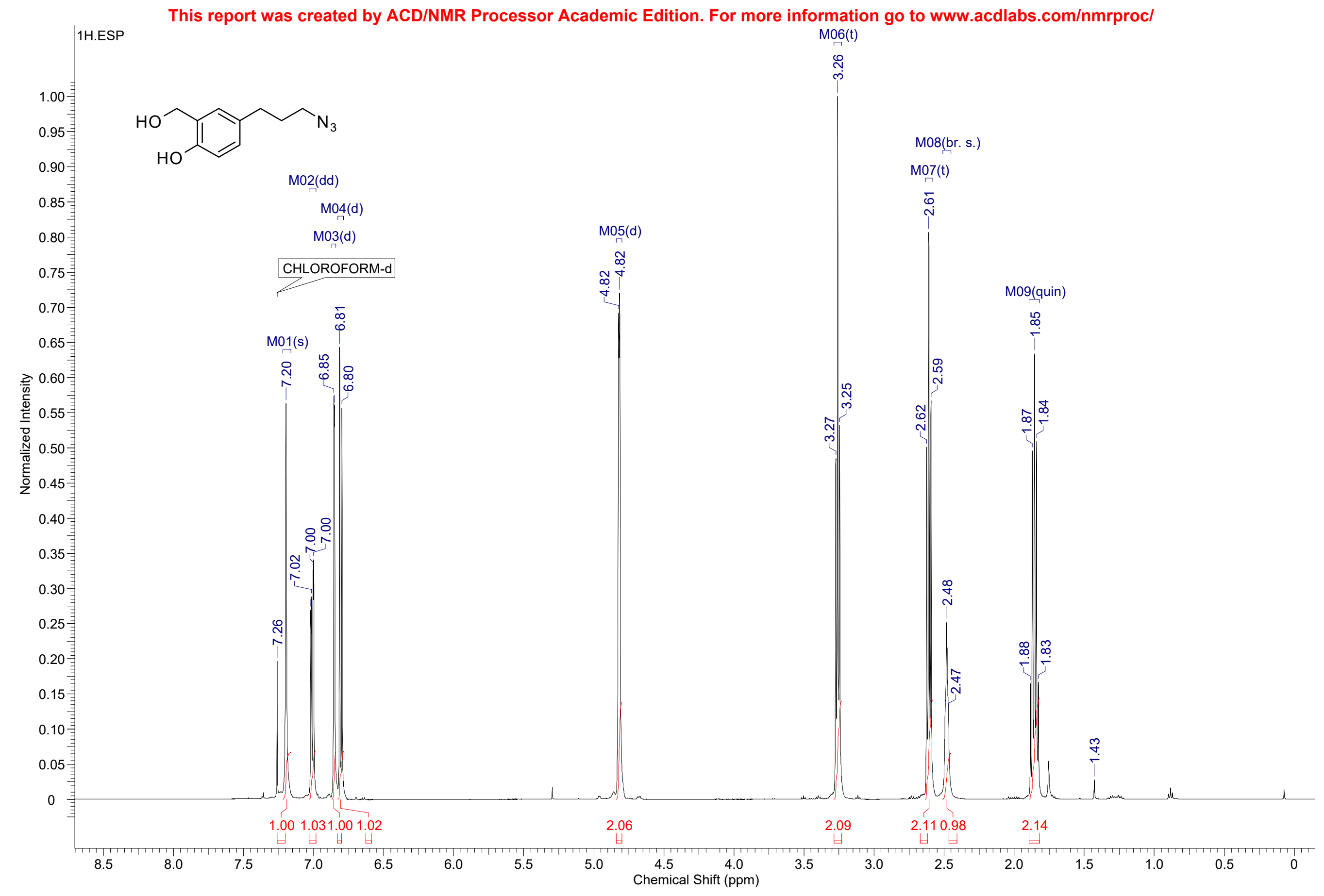




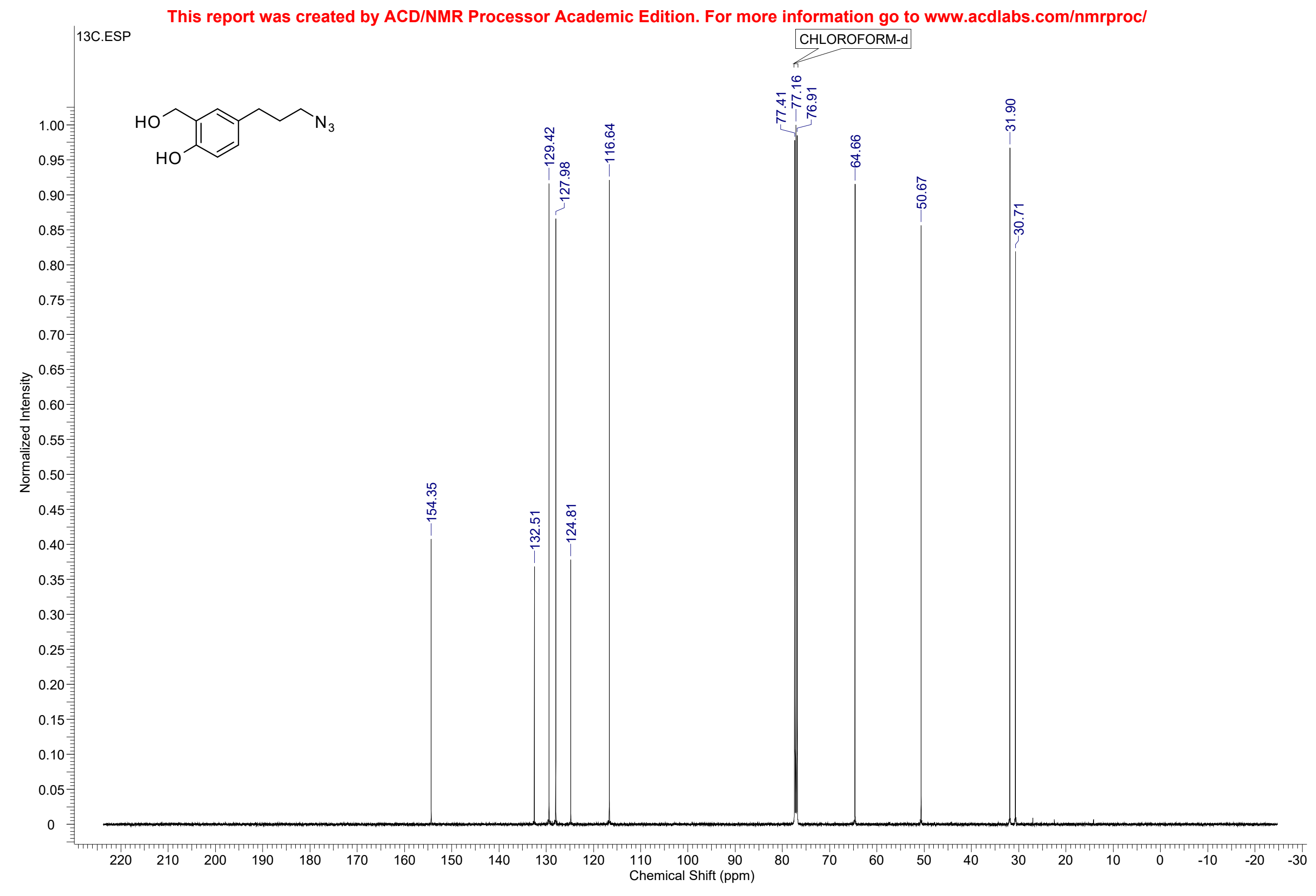




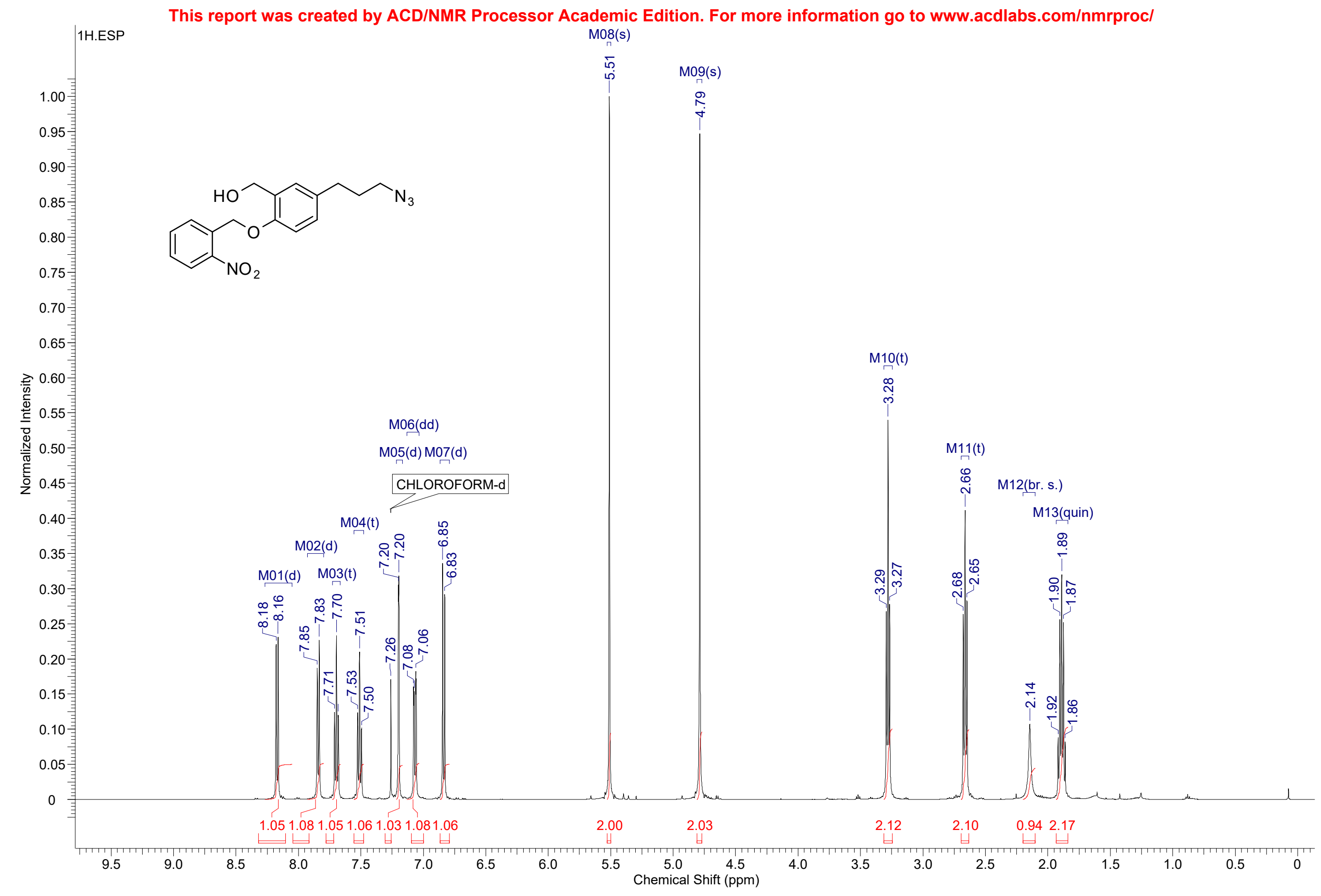




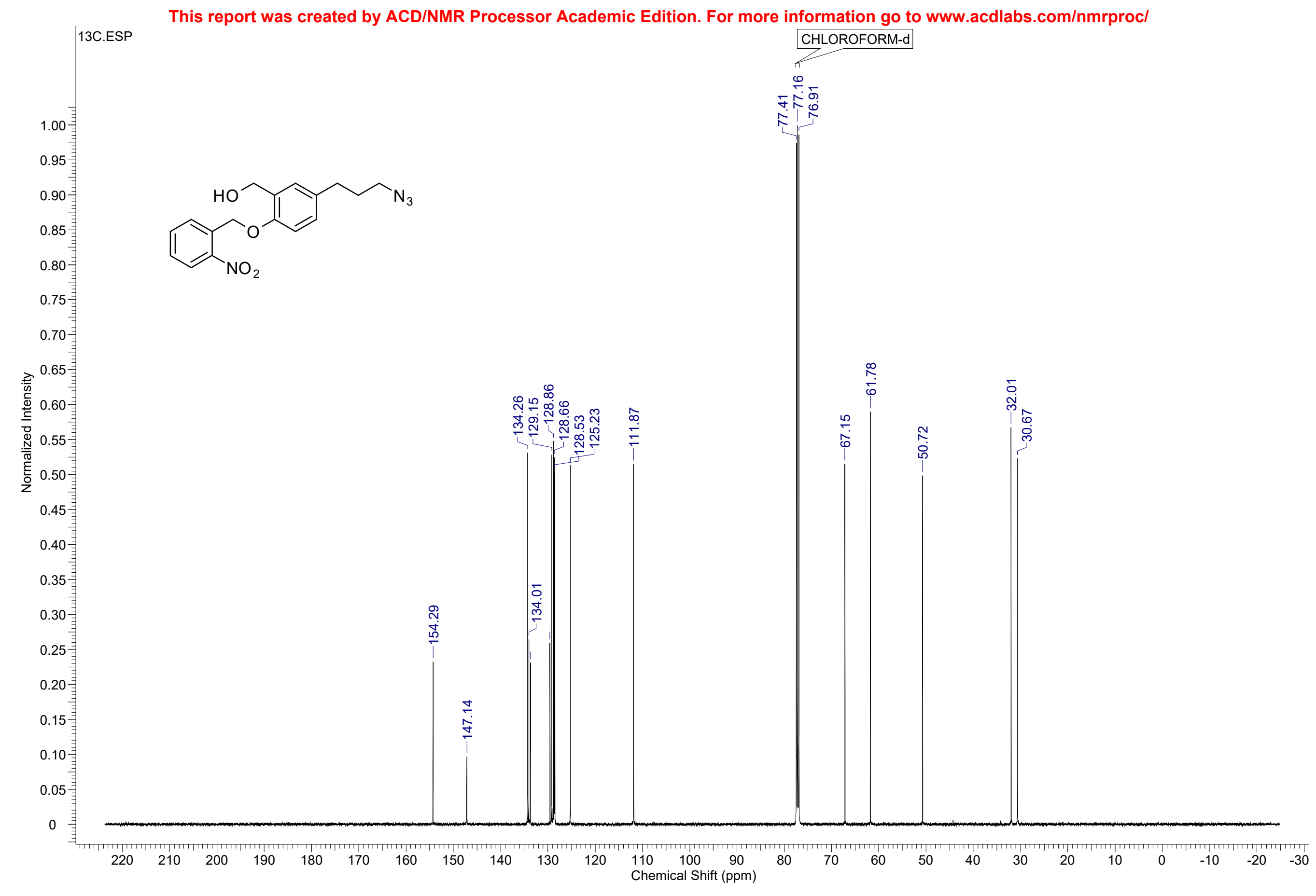




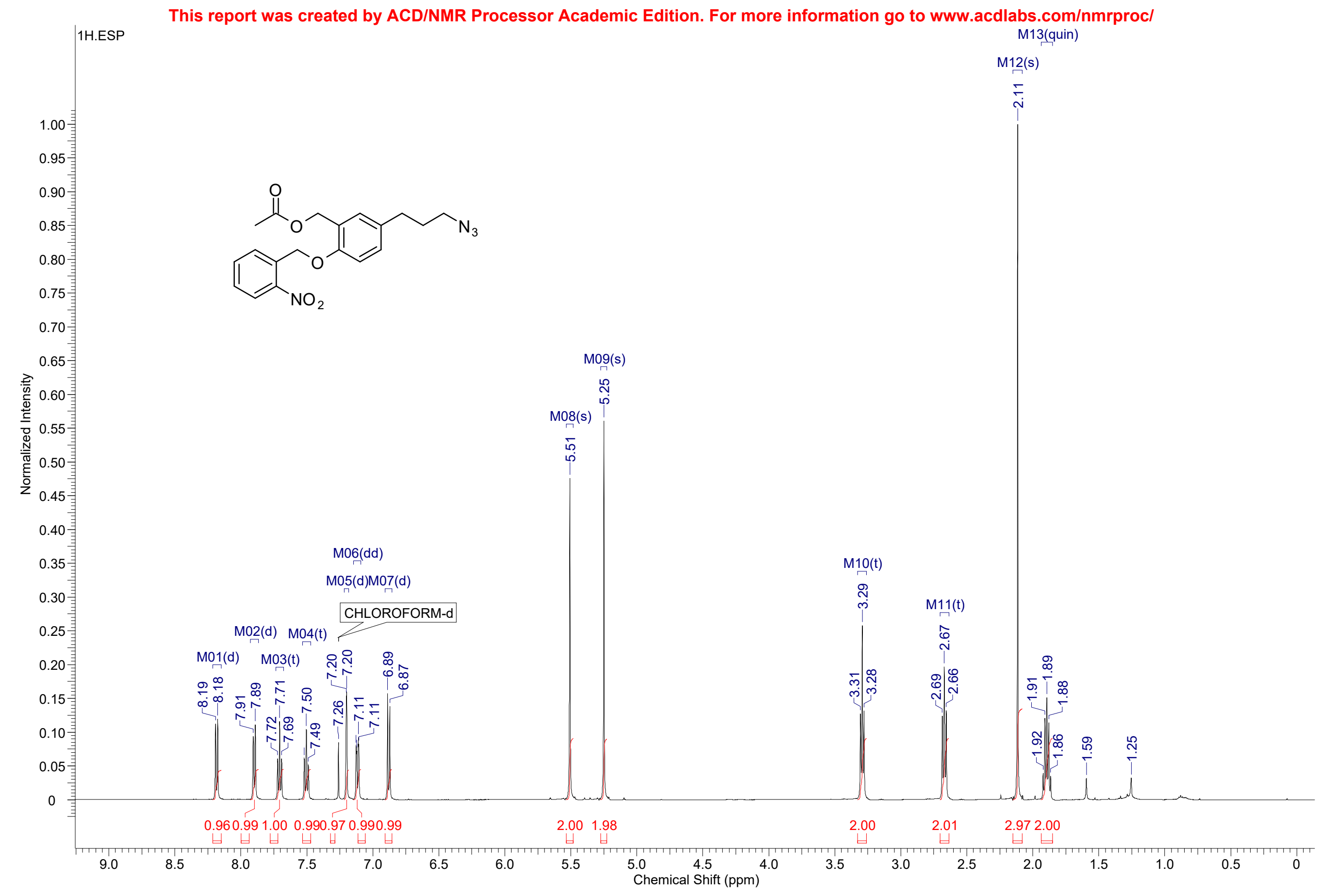




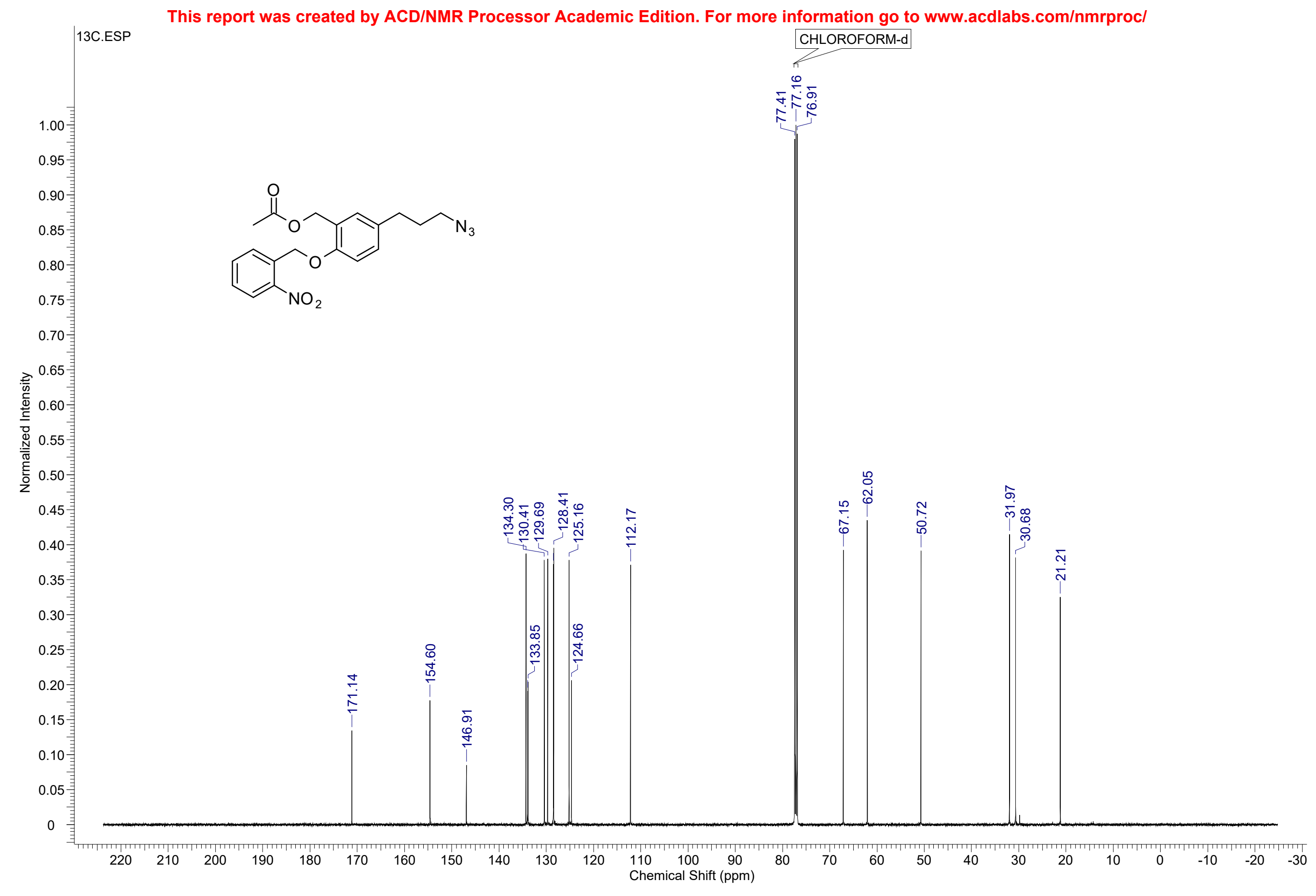




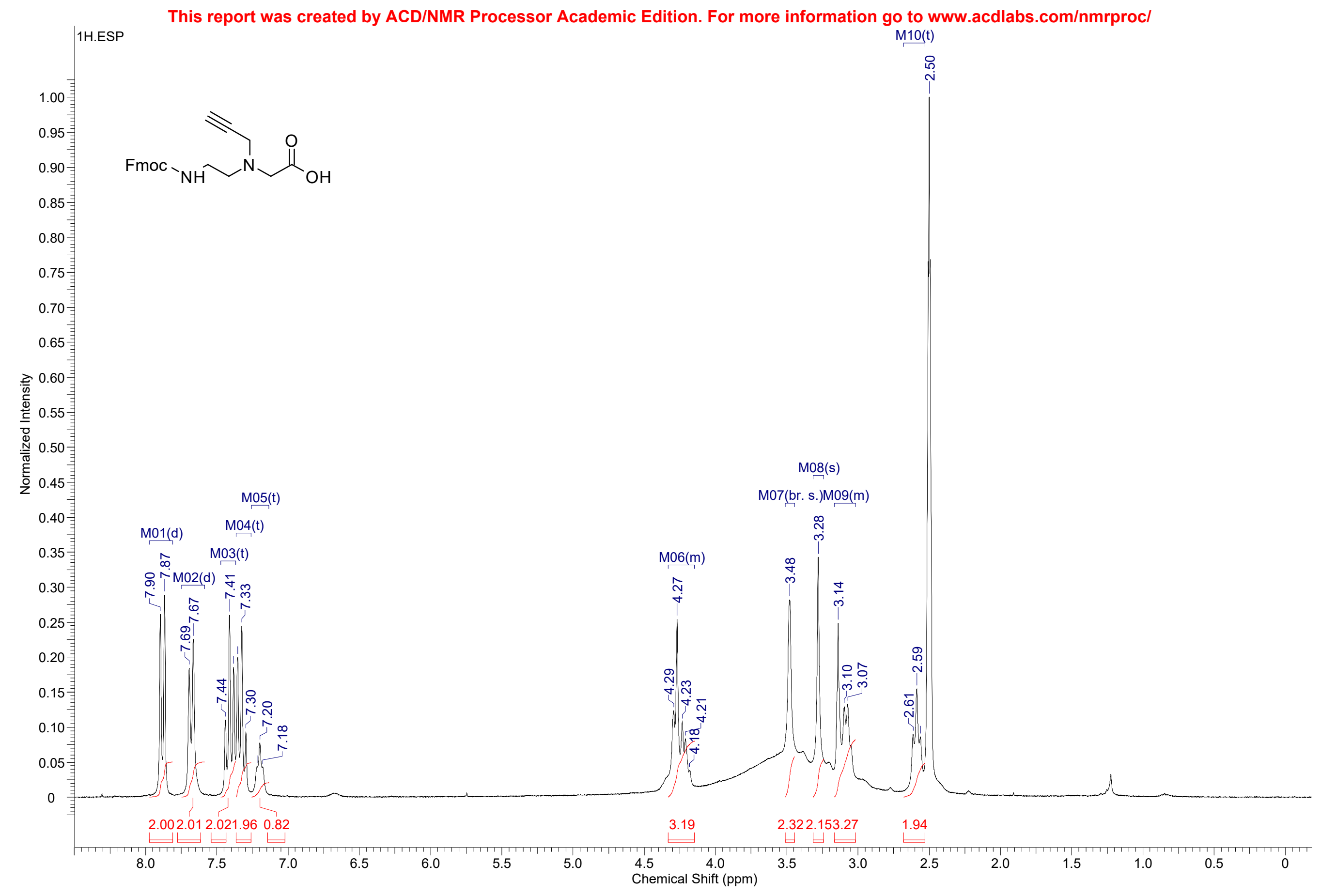




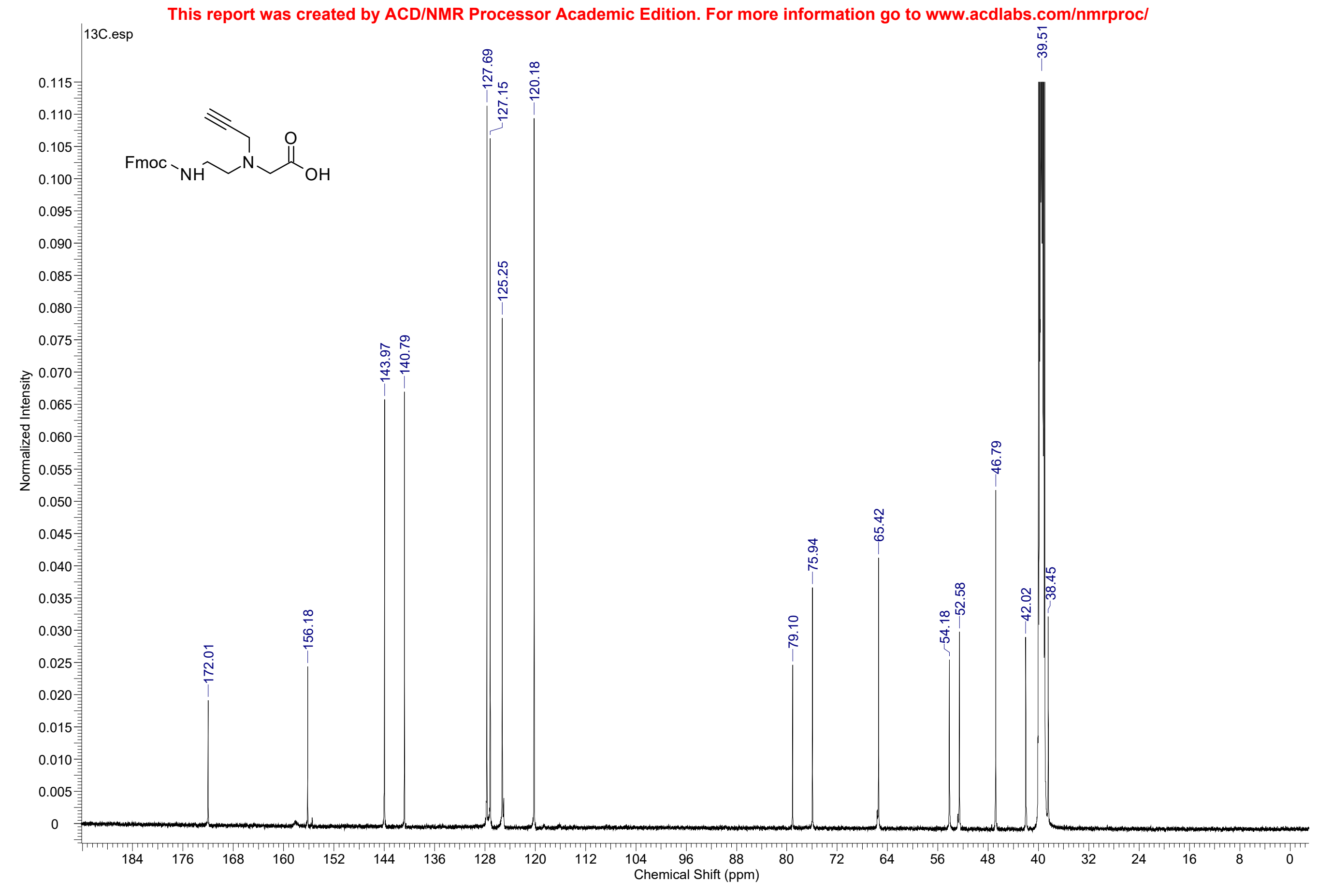

